\title{
DEVELOPMENT OF AN URBAN TRAVEL DEMAND MODEL OF THE TOWN OF OAKVILLE
}

\author{
by
}

\section{LUKASZ PAWLOWSKI}

\author{
A Dissertation \\ presented to Ryerson University \\ in partial fulfillment of the requirement for the degree of \\ Master of Engineering \\ in the Program of \\ Civil Engineering \\ Toronto, Ontario, Canada, 2003 \\ @Lukasz Pawlowski 2003
}




\section{AUTHOR'S DECLARATION}

I hereby declare that I am the sole author of this dissertation.

I authorize Ryerson University to lend this dissertation to other institutions or individuals for the purpose of scholarly research.

Name:

Signature:

Date:

I further authorize Ryerson University to reproduce this dissertation by photocopying or by other means, in total or in part, at the request of other institutions or individuals for the purpose of scholarly research.

Name:

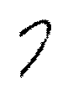

Signature:

Date: 


\section{BORROWER'S PAGE}

Ryerson University requires the signatures of all persons using or photocopying this dissertation. Please sign below, and give address and date. 


\section{ABSTRACT}

Dissertation Title: Development of an Urban Travel Demand Model of the Town of Oakville Degree and Year of Convocation: Master of Engineering, 2003

Author: Lukasz Pawlowski

Graduate Department: Department of Civil Engineering

University: Ryerson University

This dissertation documents the development of a travel demand model of the Town of

Oakville. The purpose of the model was to predict traffic demand on study area roadways during the morning peak hour. The model focused on the prediction of auto driver trips. The model was developed based on the 1996 Transportation Tomorrow Survey data, available from the Data Management Group at the University of Toronto.

The model was developed in accordance with the Urban Transportation Modelling System (UTMS) of models. Activities included: Trip Generation, Trip Distribution, and Trip Assignment. Accounting for Mode Split was unnecessary as the model focused only on auto driver trips. The final product of the model is a set of traffic flows over links in the transportation network.

The model was developed using TransCAD transportation GIS (Geographic Information System) software. TransCAD is a microcomputer software specifically designed for transportation planning and data management. 


\section{ACKNOWLEDGEMENTS}

In the course of completing this dissertation I have had the privilege of working under the supervision of Dr. Bhagwant Persaud to whom I extend my gratitude. I would also like to thank Dr. Said Easa for his guidance and input. I would also like to acknowledge the support I received from my co-workers, at Dillon Consulting Limited.

My appreciation goes to all those who provided me with data: the Data Management Group at the Joint Program in Transportation, University of Toronto who provided access to the Transportation Tomorrow Survey data; the Region of Halton; and the Town of Oakville.

I would like to thank Joe Gallivan and the City of Kingston for the use of the City's TransCAD software.

I am especially indebted to my wife Yu Lay Nwe Aung, for her love, encouragement, and understanding. 


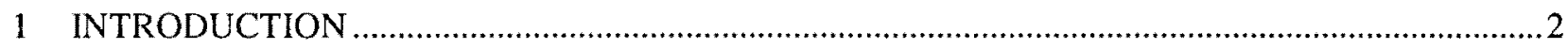

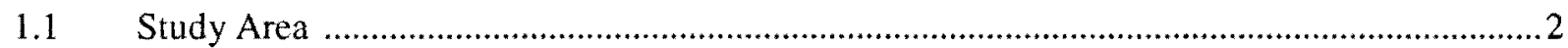

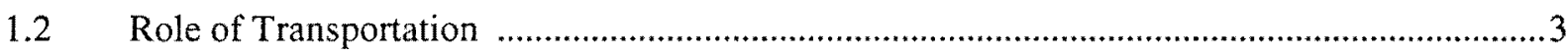

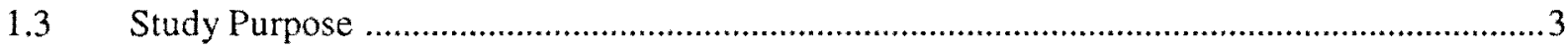

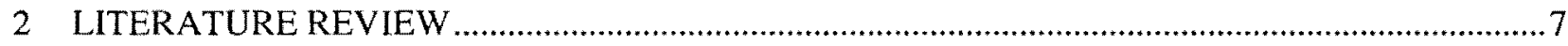

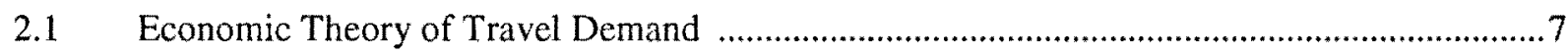

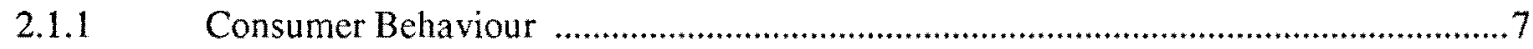

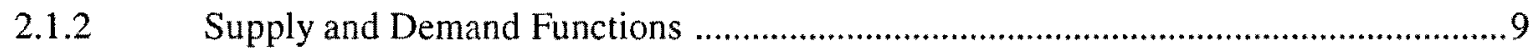

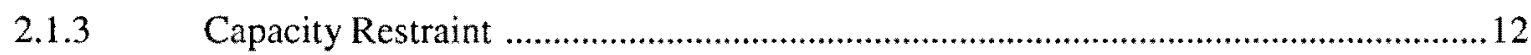

2.2 Urban Transportation Modelling System ………..............................................................

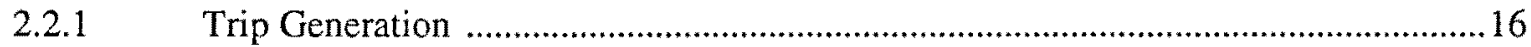

2.2.2 Mode Split .............................................................................................................

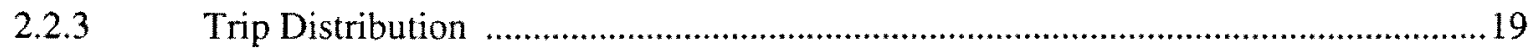

2.2.4 Traffic Assignment ……….............................................................................22

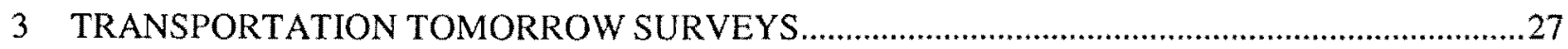

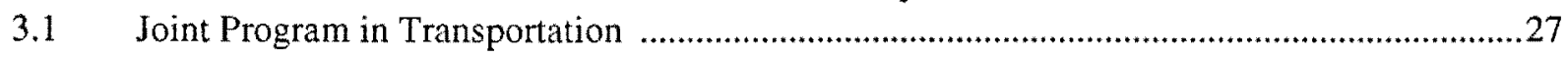

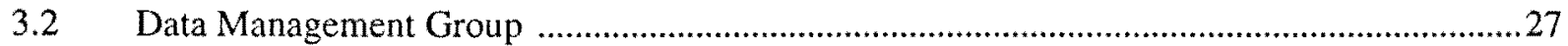

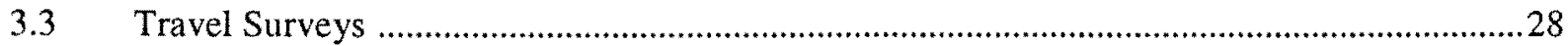

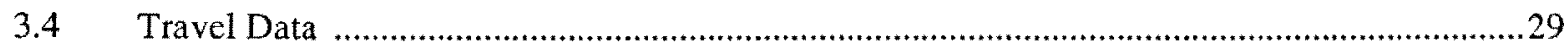


4 GEOGRAPHIC INFORMATION SYSTEMS AND TRANSCAD

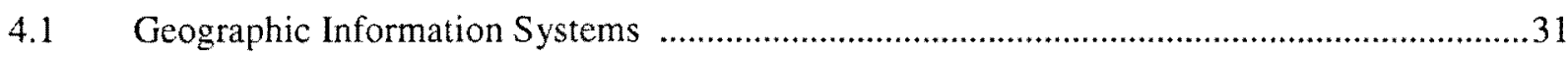

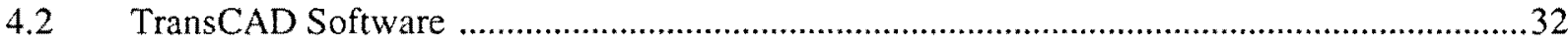

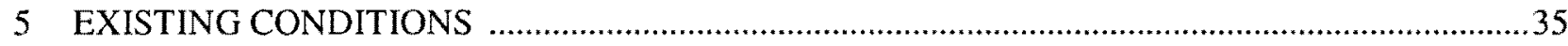

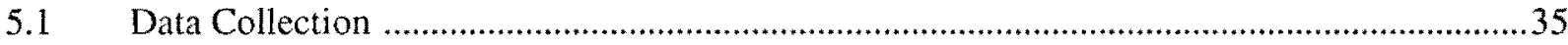

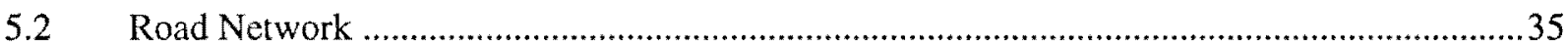

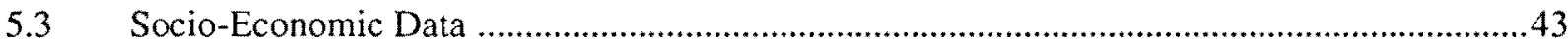

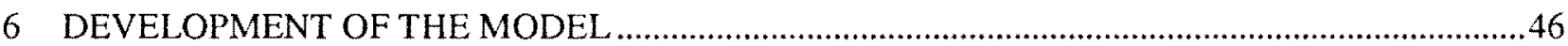

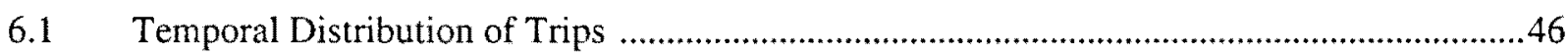

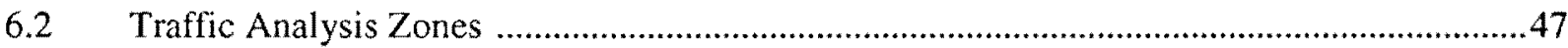

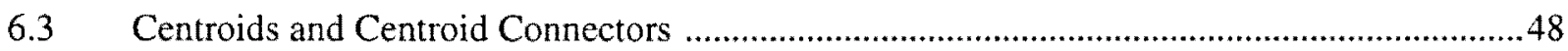

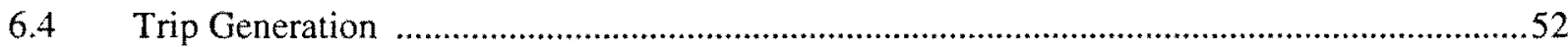

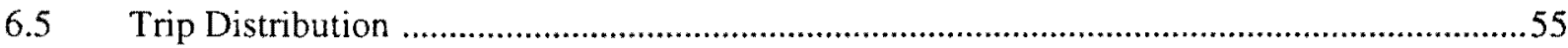

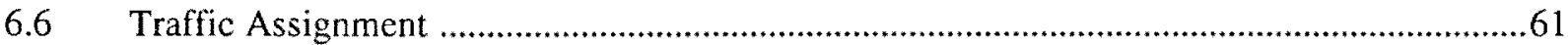

6.7 Greater Toronto Area Cordon Count Program ................................................................64

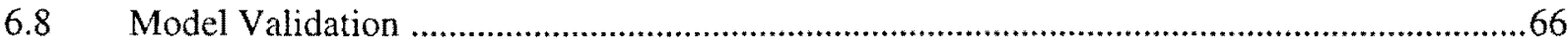

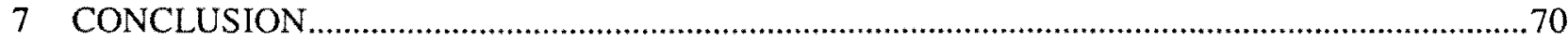

References and Bibliography

Appendix A 1996 Transportation Tomorrow Survey Boundaries, and Data Attributes

Appendix B Data Retrieval System

Appendix C Trip Generation

Appendix D Trip Distribution

Appendix E Traffic Assignment 


\section{LIST OF TABLES}

Table 1 Steps in the TTS Data Extraction Procedure 29

Table 2 Through Lane Capacity by Road Classification........................................................................40

Table 3 Population Summarized by Region ..................................................................................4

Table $4 \quad$ Employment Summarized by Region .........................................................................................4

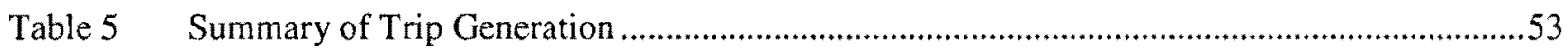

Table 6 A Further Summary of Trip Generation ...........................................................................5

Table 7 AM Peak Period Origin-Destination Matrix Summary …………………...............................60

Table 8 AM Peak Period Base Year Origin-Destination Matrix Summary ………………......................60

Table 9 Difference Between Projected and Observed AM Peak Period Traffic Volumes.....................61

Table 10 Comparison of AM Peak Hour Traffic Volumes ......................................................................66 


\section{LIST OF ILLUSTRATIONS}

Figure 1 The Study Area.

Figure 2 Consumer Utility Maximizing Behaviour

Figure 3 Equilibrium of Supply and Demand

Figure 4 Capacity Restraint Relationship.

Figure 5 Sensitivity of the Link Performance Function.

Figure 6 Alternative Positions for Mode Split Analysis 18

Figure 7 An Origin-Destination Matrix.

Figure 8 Equilibrium Assignment

Figure 9 Layered Organization of Data in GIS

Figure 10 Alternative Intersection Representations.

Figure 11 Sample of the Town of Oakville GIS Road Network Line Layer

Figure 12 Town of Oakville, 1996 Road Network with Speed Limit Data

Figure 13 Town of Oakville, 1996 Road Network and Traffic Lanes

Figure 14 Town of Oakville, 1996 Road Network and Functional Class

Figure 15 Distribution of Travel Trip Start Times.

Figure 161996 GTA Zones 
Figure 17 Town of Oakville, 1996 Traffic Zones.....

Figure 18 Town of Oakville, 1996 Traffic Zones, Centroid Connectors, and External Cordon Stations

Figure 19 Extended Road Network 57

Figure 20 Town of Oakville, Assignment of AM Peak Hour Trips .63

Figure 21 Screenline Definitions .65

Figure 22 Monthly Variation in Average Annual Traffic Volumes .67 
CHAPTER 1

INTRODUCTION 


\section{$1.1 \quad$ STUDY AREA}

The Town of Oakville is a municipality within the Greater Toronto Area, some 40 kilometers to the west of the City of Toronto, Ontario, Canada. It is a medium sized municipality with a population of 144,738 (2001 Census). In contrast, the Greater Toronto Area GTA has a total population of 5,096,682 (2001 Census). In short the Town of Oakville is part of one of the largest urban centers in North America. A map of the Study Area is illustrated in Figure 1.

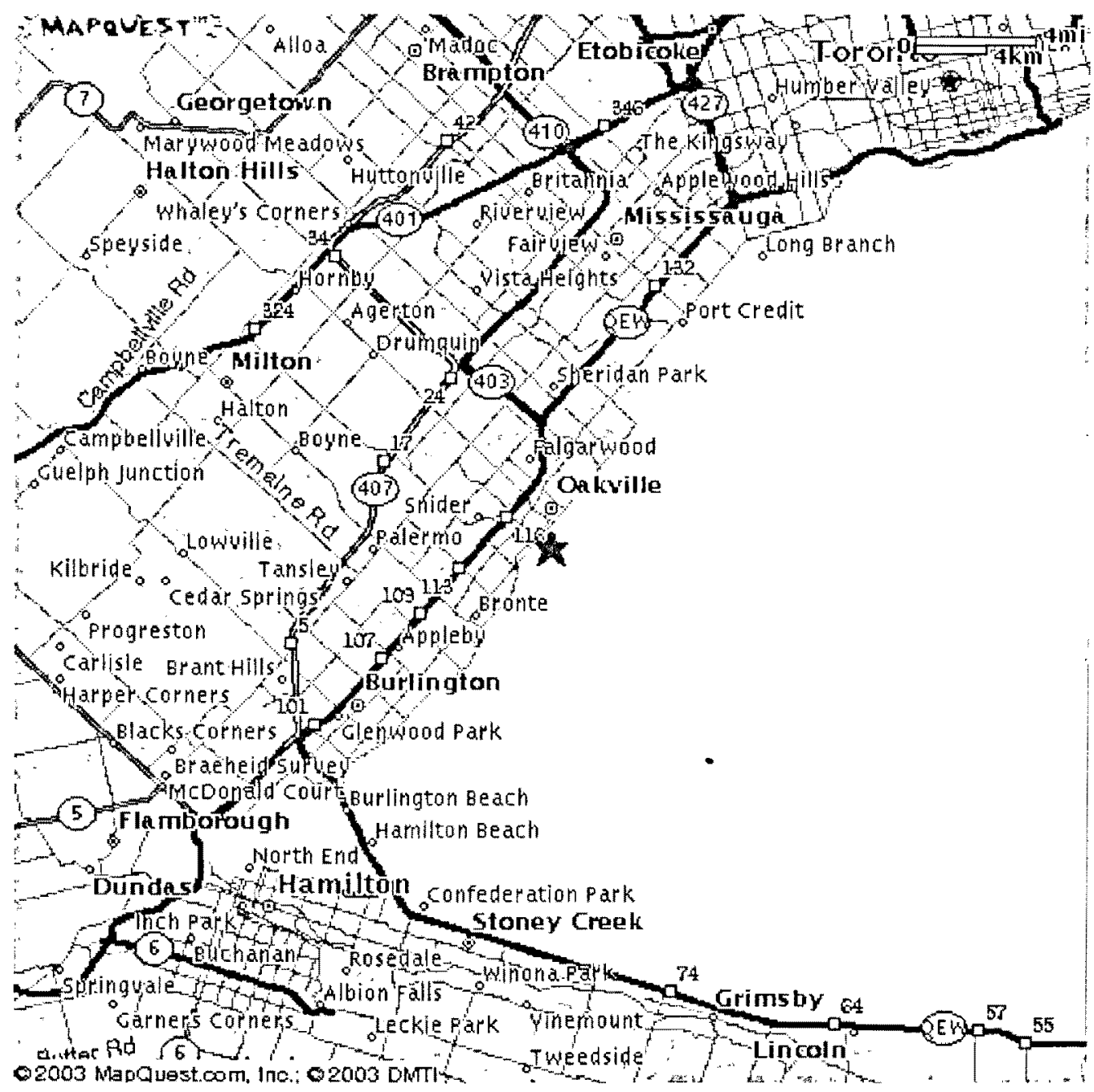

Figure 1: Study Area 


\subsection{ROLE OF TRANSPORTATION}

The role of the city is to increase exchange efficiency (i.e. optimize access to diverse exchanges while minimizing access costs, in particular travel). The role of the urban transportation system is to facilitate the movement of people and goods between different points within the urban center.

Transportation is a derived activity, in that people do not typically travel for travel's own sake. Transportation occurs to facilitate community activities, both social and economic. Traffic is thus the product of an interaction between urban land use and the transportation system.

Ortuzar defines a 'good transportation system' as one that widens the opportunities to satisfy human or industrial needs - needs that are distributed over space. That is, a system that facilitates the interaction between persons and lands distributed over a given geography. While a heavily congested and poorly connected system is one that restricts options, and as a result, limits social and economic development.

\subsection{STUDY PURPOSE}

Modelling is the process of applying scientific techniques to develop mathematicalabstract representations of real world phenomena. 'Travel demand' models, otherwise known as a 'traffic assignment' model (Easa), are a family of models designed to predict the flow of traffic over a transportation network. Developing such models involves the creation of an analytic representation of the transportation system. Socio-economic data serve as inputs to 
the model, and are used to predict the origin-destination demands over the transportation network. Procedures are then applied to determine the geographic distribution of the various origins and destinations in question. The trips between the origin and destination pairs are then assigned over routes in the transportation network. In doing so, such models are useful to transportation planners, engineers, or municipal agencies, in making system wide decisions regarding infrastructure investments, traffic management strategies, or to test the implications of alternative land use or development options. For example, such a model may be used to identify areas in need of transportation system investment under different growth scenarios. To test alternative growth scenarios, forecasts of socio-economic data would need to prepared and input into the model (Easa).

The purpose of this dissertation is to document the development of an urban travel demand model of the Town of Oakville. The model focuses on the morning peak hour, and predicts auto travel trips over the transportation network.

The project utilized data collected as part of the 1996 Transportation Tomorrow Survey, this data served as the primary source of socio-economic data input into the model. The Transportation Tomorrow Surveys, conducted periodically by the Joint Program in Transportation at the University of Toronto, are comprehensive household telephone travel surveys of the Greater Toronto Area. Survey data was available through the University of Toronto's Data Management Group, via the Data Retrieval System available through the internet. 
The model was developed using TransCAD transportation GIS (Geographic Information System) software. TransCAD is a microcomputer software specifically designed for transportation planning and data management. The software incorporates the data management capabilities of standard GIS software, and integrates these with advanced transportation modelling and logistics applications. 
CHAPTER 2

LITERATURE REVIEW 
The concepts presented in this section of the report are intended to introduce the reader to the fundamental theories that form the basis of transportation analysis. A number of economic theories are discussed, as these are particularly useful in helping understand transportation, and transportation decisions.

\subsection{ECONOMIC THEORY OF TRAVEL DEMAND}

As will be pointed out, transportation decisions: mode choice, route selection, destination location, and others, can be best be explained by the application of economic theory. "The estimation of the amount of travel on a transportation system is, in principle, a simple application of economic theory." (Highway Research Board, 1973)

The following sections present a number of the economic theories particularly useful to the understanding of transportation demand phenomena.

\subsubsection{Consumer Behaviour}

The theory is based on the premise that consumer choice is governed by the consumer's desire to maximize his/her personal utility/satisfaction. Ben-Akiva defines 'utility' as index of attractiveness of a transportation alternative, in terms of its attributes (Discrete Choice Analysis). It is a measure by which different alternatives are evaluated by the decision maker in terms of the evaluation of 'trade offs'. Individuals are seen as utility maximizers, and in making decisions they select alternatives that they perceive will give them the highest utility (alternatively, the lowest disutility). Miller describes consumer behaviour as follows “....an individual will select a bundle of goods over all other affordable bundles if it yields the 
greatest utility, that is, satisfaction". He goes on to describe that the individuals decision making process involves the maximizing of a utility function $U$ subject to a budgetary constraint:

$$
\begin{gathered}
\text { Maximize } U=U\left(X_{1}, \ldots, X_{n}\right) \\
\text { Subject to } Y=P X_{1}+\ldots+P_{n} X_{n}
\end{gathered}
$$

Where: $\quad X_{1}, X_{2}, \ldots, X_{n}=$ goods that are consumed

$$
\begin{aligned}
& P_{1}, P_{2}, \ldots, P_{n}=\text { prices of goods } \\
& Y=\text { income }
\end{aligned}
$$

An individual's income is finite, and represents the maximum dollar value of goods and services that an individual can purchase. Thus income is equal to the sum of all goods purchased at their given prices. The total utility derived by the individual is a function of the utilities of the purchased goods. The solution to the utility maximization problem is illustrated in Figure 2 assuming a two good problem. The income line indicates the different combinations of Good 1 and Good 2 that can be purchased by the consumer. A rational consumer will purchase the particular combination of the goods that maximizes the derived utility.

In transportation the 'goods' being demanded are the transportation services by different modes. The price of the good may simply refer to the monetary cost of trips or alternatively may include other costs such as travel time, inconvenience, etc. The desire to minimize 
incurred costs is a fundamental consideration in travel decision-making. The price of cost of a particular transportation decision may be thought of as the disutility associated with that transportation alternative (the cost of travel). Thus, in making transportation choices (i.e. mode choice, route choice, etc.), individuals seek to minimize both the cost and time of travel. The extent to which one goal dominates another depends on the value of time for the individual in question. For example, in assigning traffic to routes in the transportation network, a model may assume individuals make choices so as to minimize their travel time.

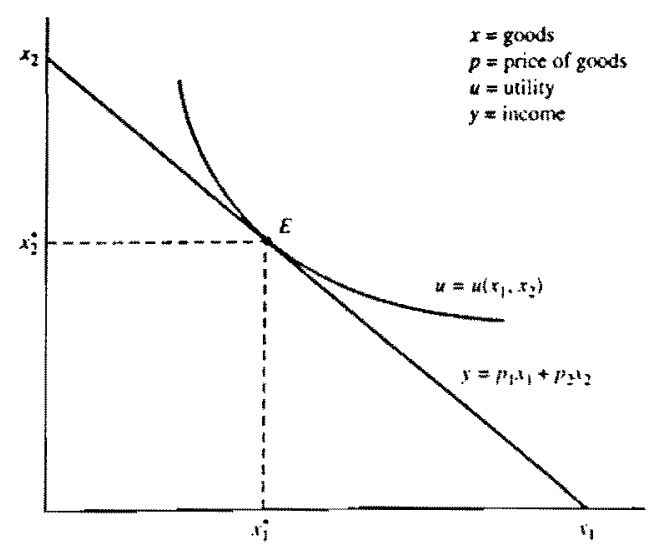

Figure 2: Consumer Utility Maximizing Behaviour (Meyer and Miller)

\subsubsection{Supply and Demand Functions}

One of the cornerstones of economic theory is the concept of a relationship between the demand and supply for a consumer good. Although these concepts are ordinarily associated with economic analysis, they can nonetheless, be utilized in the prediction of traffic volumes. In fact the prediction of traffic volumes necessitates an understanding of these concepts. 
A road network at any given time consists of a definite number of roadways of a given width, and a given number of intersections with specific control devices. These elements of the road network determine its capacity. Thus, at any given time the capacity of the road network can be thought of as fixed. The number of vehicles using the transportation system varies with different times of the day, and seasons of the year (Wohl and Martin).

If one thinks of the transportation system in economic terms, the capacity of the network at any given time may be thought of as the transportation system 'supply'. Likewise, the number of vehicles using the transportation system may be thought of as the 'demand' for the system, at that level of supply. The capacity of the roadway as well as the number of vehicles using the system/facility influence the level of service experienced by the traveler. This level of service is related to the disutility associated with a particular travel choice. Thus, the level of road system supply is related to the level of disutility associated with a given travel choice. Consumer behaviour implies that the demand for a good is related to its price, as well as its supply. Thus, transportation is related to transportation supply - changes in the transportation supply (changes in road network capacity or price) will affect transportation demand. The short-run relationship between supply and demand is illustrated in Figure 3. 


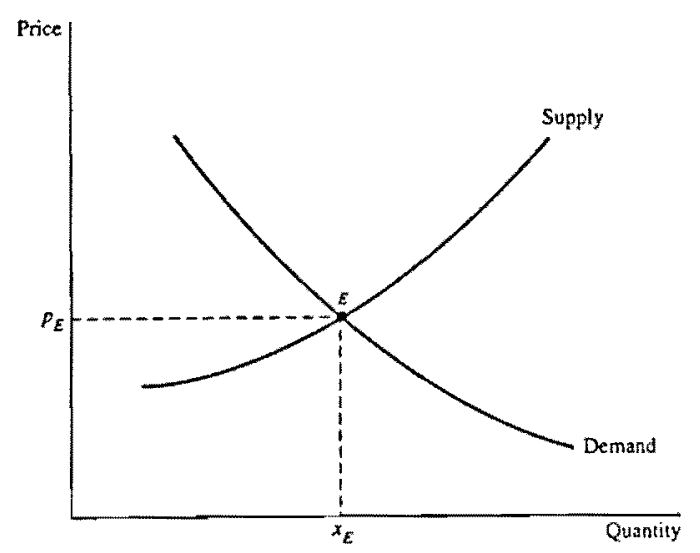

Figure 3: Equilibrium of Supply and Demand (Meyer and Miller)

Miller suggests that, markets generally move toward an equilibrium position; that is, the quantity demanded is equal to the quantity supplied. In the short run shifts in the supply and demand curves do not occur (there are no changes in the capital, labour, production techniques) that would reduce the marginal production cost for a given good. If excess demand were to exist, prices would rise as people would bid up the price of available goods, this would stimulate an increase in the production of the good - putting downward pressure on prices. Thus the system would tend toward equilibrium.

Such a relationship between transportation supply and transportation demand is also thought to exist. If the supply of the transportation system were to be increased (the widening of a roadway), travel cost over the widened section of roadway would decrease and would result in increased capacity. A decrease in the travel cost would make that alternative (section of roadway) more attractive. Traffic would be drawn from other roadways - increasing the congestion, delay, and travel cost (decreasing its attractiveness). This process would continue until a state of equilibrium is achieved. 


\subsubsection{Capacity Restraint}

Conceptually, when dealing with vehicular traffic, it is easiest to think of the performance of a given section of roadway as the travel time over that section of roadway. The travel time for each additional vehicle to use that section of road is dependent on the capacity of the road, and the volume of traffic already using the roadway. Keeping this in mind, it can be seen how the economic theories described above can be thought to influence traveler route choice over the transportation network.

It is assumed that route choice is made such that traveler travel time is minimized (utility maximization). Thus, the travel time likely to be incurred by the traveler influences his/her route choice. The U.S. Department of Commerce, Bureau of Public Roads had presented the following relationship between travel time, assigned volume, and capacity (link performance function).

$$
T=T_{0}\left(1+\alpha(\text { Assigned Volume/Capacity })^{\beta}\right)
$$

Where: $\quad T=$ the travel time at which the assigned volume can travel over the subject link

$T_{0}=$ the base travel time at zero volume

$\alpha, \beta=$ parameters to be estimated during model calibration (typically, $\alpha=$ $0.15, \beta=4.0$ ) 
The capacity restraint relationship is illustrated in Figure 4. The illustration assumes a base travel time of $60 \mathrm{~km} / \mathrm{h}, \alpha=0.15, \beta=4.0$, for a 1 kilometre section of road.

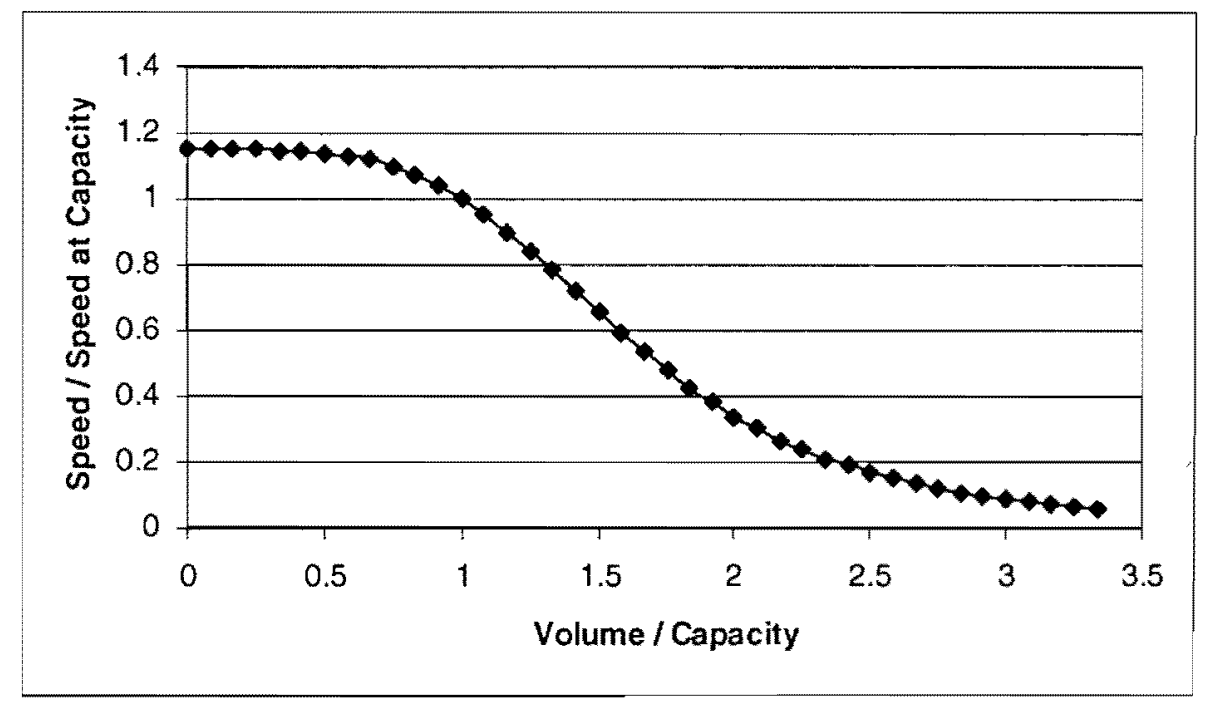

Figure 4: Capacity Restraint Relationship (Bureau of Public Roads)

Figures 5A and 5B illustrate the sensitivity of the link performance function to changes in model parameters. The model parameters ( $\alpha$ and $\beta$ ) affect the sensitivity of the projected travel time over the link to assigned traffic volumes. 

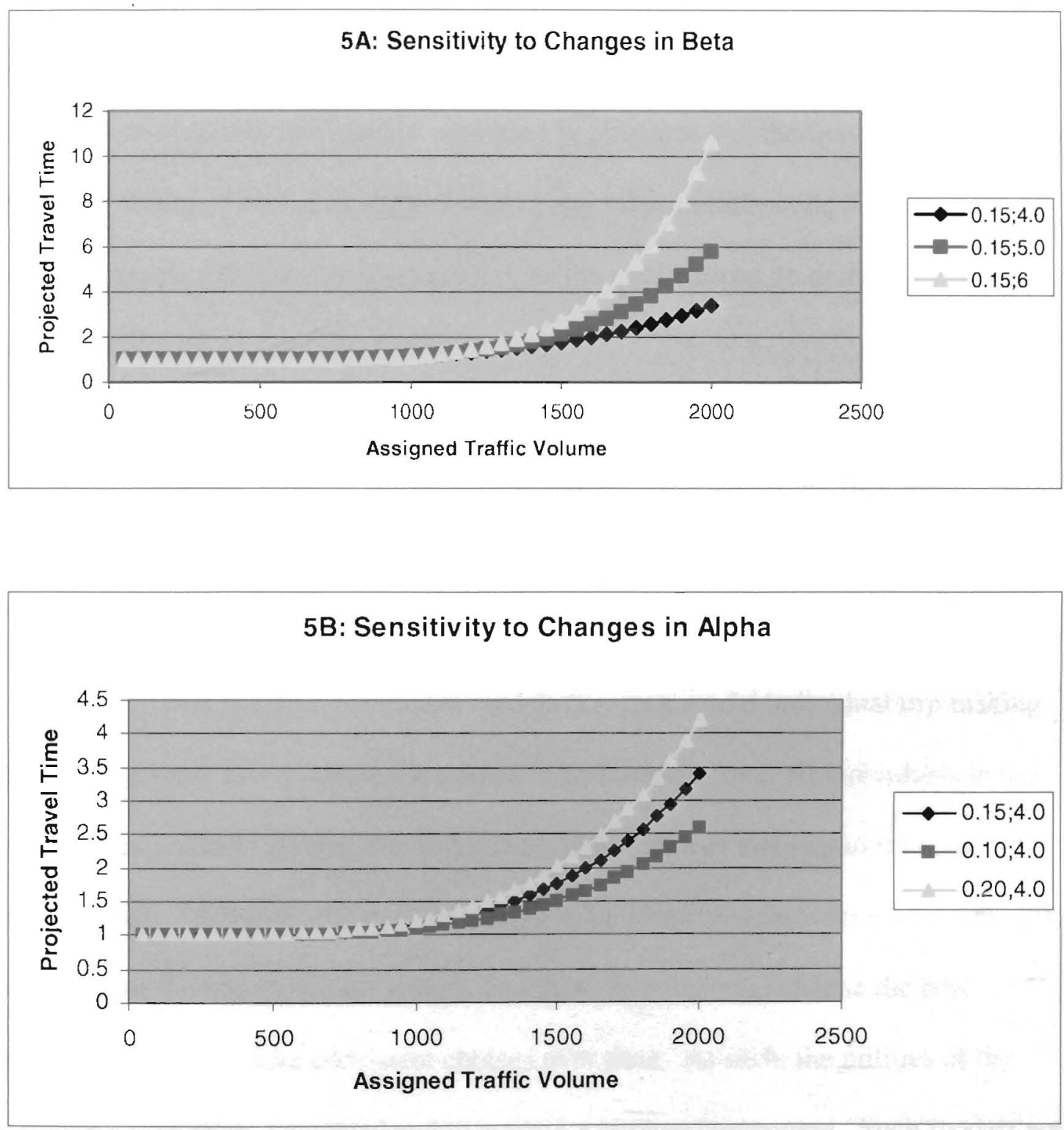

Figure 5A and 5B: Sensitivity of the Link Performance Function 


\subsection{URBAN TRANSPORTATION MODELLING SYSTEM}

The purpose of a transportation model is to estimate travel demand over the transportation network based on available information regarding populations and the transportation system. The predictive ability of such a model can be of great value in estimating the future transportation needs of future growth scenarios, or the implications on demand of changes in development scenarios and transportation system.

Two of the most common types of transportation models are Random Utility models, and UTMS (Urban Transportation Modelling System) models.

Random utility models are discrete choice models (i.e. they model individual trip making behaviour). Aggregate travel demand is estimated by summing over all individuals in the population. These models assume that individuals make choices that maximize their individual utilities. However, the models acknowledge that individuals do not always have full knowledge of the transportation system, and thus, do not always choose the best alternatives, nor do they make consistent choices over time. As such, the utilities of the transportation alternatives are considered to contain a random component. Such models are useful in associating travel choices with individual's socio-economic attributes. As a result they are often used to test estimate the effects of policy changes (i.e. an increase in gasoline taxes or auto ownership, etc) on travel demand.

UTMS models are aggregate models. These models typically estimate travel demand based on the average attributes of different geographic zones within the municipality. These models 
do not attempt to model travel behaviour (i.e. they do not estimate the individual decision making process). UTMS models estimate travel throughout the transportation network based on predictions of trips made between pairs of zonal origins and destinations for a given time period. The models commonly comprise of four stages of analysis: trip generation - the prediction of trips produced and attracted to each zone; trip distribution - the prediction of origin-destination flows, the linking of trip ends predicted by trip generation; mode split - the estimation of percentages of trip flows made by each transportation mode in the model; and trip assignment - the allocation of trips to routes in the transportation network. The four stages represent a sequential decision structure. The transportation model developed for the Town is a four-stage UTMS model. Since the model focuses solely on the prediction of automobile trips, mode split may be seen as the first stage in the model's development.

\subsubsection{Trip Generation}

Trip generation involves the prediction of trips produced and attracted to each traffic analysis zone. Any number of variables may be used as predictors of trip production including: household income, auto ownership and size, number of workers per household, residential density, population. Predictors of trip attractions may include, employment levels, commercial floor space, etc. (Meyer and Miller).

Two common approaches to determining trip generation are regression models and category analysis. Regression models apply least square methods to trip generation as a linear function of one or more socio-economic variables (for a given zone). Households are grouped spatially, and zonal total or averages of given attributes are determined. Category analyses 
group households according to common socio-economic characteristics (i.e. household income, auto ownership, etc.). Average trip rates are then computed for each category from observed data (Meyer and Miller). Category analysis was first developed in the late 1960's three variables are assumed to influence household trip generation: car ownership, household size, and household income (Black).

\subsubsection{Mode Split}

The determination of the mode split, essentially entails the determination of the proportion of trips made using each of the transportation modes available to the trip makers (auto, transit, walk, etc.). The determination of the mode split can be undertaken at different points in the Universal Transportation Modelling System. Meyer and Miller identify two types of UTMS models depending on the stage at which the mode split is determined. Trip-end models, where mode split is determined prior to trip distribution, and trip-interchange models, where the mode split is determined after trip distribution. Trip-interchange models are useful in testing the response of mode split to changes in various socio-economic, as well as service characteristics, particularly where there is competition between modes. Interchange models can, for example be used to test the sensitivity of the mode split to the cost of a given, or competing mode. Trip-end models, by splitting modes prior to trip distribution, are more limited in their usefulness (for testing sensitivities of mode split), since they are based on the assumption that users of certain modes are captive (e.g. transit users take transit because they do not have access to a car, etc.). 
John Black identifies four types of mode choice models: Type I models, where mode split is combined with trip generation (i.e. the trip generation procedure is specific to each mode, thus, trips using each mode, are generated separately). This method has the same limitations as the trip-end mode choice model previously described. Type II models, these are the tripend models described above. Type III models, combine trip distribution with mode split, where the proportion of trips using each mode is a function of the impedances to travel between traffic zones for each given mode. Type IV models, these are the trip-interchange models described above. The four types of mode choice models possible with UTMS models are illustrated in Figure 6.

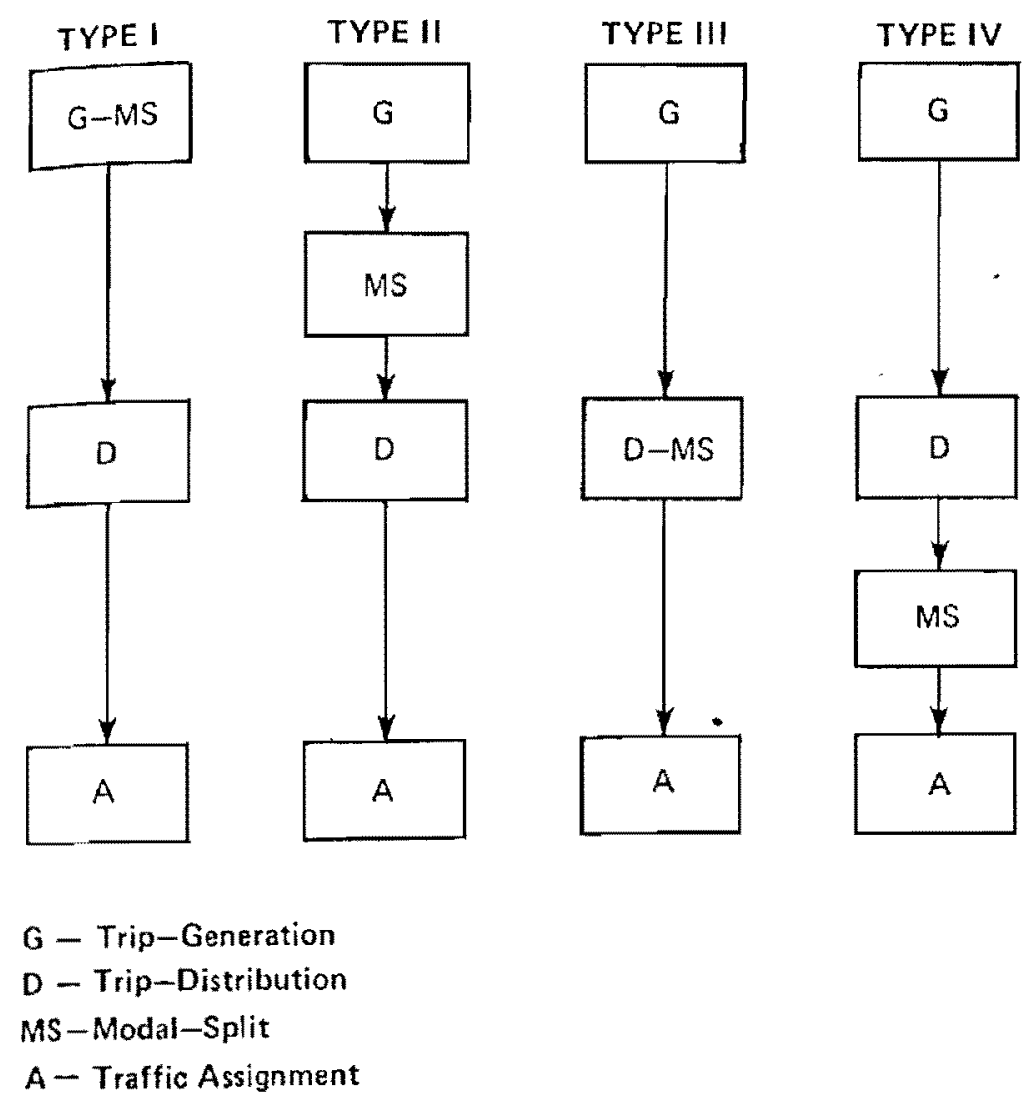

Figure 6: Alternative Positions for Mode Split Analysis (Black) 


\subsubsection{Trip Distribution}

The purpose of any trip distribution model is to predict the spatial pattern of trips between origins and destinations. "The purpose of trip distribution modelling is to find an equation that reproduces the intra- and inter-zonal patterns of traffic survey" (Black, pg. 72). The task of trip distribution is link the trip ends together. Essentially, it is to determine where the trips destined to each zone are expected to originate, and likewise, to determine where trips originating from each zone are destined. The goal is to produce an origin-destination matrix for the study area. A typical origin-destination matrix is illustrated in Figure 7.

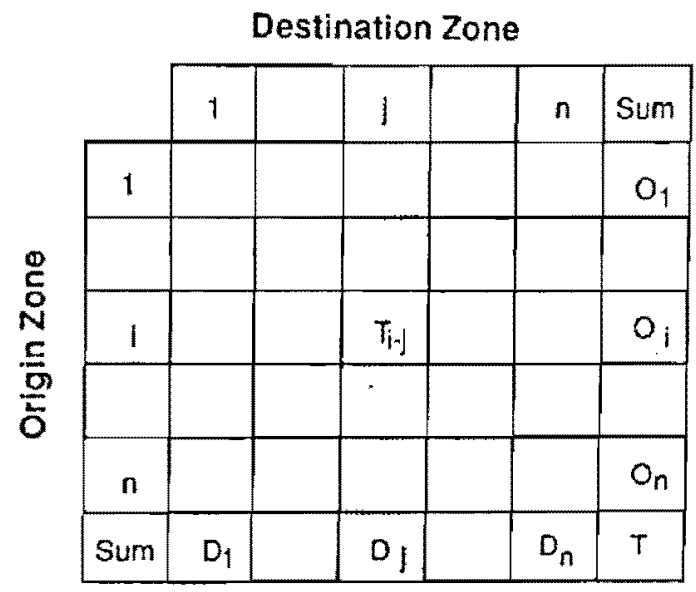

Figure 7: An Origin-Destination Matrix (Easa)

In the above matrix, $T_{i-j}$ represents the number of trips originating in zone $i$ and destined to zone j.

There are a number of methods that can be applied to determine trip distribution. Two common methods include the Fratar Method, and the Gravity Model for trip distribution. 
The fratar method is the simpler of the two to apply, however, the model is subject to some limitations. Essentially, the method requires an existing origin-destination matrix. Having projected future trip ends (origins and destinations). A future origin-destination matrix can be determined by proportionally factoring up the existing origin-destination matrix. This procedure is applied iteratively to ensure that projected trip ends are met to within a specified error. As noted by Easa, one advantage of the model is the ease with which it can be applied, however, the model is generally useful for short-range analysis, and is not sensitive to characteristics in the road network. Most notably, entries in the present o-d matrix that indicate zero trips would be unaltered in the determined future matrix. In addition, the method is not applicable where there is a change in the number of traffic zones in the transportation system. New future zones are simply not present in the existing matrix, and therefore, there would be no trips in the existing matrix, that could be factored up to represent the future condition.

The more common of these is the gravity model for trip distribution. The underlying premise of the gravity model of trip distribution is that human travel behaviour is governed by something analogous to Newton's law of gravity. The gravity model for trip distribution is described by the following relationship.

$$
T_{i j}=\left(P_{i}\left(A_{j} f_{i j} k_{i j}\right)\right) /\left(\Sigma A_{j} f_{i j} k_{i j}\right)
$$


Where: $\quad P_{i}=$ the number of trips produced in zone $\mathrm{i}$

$$
\begin{aligned}
& A_{j}=\text { the number of trips attracted to zone } \mathrm{j} \\
& f_{i j}=\text { a friction factor between zones } \mathrm{i} \text { and } \mathrm{j} \\
& k_{i j}=\text { an adjustment factor for trip interchanges between zones } \mathrm{i} \text { and } \mathrm{j}
\end{aligned}
$$

“...the amount of traffic interaction between two places is directly proportional to the amount of land-use intensity in both places and inversely proportional to the transport difficulty in getting from one place to the other..." (Black, pg. 74)

These "transport difficulties" are the impedances to travel between traffic analysis zones. These impedances are generally a function of travel time or travel distance between the traffic zones.

The application of a gravity model of trip distribution, required a number of inputs:

$>$ The number of trips originating in each zone;

The number of trips terminating in each zone;

The impedance between the origin and destination zone pairs; and

$>$ The friction factor between the origin-destination zone pairs.

A friction factor matrix is based in the impedance matrix and a friction factor function. The function can take the form of the following exponential function:

$$
f(d i j)=\exp \left(-c * d_{i j}\right)
$$


Where: $\quad d_{i j}$ represents the impedance between each $\mathrm{i}, \mathrm{j}$ pair of zones.

$f\left(d_{i j}\right)$ represents the friction factor between each $\mathrm{i}, \mathrm{j}$ pair of zones.

$c$ represents a parameter established through calibration.

The purpose of the friction factor function is to account for the trip length frequency distribution. Where in general, the frequency of trips diminishes with increasing trip length. "Calibrating the gravity model consists of evaluating the parameters of the impedance function ... so that the gravity model reproduces as closely as possible, the base year productions and/or productions and the base year trip length distribution." (Caliper, p.93).

\subsubsection{Traffic Assignment}

The purpose of traffic assignment is to predict the flow of trips between pairs of origins and destinations over the transportation network. In building the model the intent is to replicate the amount of traffic on the principal routes of the transportation network.

Several methods of performing traffic assignment have been documented in professional literature. The methods differ in their underlying assumptions regarding the information possessed by the traveler at the time route choice decisions are made, and the overall objective of the traveler.

All-or-nothing assignment is the most basic of the assignment techniques. This procedure assumes travelers have perfect information regarding the transportation network, all of the 
travelers between a given origin-destination pair are assumed to take the shortest path (based on travel distance or travel time). This method is relatively straightforward to apply, however, its strength is also its greatest weakness. In assuming all travelers take the shortest path, the procedure is useful only in predicting the routes likely to be taken by most travelers given uncongested roadways. The procedure is likely to result in and unrealistic assignment of trips given that alternative routes between origins and destinations are unaccounted for, nor is the effect of roadway capacity/congestion. The assumption that all users have perfect information regarding the transportation system is also likely to be unrealistic.

Equilibrium assignment techniques were developed to account for the effect of congestion in influencing driver route choice. As described by Kanafani, "...it is assumed that the users will choose routes in such a way that no individual trip maker can improve the choice by unilaterally changing routes". Equilibrium is thus achieved when all travelers are on their minimum cost routes. The concept is illustrated graphically in Figure 8 - in this case, traffic flow from a single origin-destination pair has the choice of two alternative routes, $S_{I} V_{I}$ and $S_{2} V_{2}$, are volume delay function for the two routes in question. The equilibrium position is achieved at the intersection of the respective volume delay (link performance) functions. This procedure is applied iteratively. As long as the travel costs @̣n the two routes do not equal, additional road users will alternate between route choices. What has been described thus far is a deterministic approach in which users are assumed to have perfect route and travel cost information. 
Stochastic (random) assignment methods are ones that recognize and explicitly account for travelers possessing imperfect information regarding the road network, and potential route choices.

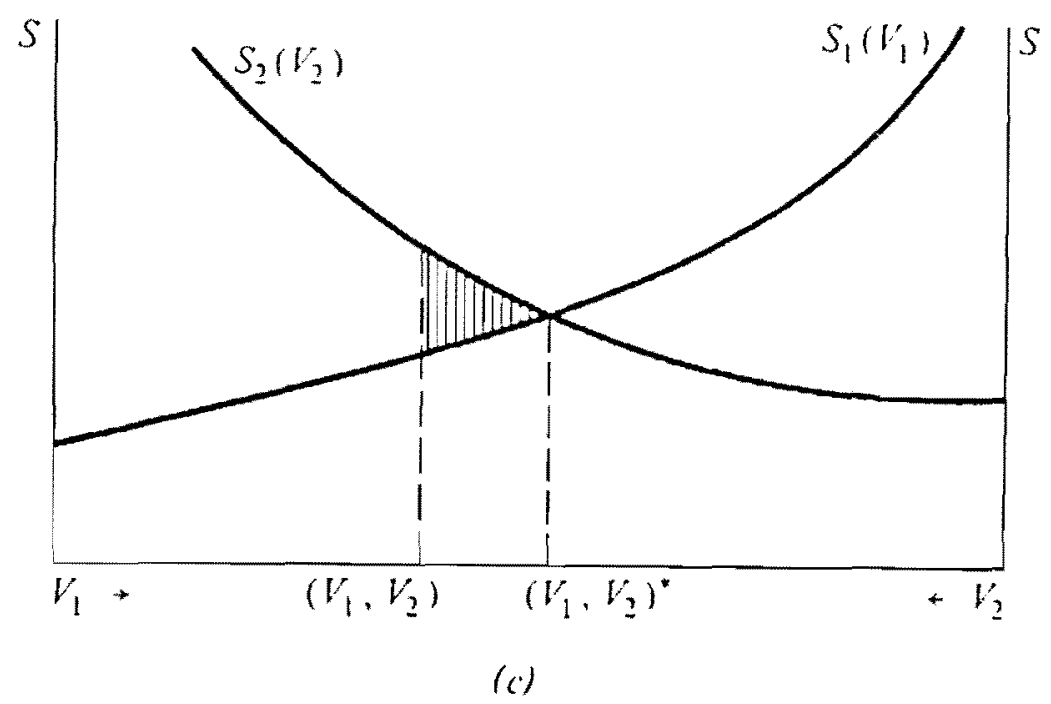

Figure 8: Equilibrium Assignment (Kanafani)

Stochastic User Equilibrium traffic assignment is an assignment procedure that accounts for the fact that users, while seeking to maximize their travel utility, have imperfect information regarding alternative paths through the network. Thus, they make rational route choices, however their choices are based on less than complete information.

This assignment method also acknowledges that the transportation link costs depend on the volume using the link (as in deterministic user equilibrium). In this method the link performance function discussed in an earlier section of the report is assumed to be valid. Thus, as more volume is assigned to a particular link, travel times over the link increase. When travel times over a link increase, subsequent road users are discouraged from using the 
link. In this way, the assignment method applies the principles of supply and demand, in that, as routes become congested, the available capacity over the route is diminished (supply), this results in a fewer additional travelers using the route (demand). 
CHAPTER 3

TRANSPORTATION TOMORROW SURVEYS 


\subsection{JOINT PROGRAM IN TRANSPORTATION}

The Joint Program in Transportation is a research center of Faculty of Applied Science and Engineering at the University of Toronto. Established in 1970, the Centre specializes in research on issues relating to the Canadian transportation system. The primary objectives of the Centre (as noted on the Centre's web page) are:

$>$ To encourage research relevant to improved transportation in Canada through the influence of research findings in investment planning, policy development, operations, and the development of human resources and expertise;

$>$ To serve government and the transportation industry by acting as a source of information, expertise and special purpose training programs; and

$>$ To provide an environment within the university community that is productive to high quality teaching and research in the transportation field.

\subsection{DATA MANAGEMENT GROUP}

The Data Management Group is a research project located at the Joint Program in Transportation. The Group was established in 1988 (DMG - Annual Report), and has been entrusted with conducting comprehensive surveys of the demographic and travel characteristics of the Greater Toronto Area (GTA) population: The group is funded and overseen by a Steering Committee made up of representatives of the City of Toronto, GO Transit, Toronto Transit Commission, Ontario Ministry of Transportation, and the Regional Municipalities of Durham, Halton, Hamilton-Wentworth, Peel, and York. 


\subsection{TRAVEL SURVEYS}

The travel surveys conducted by the Data Management Group are the Transportation Tomorrow Surveys (TTSs). Beginning in 1986, the surveys have been conducted every 5 years. In total, four such surveys have been conducted - the surveys have been conducted in $1986,1991,1996$, and 2001 . The data from the 2001 TTS has only recently become available.

The surveys are household telephone surveys, based on a random sample of household telephone numbers within the Greater Toronto Area. The 1996 survey collected data from 115,193 households within the GTA (1996 TTS Data Guide).

Data contained in the survey includes:

$>$ Household Attributes - location, number of residents, number of vehicles, number of persons possessing a drivers license, number of workers, number of students, etc.

$>$ Person Attributes - age, gender, possession of a drivers license, occupation (based on five categories), student status, place of work, etc.

$>$ Trip Attributes - household and person number, origin, destination, primary mode of travel, start time, trip length, etc.

Details of the household, person, and trip attributes are presented in Appendix A. 


\subsection{TRAVEL DATA}

Data from all of the Transportation Tomorrow Surveys is available to interested parties via the Internet Browser Data Retrieval System (iDRS). One simply needs to submit an Access Request form to the Data Management Group to be provided with a 'username' and 'password' that will permit one to access the system via the internet.

Once internet access is obtained, a series of links can be followed to the TTS database. There the user can customize a desired query based on the person, trip, or household attributes in the database. Appendix B presents a number of screenshots illustrating the data extraction procedure. In the example, the 1996 TTS database is queried to provide an origin-destination matrix of all trips at the planning district level. Extraction results can be summarized based on a number of geographic boundaries (traffic zones, planning districts, regional and municipal boundaries, etc.). Steps in the data extraction procedure are described in Table 1.

\begin{tabular}{|c|c|}
\hline \multicolumn{2}{|r|}{$\begin{array}{c}\text { Table } 1 \\
\text { Steps in the TTS Data Extraction Procedure }\end{array}$} \\
\hline Step* & Description \\
\hline 1 & $\begin{array}{l}\text { Go to the secure website of the Joint Program in transportation } \\
\text { (https://www.jpint.utoronto.ca), click the link to the Data Retrieval System. This } \\
\text { will lead to a page requesting the user to enter the 'username' and 'password'. }\end{array}$ \\
\hline 2 & When prompted, enter the 'username' and 'password'. \\
\hline 3 & The next page requests the user to identify the required dataset. Select 'TTS'. \\
\hline 4 & $\begin{array}{l}\text { Identify the survey year and data unit (household, person, trip) to which the query } \\
\text { will apply. On this page, the method of tabulation is also specified. }\end{array}$ \\
\hline 5 & $\begin{array}{l}\text { The next page is the 'query form' where the desired variables for tabulation are } \\
\text { specified. The query can then be initiated. }\end{array}$ \\
\hline 6 & $\begin{array}{l}\text { The following screen indicates that the query has been executed and prompts the } \\
\text { user to get the query results. }\end{array}$ \\
\hline 7 & The results of the query are provided in the form of a comma delimited text file. \\
\hline 8 & $\begin{array}{l}\text { The text file can then be imported into Excel (or other program) to view in matrix } \\
\text { form. }\end{array}$ \\
\hline
\end{tabular}

*Appendix B provides a separate screenshot for each step in the extraction procedure. 
CHAPTER 4

GEOGRAPHIC INFORMATION SYSTEMS AND TRANSCAD 
This section provides a brief introduction to Geographic Information Systems (GIS), as well as to the specific software used in the development of the transportation model.

\subsection{GEOGRAPHIC INFORMATION SYSTEMS}

Geographic Information Systems are a family of software used to integrate geographic mapping and data storage capabilities. GIS software links map elements to specific databases, enabling the data to be mapped, displayed, queried, or altered, simply by interfacing with the mapped image, or the database directly. The software's power comes from the ability to display and analyze data geographically, and the ability to help the user analyze geographic trends and patterns.

Geographic information systems typically, employ a layered data management strategy, where map features (points, lines, or areas) are displayed on separate layers. The layers can be superimposed on one another much like transparencies, in such a way that all or some of the features and layers can be viewed together, thus, forming a map. An example of the manner in which data is organized into layers is illustrated in Figure 9.

Maps can be used to represent any number of and type of geographic information: transportation networks, municipal boundaries, population demographics, statistics, sales and marketing trends, traffic zones, individual addresses, any information that can be found in an atlas, and more. Most importantly, all these features are linked directly to databases containing the feature's attributes. Examples of some of the capabilities of GIS are presented in the following section of the report. 

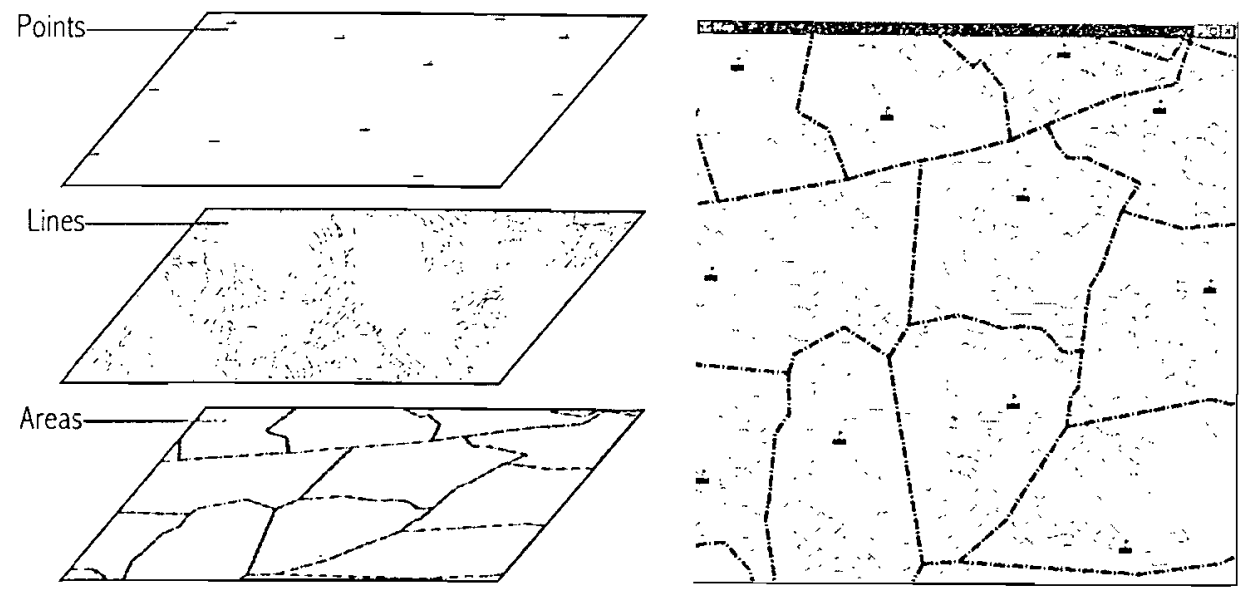

Figure 9: Layered Organization of Data in GIS (Caliper)

Geographic information systems are particularly useful to planning analysis because they lend themselves to the analysis, and display of spatially referenced data. As noted by Meyer and Miller:

“...the primary purpose of the planning effort...is to generate information useful to decision makers for the specific types of decisions they are facing"

The ease with which GIS enables us to display information makes it an important tool in transportation planning. Apart from the ability to manipulate data, geographic information systems make it possible to display and thus, visualize both the inputs and outputs of a particular transportation model.

\subsection{TRANSCAD SOFTWARE}

TransCAD is a geographic information system designed specifically for the planning, managing, and analyzing of transportation systems. The software provides a set of tools for 
travel demand modelling as well as capabilities for geographic database management, presentation graphics and transportation models. The software provides tools which can be used in all phases of the model development process - mode split, trip generation, trip distribution, and trip assignment. The software was provided by the City of Kingston. Much of the analysis undertaken in the completion of the assignment, as well as the figures presented in the report were prepared using TransCAD software. 
CHAPTER 5

\section{EXISTING CONDITIONS}




\subsection{DATA COLLECTION}

A transportation model developed is an analytic representation of the road network of the Town of Oakville. The development of the model relied on obtaining accurate and reliable data regarding travel within the Town. This section documents the data collection that was undertaken in the course of completing the project. Travel and transportation system data were collected from three sources: the Data Management Group (DMG), Joint Program in Transportation - University of Toronto; the Regional Municipality of Halton (the Region); and the Town of Oakville (the Town).

\subsection{ROAD NETWORK}

A digital representation of the street network was obtained from the Town of Oakville in GIS format. The GIS files contained all of the roads within the Town's boundary under all three jurisdictions, municipal, regional, and provincial. The street network files were provided in ESRI shape file format (a particular GIS file format).

TransCAD permits the import and export of files among many CAD and GIS software packages. The GIS files provided by the Town were imported into TransCAD.

Traffic assignment compute models require the representation of the transportation network in terms of links and nodes. Figure 10 illustrates alternative intersection representations. The macro link-node representation, utilizes a single node to represent the entire intersection, and is used for system level planning studies. The micro link-node representation can be used to account for capacities and travel times of different movements (Easa). 


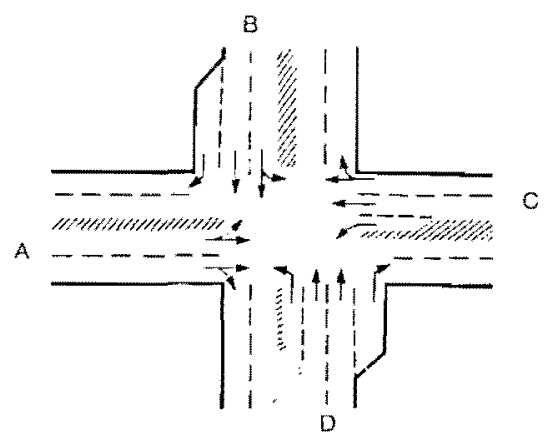

a) Intersection Contiguration

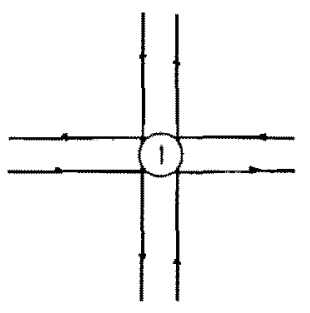

b) Macro Link-Node Hepresentation

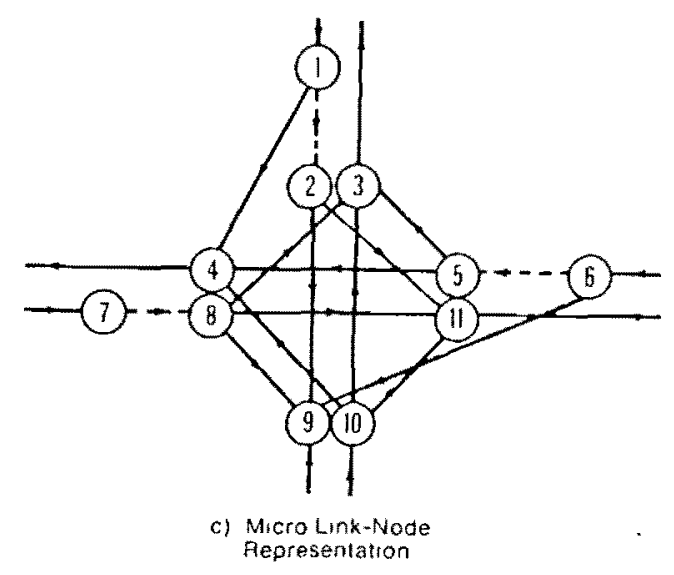

\section{Figure 10: Alternative Intersection Representations (Easa)}

In a geographic information system line layers are stored as a series of links and nodes. Thus, the road network files obtained from the Town, were by default in the macro link-node format. A close-up view of the Towns road network line layer is illustrated in Figure 11. Evident in the figure are the roadway links, and the intersection node numbers.

Analysis at a system level of detail is sufficient and thus, the marco link-node network representation is acceptable. Attention was given to ensuring connectivity of the street network links, particularly for major roadways and freeways. 


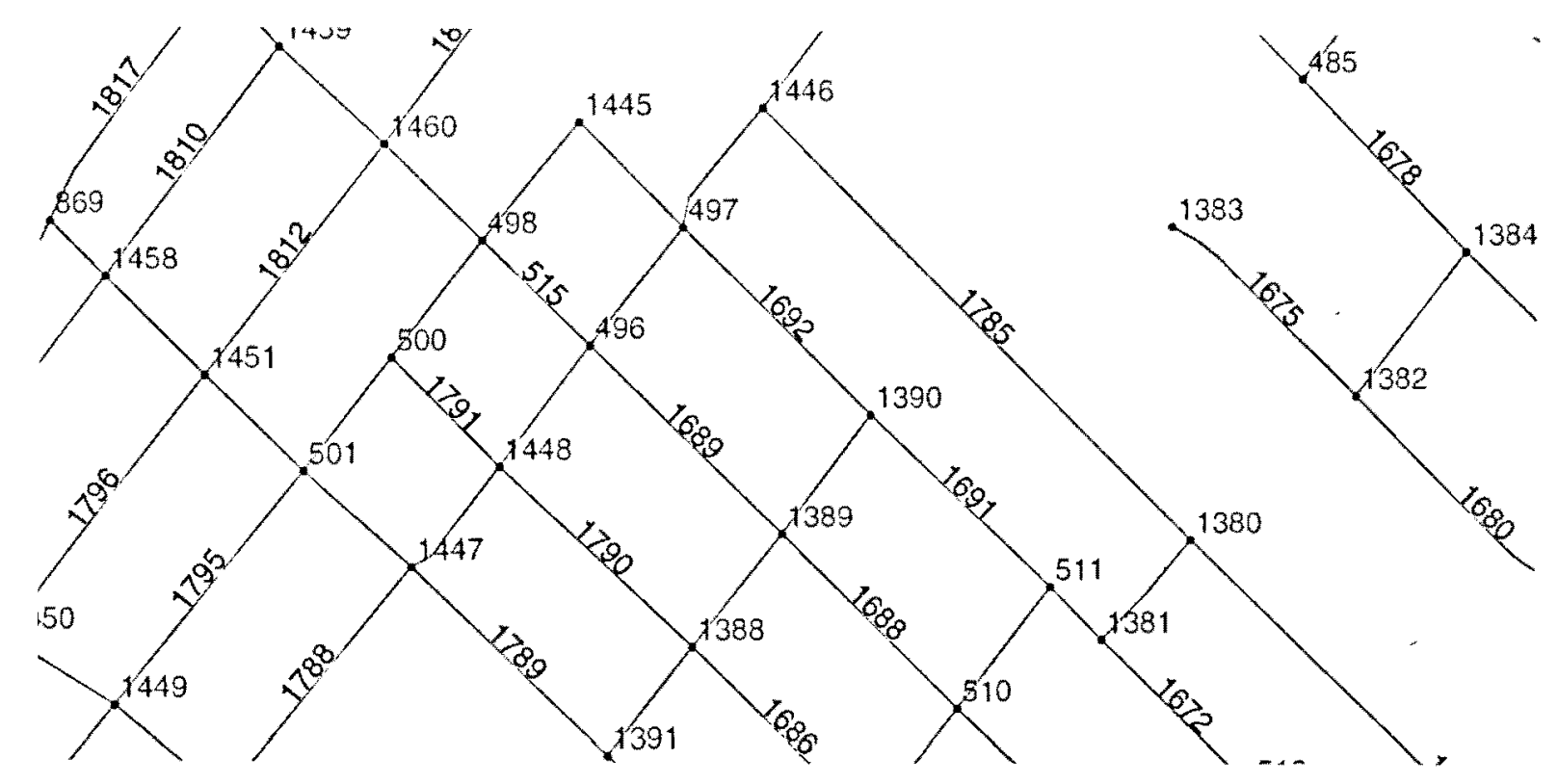

Figure 11: Sample of the Town of Oakville GIS Road Network Line Layer

Given that GIS files can be linked to databases containing attributes of map features, it should be noted that the following information was contained in the street network file: section identification number, section length, road name, and address range information. A number of data, particularly relevant for the development of an assignment model was omitted from the GIS database. Specifically, the street network files did not contain information regarding link capacity, and travel speed. These data are needed to apply capacity restraint assignment techniques.

Commuter use of a transportation network is largely dependant upon the characteristics of the individual streets within the network. The use of a particular street is influenced by the capacity and function of that street. The capacity of a street is influenced by the street's 
cross-section (number of lanes) and the free flow speed for the street. Posted speed limit data, as well as road cross-section data for the street network were obtained from the Town and Region - these data were obtained in hard copy format in the form of the speed limit by-law for the Town. Considerable effort went into populating the network GIS files with the lane and speed limit data. Cross-section data included the number of through lanes available for each roadway link in the network. Auxiliary left, and right-turn lanes were excluded from the dataset. Where necessary, assumptions regarding network data were made.

Figures 12 illustrates the 1996 street network for the Town of Oakville including speed limit data. For the most part, the Town is served by a grid-like road system.

Key east-west corridors include, Lakeshore Road, the Queen Elizabeth Way (QEW), Dundas Street, and Highway 407. Upper Middle Road is another important east-west corridor. Key north-south corridors within the Town include: Winston Churchill Boulevard, Ford DriveNinth Line, Eighth Line, Trafalgar Road, Sixth Line, Fourth Line, Dorval Drive, Third Line, and Bronte Road. 


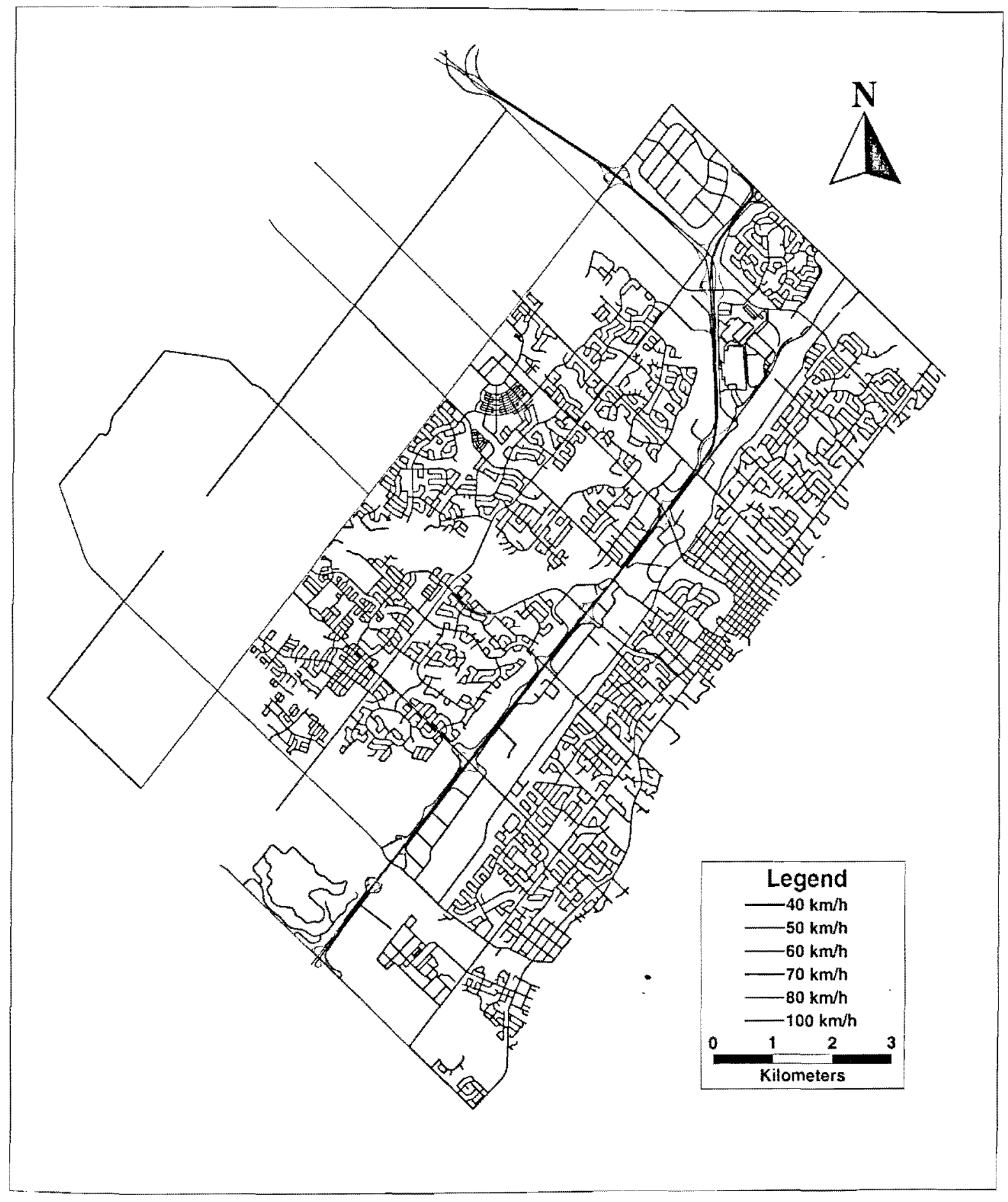

Figure 12: Town of Oakville, 1996 Road Network with Speed Limit Data 
Existing through-lane cross-sections are illustrated in Figure 13. Lane capacities were assigned based on roadway functional classification. Table 2 presents the capacity per through lane by road classification. Roadway functional classifications are illustrated in Figure 14.

\begin{tabular}{|c|c|}
\hline \multicolumn{2}{|c|}{ Table 2 } \\
Through Lane Capacity by Road Classification \\
\hline Classification & Lane Capacity (veh/hour/lane) \\
\hline Freeway & 2,000 \\
\hline Freeway Ramp & 1,300 \\
\hline Arterial & 900 \\
\hline Collector & 600 \\
\hline Local & 500 \\
\hline
\end{tabular}

Source: City of Oshawa Transportation Study. 


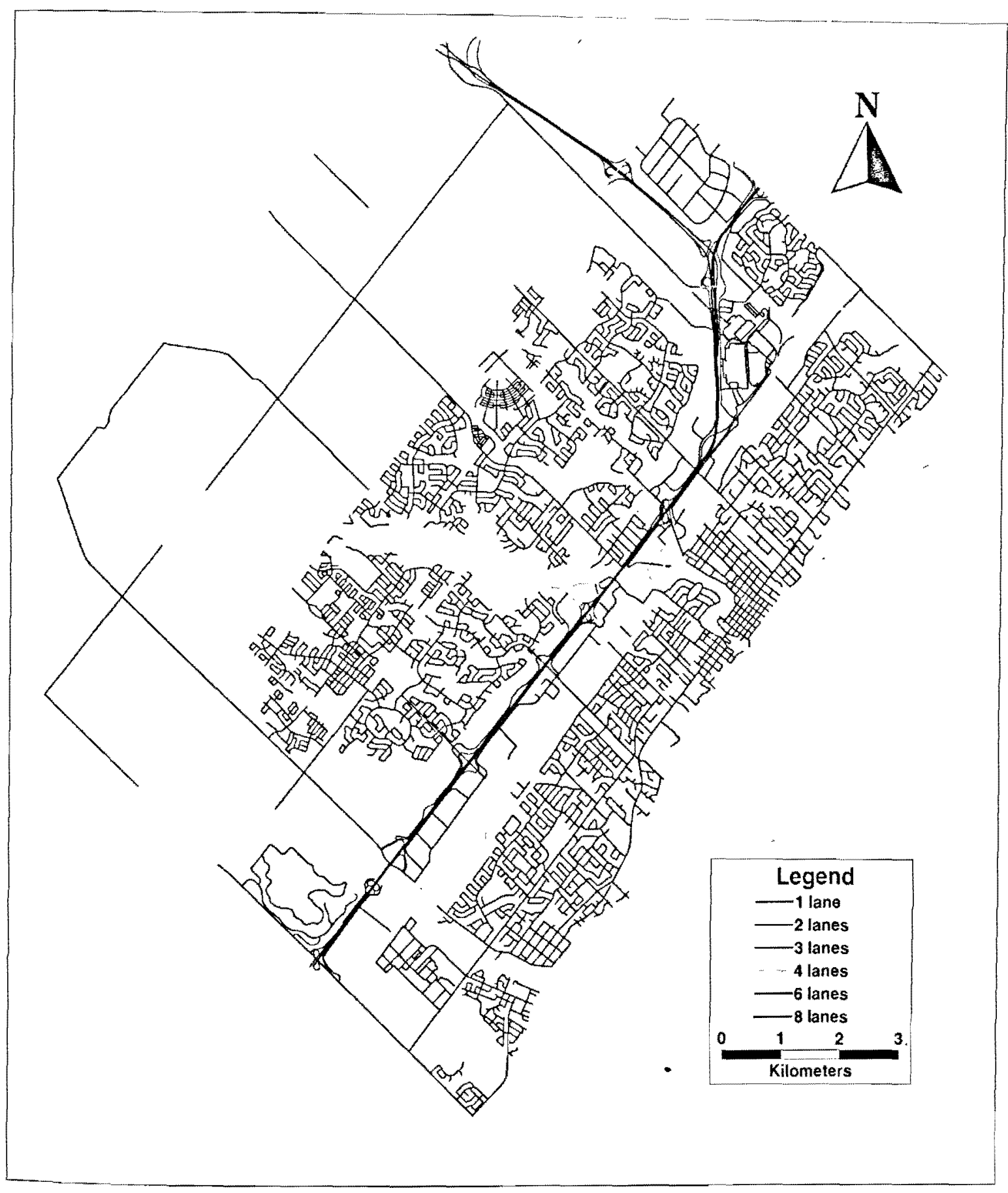

Figure 13: Town of Oakville, 1996 Road Network and Traffic Lanes 


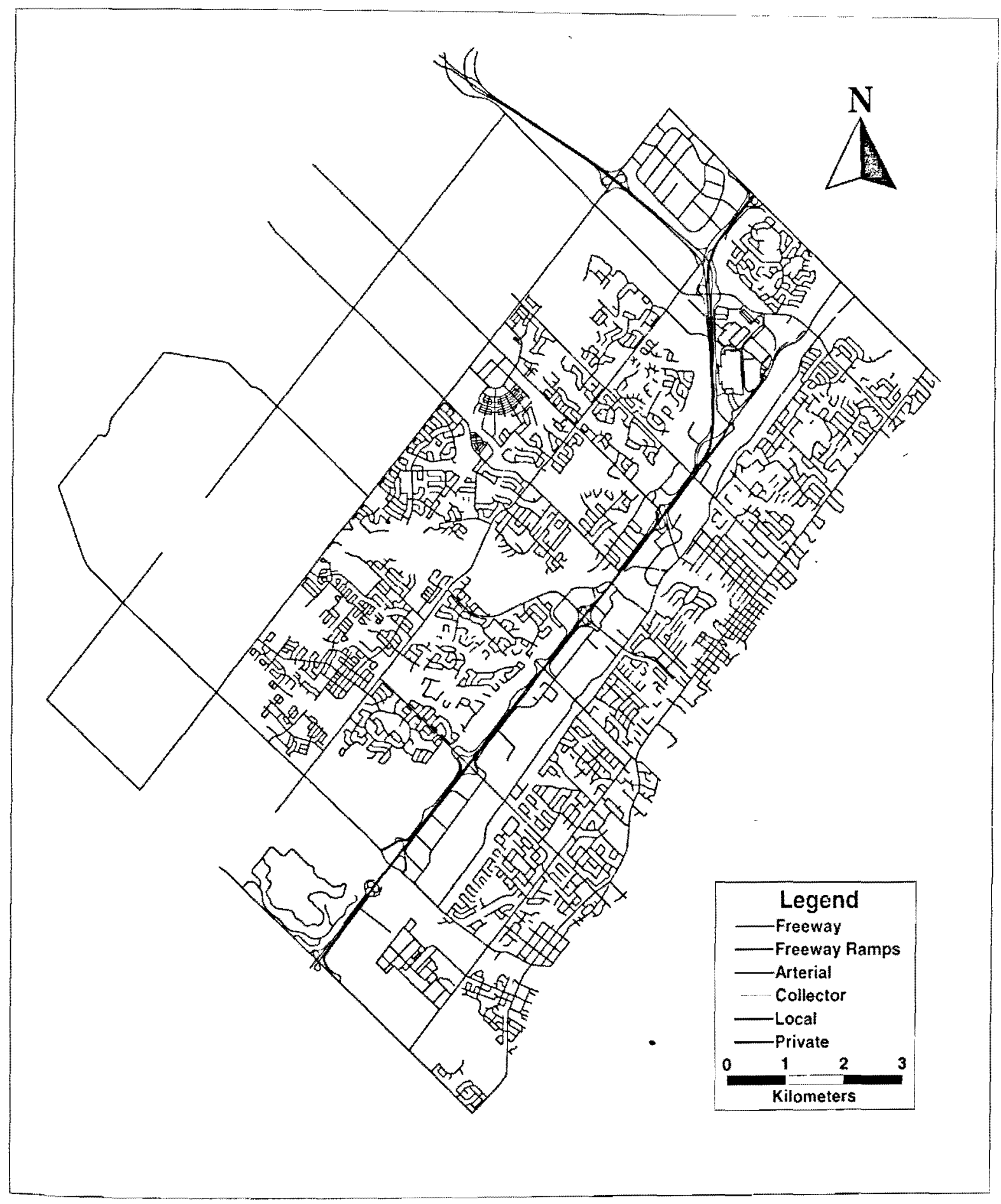

Figure 14: Town of Oakville, 1996 Road Network and Functional Class 


\subsection{SOCIO-ECONOMIC DATA}

Transportation is a derived activity, in that people do not typically travel for travel's own sake. Transportation occurs to facilitate community activities, both social and economic. Traffic is thus, the product of an interaction between urban land use and the transportation system. Thus a travel demand model needs to consider the distribution of socio-economic activities throughout the study area. In this model all travel over a transportation network is assumed to be a function of the population and employment throughout the Greater Toronto Area.

Socio-economic data were extracted from two sources: the 1996 Canada Census, and the 1996 Transportation Tomorrow Survey (TTS). Given that the TTS data was readily available for each individual traffic zone (subsequent sections of the report will describe the traffic zone system adopted for the study), it was applied in the development of the transportation model.

The traffic zones used are consistent with those developed and documented by the Data Management Group. Census data were used to check the validity of the TTS data. Data regarding the population and employment within the Town, and surrounding GTA are summarized in the Tables 3 and 4 .

A comparison of the population and employment data contained in each of the 1996 TTS and 1996 Census databases reveal that the data are comparable, as the data vary by only a few percentage points. 
Table 3

Population Summarized by Region

\begin{tabular}{|c|c|c|c|c|}
\hline Geographic Area & $\mathbf{1 9 9 6}$ TTS & $\mathbf{1 9 9 6}$ Census & Difference & Difference (\%) \\
\hline Toronto & $2,305,558$ & $2,386,213$ & $(80,655)$ & 3.4 \\
\hline Durham & 450,354 & 458,616 & $(8,262)$ & 1.8 \\
\hline York & 567,689 & 592,445 & $(24,756)$ & 4.2 \\
\hline Peel & 812,512 & 852,526 & $(40,014)$ & 4.7 \\
\hline Halton & 328,264 & 339,875 & $(11,611)$ & 3.4 \\
\hline Hamilton-Wenthworth & 461,990 & 467,799 & $(5,809)$ & 1.2 \\
\hline Total GTA & $4,926,367$ & $5,097,474$ & $(171,107)$ & 3.4 \\
\hline
\end{tabular}

*Source - 'GTA A.M. Peak Model Documentation and User's Guide' Peter Dalton.

\begin{tabular}{|c|c|c|c|c|}
\hline \multicolumn{5}{|c|}{ Table 4 } \\
\hline Employment Summarized by Region \\
\hline Geographic Area & $\mathbf{1 9 9 6}$ TTS & $\mathbf{1 9 9 6}$ Census & Difference & Difference (\%) \\
\hline Toronto & $1,257,005$ & $1,209,010$ & 47,995 & 4.0 \\
\hline Durham & 149,552 & 148,545 & 1,007 & 0.7 \\
\hline York & 275,724 & 267,550 & 8,174 & 3.1 \\
\hline Peel & 389,275 & 390,755 & $(1,480)$ & 0.4 \\
\hline Halton & 141,390 & 148,275 & $(6,885)$ & 4.6 \\
\hline Hamilton-Wenthworth & 181,219 & 183,615 & $(2,396)$ & 1.3 \\
\hline Total GTA & $2,394,165$ & $2,347,750$ & 46,415 & 2.0 \\
\hline
\end{tabular}

*Source - 'GTA A.M. Peak Model Documentation and User's Guide' Peter Dalton.

The overall population for the GTA recorded in the 1996 TTS database is $3.4 \%$ lower than that recorded in the 1996 Census. The overall employment for the GTA recorded in the 1996 TTS is $2.0 \%$ higher than the employment levels enumerated in the 1996 Census. The 1996 census and 1996 TTS were conducted at different times of the year which could partially explain the differences between the two databases. The population and employment totals determined by the 1996 TTS are a reasonable approximation of the population and employment for the GTA. 
CHAPTER 6

DEVELOPMENT OF THE MODEL 
The purpose of a transportation model is to estimate travel demand over the transportation network based on available information regarding populations and the transportation system. The predictive ability of such a model can be of great value in estimating the future transportation needs of future growth scenarios, or the implications on demand of changes in development scenarios and transportation system.

\subsection{TEMPORAL DISTRIBUTION OF TRIPS}

The development of the model is based on the travel behaviour captured in the 1996 TTS. To increase the number of observations upon which the model is based, trips were generated and distributed for the three-hour morning peak period. Peak period traffic volumes were then converted to represent the morning peak hour traffic volumes by applying a 'peak hour' factor.

Data were extracted from the 1996 TTS that indicated the total automobile trips captured in the survey. The data indicated a morning Peak Period of 6:00 to 9:00AM, in which a total of 1,737,751 auto driver trips were made, and an AM Peak Hour from 8:00 to 9:00 AM in which a total of 778,427 automobile trips were made. Thus, AM Peak Period traffic volumes can be converted to AM Peak Hour traffic volumes by applying a factor of 0.448 . Figure 15 illustrates the distribution of trip start times by mode of travel. 


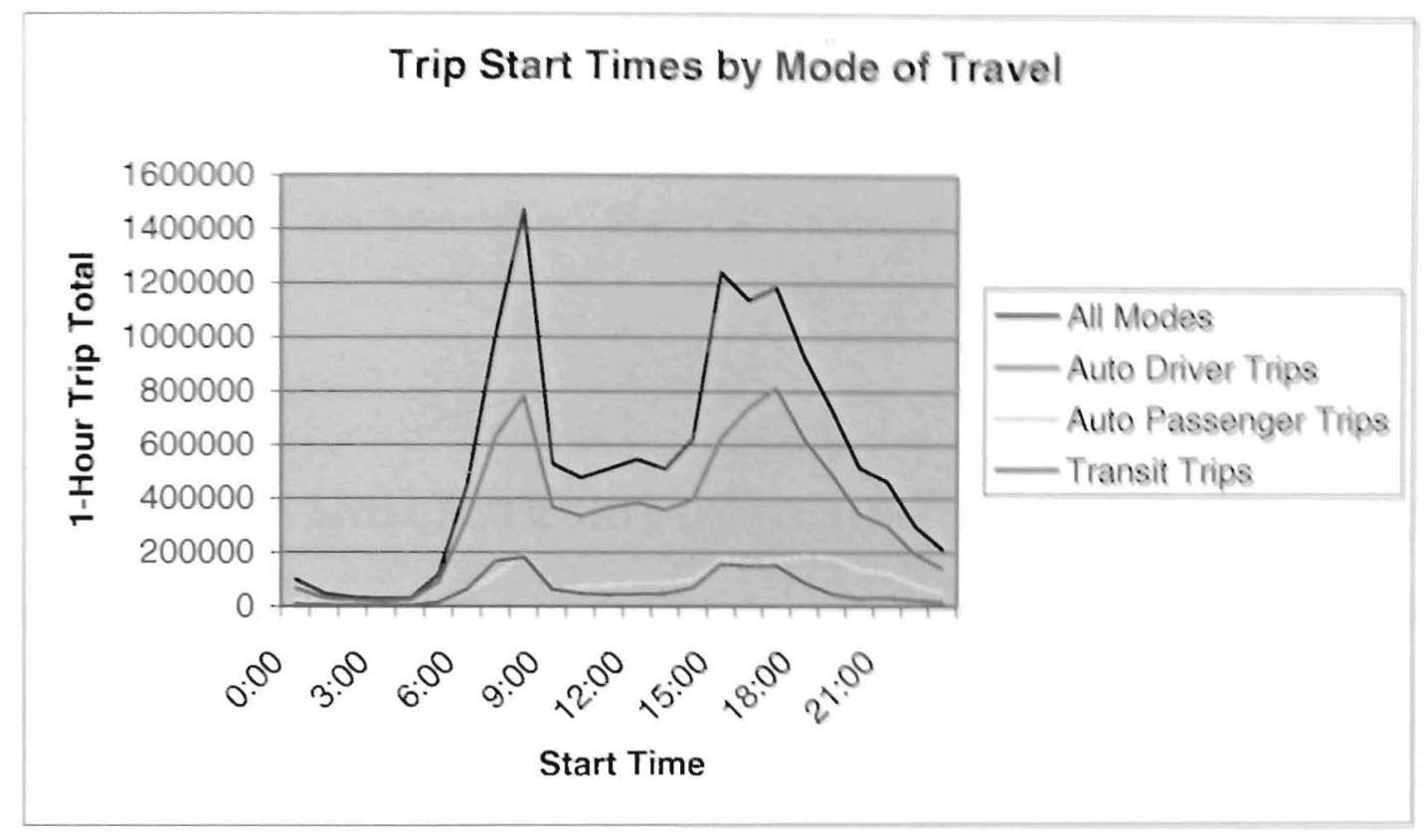

Figure 15: Distribution of Travel Trip Start Times

The above figure illustrates the mode split of travel trips in the GTA. The dominance of auto trips is quite evident.

\subsection{TRAFFIC ANALYSIS ZONES}

The nature of the model being developed necessitated the development of traffic analysis zones (TAZ's). Zonal attributes were used in the generation and distribution of trips. To facilitate data analysis and the extraction of data from the TTS database, traffic zone boundaries as applied in the TTS were followed in this assignment. The extent of the boundaries was obtained from 1996 GTA Boundaries, (a complete list of References is provided). It was initially intended to use the numbering convention followed by the DMG. This was later abandoned and a numbering convention corresponding to the road network endpoint identification numbers (at zone centroids) was adopted. 
The GTA is comprised of over 2,500 TAZ's. The Town of Oakville is divided into 49 traffic zones. Figure 16 illustrates the Greater Toronto Area included in the 1996 TTS, and identifies the regional zone boundaries. Figure 17 illustrates the traffic zones within the Town of Oakville.

\subsection{CENTROIDS AND CENTROID CONNECTORS}

In building the model, it is necessary to connect the traffic analysis zones to the road network. This is accomplished by connecting the centroid of each TAZ to one or more network links.

Centroids are special nodes in the transportation network that represent the centers of the transportation analysis zones. Trips originating from a zone or destined to a zone are assumed to originate from or be destined to the centroid of the zone in question.

Centroid connectors are not real physical links, but instead are a simplified representation of the local road network. It should be noted that a special property of centriod connector links is that paths between an origin and destination travel over one centroid connector at the beginning and end of the trip respectively, but never use centroid connectors in any other way.

Trips originating from or destined to zones beyond the Town of Oakville boundary are assumed to originate from or be destined to External Cordon Stations. These cordon stations are simply nodes in the transportation network where principal external routes connect to the transportation network within the Town's boundary. Figure 18 illustrates the traffic zone centroid connectors, as well as the external cordon Stations. 


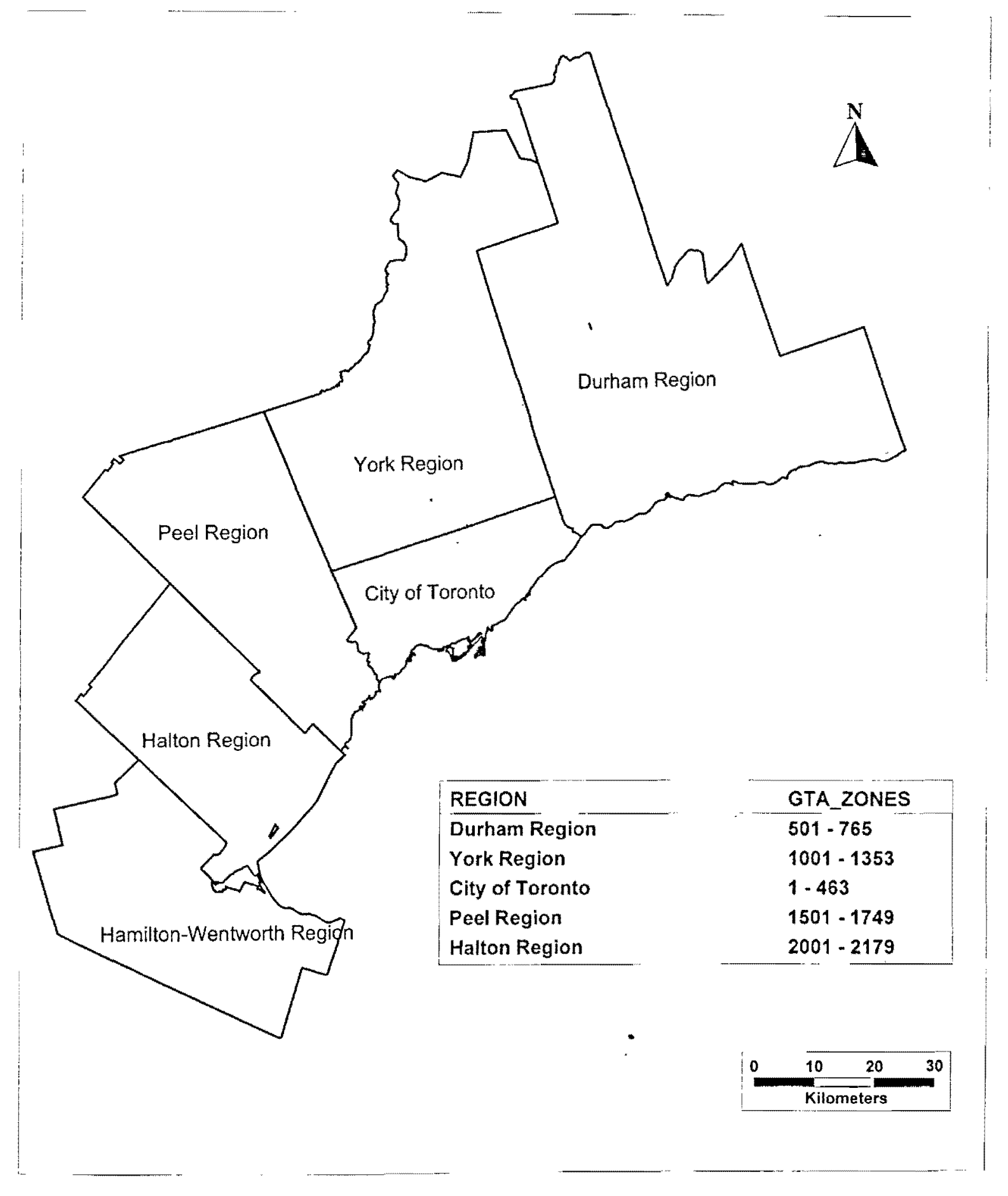

Figure 16: 1996 GTA Zones 


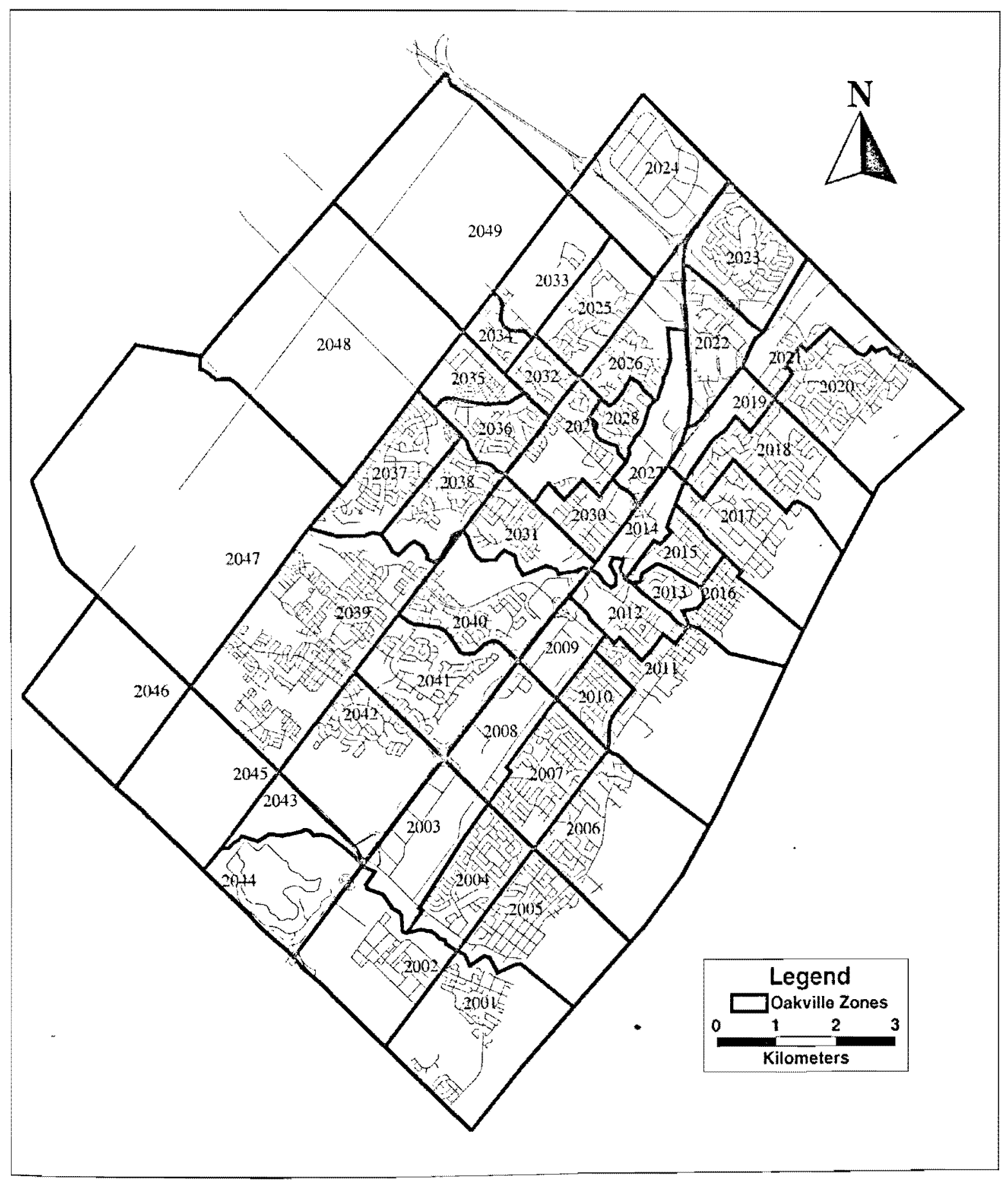

Figure 17: Town of Oakville, 1996 Traffic Zones 


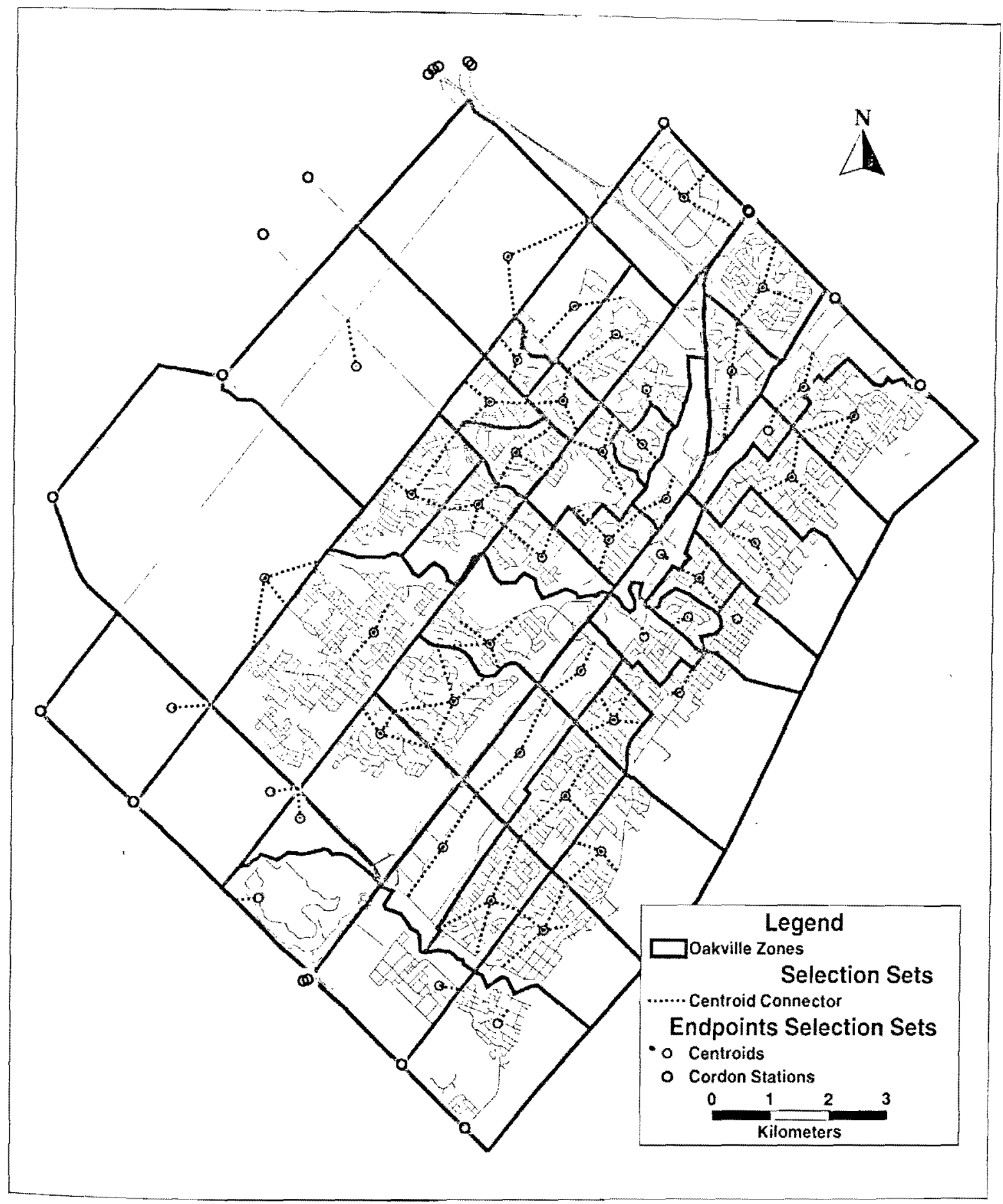

Figure 18: Town of Oakville, 1996 Traffic Zones, Centriod Connectors, and External Cordon Stations 


\subsection{TRIP GENERATION}

Trip generation is the first stage of the development of a travel demand model. The aim of this process is to predict the total number of trips produced and attracted to each traffic zone within the study area (i.e. how many trips originate from and are destined to each traffic zone).

For the model developed, trips are generated for the entire AM peak period, and then a factor is used at a subsequent stage in the modelling process to convert the peak period trips generated to AM peak hour trips.

Relationships were developed between trips originating and destined to each traffic zones and the employment and population levels within the zone. This was done for aggregations of traffic zones at the regional level: Durham Region, York Region, City of Toronto, Peel Region, Halton Region, and the Hamilton-Wentworth Region. The trip generation equations were developed by trip purpose (i.e. for Home-Based trips), these are assumed to account for the majority of automobile trips on the road network during the AM peak period. HomeBased trips are trips for which the home is either the origin or destination of the journey. Since I am dealing with an AM peak period model, Home-Based trips are work trips that originate at home. It should be noted that I dealt with only auto driver trips. Thus, the trips generated refer to automobile trips only.

Table 5 summarizes the results of the trip generation procedure. Details of the trip generation procedures can be found in Appendix C. In applying the trip generation procedure trip 
productions and attractions were determined separately. This results in a minor discrepancy between productions and attractions. The trips presented below were balanced so that the total number of trip productions and attractions are equal.

\begin{tabular}{|c|c|c|}
\hline \multicolumn{3}{|c|}{$\begin{array}{c}\text { Table } 5 \\
\text { Summary of Trip Generation }\end{array}$} \\
\hline Zone & Productions & Attractions \\
\hline 2001 & 1,693 & 186 \\
\hline 2002 & 16 & 93 \\
\hline 2003 & 0 & 2,371 \\
\hline 2004 & 2,200 & 132 \\
\hline 2005 & 2,602 & 273 \\
\hline 2006 & 948 & 185 \\
\hline 2007 & 1,815 & 188 \\
\hline 2008 & 0 & 1,612 \\
\hline 2009 & 0 & 2,518 \\
\hline 2010 & 959 & 31 \\
\hline 2011 & 1,545 & 640 \\
\hline 2012 & 1,984 & 742 \\
\hline 2013 & 681 & 0 \\
\hline 2014 & 33 & 1,129 \\
\hline 2015 & 667 & 523 \\
\hline 2016 & 773 & 1,404 \\
\hline 2017 & 1,100 & 189 \\
\hline 2018 & 1,070 & 364 \\
\hline 2019 & 165 & 109 \\
\hline 2020 & 2,019 & 31 \\
\hline 2021 & 440 & 774 \\
\hline 2022 & 0 & 1,496 \\
\hline 2023 & 2,813 & 76 \\
\hline 2024 & 0 & 2,354 \\
\hline 2025 & 1,584 & 122 \\
\hline 2026 & 2,054 & 283 \\
\hline 2027 & 292 & 1,087 \\
\hline 2028 & 639 & 48 \\
\hline 2029 & 2,547 & 1,077 \\
\hline
\end{tabular}

\begin{tabular}{|c|c|c|}
\hline \multicolumn{3}{|c|}{$\begin{array}{c}\text { Table } 5 \text { (Continued) } \\
\text { Summary of Trip Generation }\end{array}$} \\
\hline Zone & Productions & Attractions \\
\hline 2030 & 1,283 & 879 \\
\hline 2031 & 1,581 & 63 \\
\hline 2032 & 1,141 & 32 \\
\hline 2033 & 15 & 0 \\
\hline 2034 & 0 & 18 \\
\hline 2035 & 0 & 300 \\
\hline 2036 & 1,490 & 16 \\
\hline 2037 & 1,736 & 48 \\
\hline 2038 & 1,736 & 49 \\
\hline 2039 & 915 & 135 \\
\hline 2040 & 2,360 & 996 \\
\hline 2041 & 3,085 & 721 \\
\hline 2042 & 2,019 & 481 \\
\hline 2043 & 24 & 0 \\
\hline 2044 & 0 & 31 \\
\hline 2045 & 32 & 0 \\
\hline 2046 & 0 & 40 \\
\hline 2047 & 34 & 99 \\
\hline 2048 & 130 & 62 \\
\hline 2049 & 7 & 31 \\
\hline Durham & 151,754 & 114,738 \\
\hline York & 214,592 & 209,782 \\
\hline Toronto & 582,795 & 666,340 \\
\hline Peel North & 250,303 & 265,200 \\
\hline Peel South & 48,012 & 19,376 \\
\hline Halton North & 28,684 & 65,505 \\
\hline Halton South & 51,132 & 22,601 \\
\hline Hamilton & 137,622 & 125,542 \\
\hline Total & $1,513,120$ & $1,513,120$ \\
\hline
\end{tabular}

The trip generation procedures were applied for the entire GTA. The travel demand model should not consider the Town of Oakville in isolation. Trips from various parts of the GTA are expected to travel on the Town's roadways. In addition trips originating in the Town are 
expected to be distributed to other parts of the GTA. - Conversely, zones within the Town are expected to attract traffic from many parts of the GTA.

Peel and Halton Regions were divided into north and south sections in preparation for traffic assignment (further explanation are provided in Section 6.6). It should be noted that Halton South excludes the Town of Oakville, which is made up of zones 2001 to 2049. A further summary of the trip generation data is presented in Table 6.

\begin{tabular}{|c|c|c|c|c|}
\hline \multicolumn{5}{|c|}{ Table 6 } \\
\hline Jurisdiction & Population & Employment & Productions & Attractions \\
\hline Oakville & 123,639 & 30,306 & 48,227 & 24,037 \\
\hline Durham & 450,354 & 149,552 & 151,754 & 114,738 \\
\hline York & 567,689 & 275,724 & 214,592 & 209,782 \\
\hline Toronto & $2,305,558$ & $1,257,005$ & 582,795 & 666,340 \\
\hline Peel & 812,512 & 389,275 & 298,315 & 284,576 \\
\hline Halton & 204,625 & 111,084 & 79,816 & 88,105 \\
\hline Hamilton & 461,990 & 181,219 & 137,622 & 125,542 \\
\hline Total & $4,926,367$ & $2,394,165$ & $1,513,120$ & $1,513,120$ \\
\hline
\end{tabular}

The data presented in the above table indicates that the Town of Oakville, the Regional Municipality of Durham, and to a lesser extent, the Regional Municipalities of York, Peel, Halton, and Hamilton-Wentworth, are net producers of autodriver trips. The City of Toronto is a net attractor of trips. This suggests that the City of Toronto is the strongest employment draw in the GTA, and as such, attracts travelers from the neighbouring municipalities. 


\subsection{TRIP DISTRIBUTION}

Given the shortcomings of the fratar methods of trip distribution, trip productions and attractions were distributed by applying a gravity model of trip distribution. Fortunately, TransCAD software contains procedures for both the calibration, and evaluation of gravity models.

As noted by Easa (\#15), the process of calibrating the gravity model depends on the assumed mathematical function of the friction factor function. In this case the friction factor function is assumed to take the exponential form (as discussed in Section 2.2.3).

As noted in Section 2.2.3, in order to apply a gravity model, the following inputs are required:

The number of trips originating in each zone;

The number of trips terminating in each zone;

The impedance between the origin and destination zone pairs; and

The friction factor between the origin-destination zone pairs.

The first two of these inputs are the products of the trip generation procedure. The impedance to travel between origin-destination zone pairs was for this assignment, assumed to be the travel distance between the zones in question (alternatively, the impedance may have been determined based on the travel time between zones). The use of travel distance is consistent with the Newtonian analogy, as the distribution is a function of the geographic separation between zones. 
Before continuing to discuss the application of the gravity model, a number of points need to be noted:

$>$ An impedance matrix needs to consider the impedances to travel between all zones within the GTA, not only those of the Town of Oakville. However, the original road network that I was provided with contained roadways only within the Town of Oakville's municipal boundary.

$>$ The impedances to travel between zones external to the Town of Oakville, needed to be accounted for.

$>$ The solution to this dilemma was to arbitrarily extend the road network from the Town to the centroids of the neighbouring regions. These additional connectors were simply intended to enable the measurement of the impedances to travel between the Town's zones, and the centers of gravity (assumed to be the geographic centers) of the neighbouring municipalities. This extended road network is illustrated in Figure 19.

Given this extended road network, a 'shortest path' procedure was executed in the TransCAD software. The output of this procedure was a shortest path matrix between origin-destination pairs throughout the entire Greater Toronto Area. This matrix is provided in Appendix D.

Given that three of the four inputs required for gravity model evaluation are determined, a gravity model has now be calibrated. Calibration involves the determination of the friction factor equation parameters such that the gravity model can satisfactorily reproduce the trip length distribution for the entire study area. 


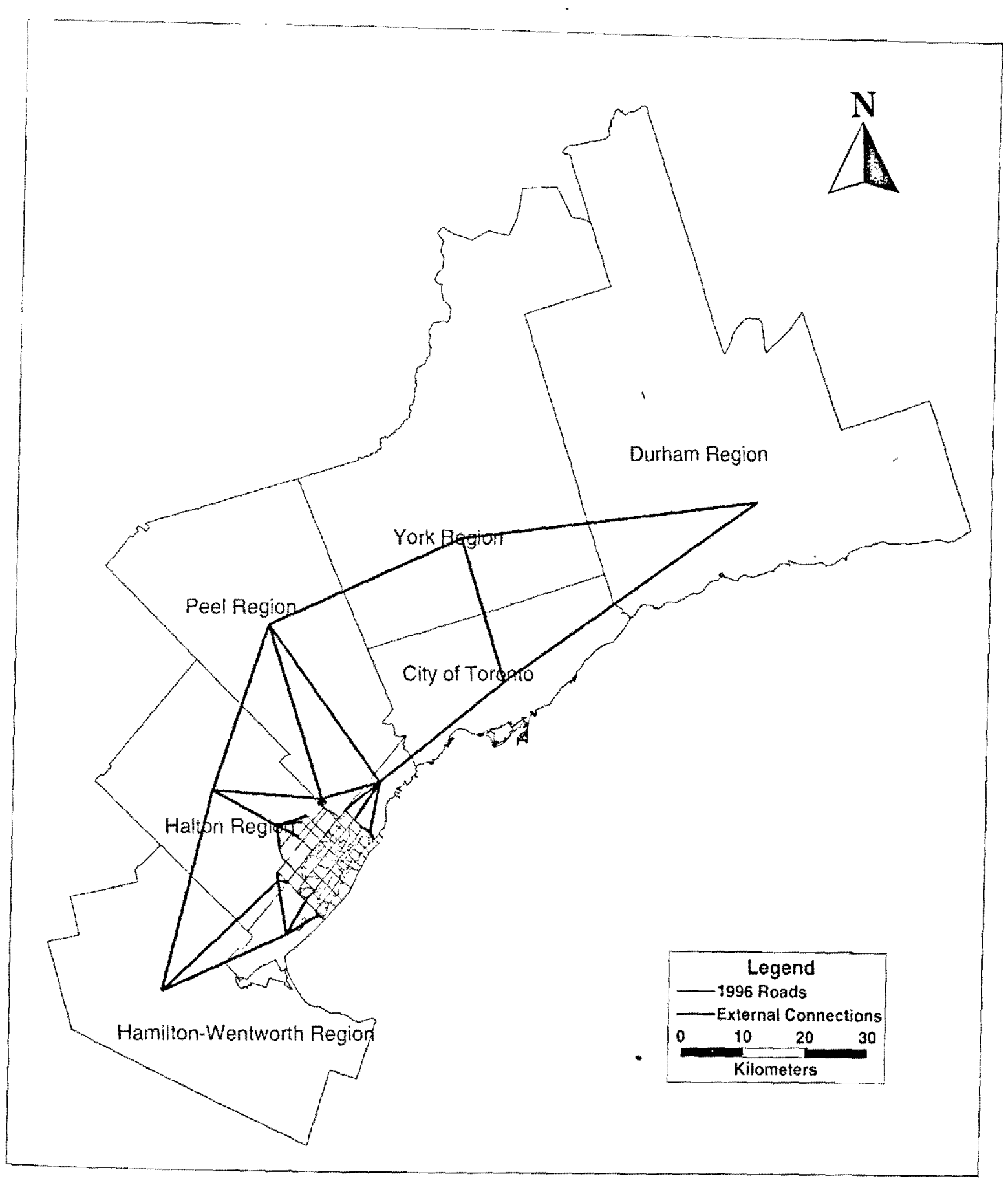

Figure 19: The Extended Road Network 
TransCAD software permits the calibration of a Gravity Model given a base year productionattraction matrix, an impedance matrix, and a zone layer. The calibration procedures use the base year production-attraction matrix to generate an Observed Trip Length Distribution (OTLD). The model is then calibrated such that the OTLD is reproduced as closely as possible.

The required base-year production-attraction matrix was extracted from the Transportation Tomorrow Survey directly using the Internet Data Retrieval System. Details of the extraction are presented in Appendix D. The extraction can be summarized as follows:

1996 TTS;

Row attribute - 1996 GTA zone of origin;

Column attribute - 1996 GTA zone of destination;

Start time -600 to $900 ;$ and

Primary travel mode of trip - auto driver

The results of the extraction were then grouped for external zones so as to represent the origins and destinations to each of City of Toronto, and the Regional Municipalities of Durham, York, Peel North, Peel South, Halton North, Halton South, and HamiltonWentworth, as a whole, rather than the individual TTS traffic zones that make up these neighbouring municipalities, 
The gravity model calibration procedure iteratively estimates the parameter $(c)$, and at each iteration compares the observed mean impedance of the forecast to the observed mean impedance. The mean impedance is defined by the following relationship (Caliper).

$$
D=\left(\Sigma t_{i j} * d_{i j}\right) / T
$$

Where $\quad t_{i j}=$ the number of trip between zones $i$ and $j$

$$
\begin{aligned}
& d_{i j}=\text { the impedance to travel of going from zone } \mathrm{i} \text { to } \mathrm{j} \\
& T=\text { the total number of trips }
\end{aligned}
$$

The model was then calibrated using the software's gravity model calibration procedure, to a mean cost convergence of 0.01 (difference between the computed and observed trip average trip length in kilometers) such that the friction factor function was given by:

$$
f(d i j)=\exp \left(-0.0523 * d_{i j}\right)
$$

Details of the calibration procedure are provided in Appendix D.

The gravity model was then evaluated, given the estimated productions and attractions determined from the trip generation procedure. Other inputs to the procedure included the trip length impedance matrix, and the calibrated friction factor function. 
The development of an origin-destination matrix requires that the model be solved iteratively.

Such a matrix is based on applying the model to the productions and attractions (by zone).

Details of the Trip Distribution procedure, as well as the resulting AM peak period auto driver origin-destination matrix are presented in Appendix D. Also in the appendix is the AM peak hour origin-destination matrix (AM peak period multiplied by the peak hour factor 0.448 determined in Section 6.1). The AM peak period origin-destination matrix is summarized in Table 7.

\begin{tabular}{|c|c|c|c|c|c|c|c|}
\hline \multicolumn{7}{|c|}{ Table 7 } \\
\hline & \multicolumn{7}{|c|}{ AM Peak Period Origin Destination Matrix Summary } \\
\cline { 2 - 9 } Origin & Halton & Durham & York & Toronto & Peel & $\begin{array}{c}\text { Hamilton- } \\
\text { Wentworth }\end{array}$ & Total \\
\hline Halton & 49,902 & 470 & 4,003 & 27,682 & 23,829 & 22,157 & $\mathbf{1 2 8 , 0 4 3}$ \\
\hline Durham & 693 & 99,631 & 14,708 & 32,565 & 3,966 & 192 & $\mathbf{1 5 1 , 7 5 4}$ \\
\hline York & 3,032 & 4,738 & 105,342 & 74,406 & 26,542 & 533 & $\mathbf{2 1 4 , 5 9 2}$ \\
\hline Toronto & 10,271 & 8,197 & 58,142 & 482,590 & 20,748 & 2,846 & $\mathbf{5 8 2 , 7 9 5}$ \\
\hline Peel & 25,282 & 1,439 & 26,185 & 40,273 & 199,463 & 5,673 & $\mathbf{2 9 8 , 3 1 5}$ \\
\hline $\begin{array}{c}\text { Hamilton- } \\
\text { Wentworth }\end{array}$ & $\mathbf{2 3 , 2 8 2}$ & 134 & 1,152 & 7,867 & 10,277 & 94,910 & $\mathbf{1 3 7 , 6 2 2}$ \\
\hline Total & $\mathbf{1 1 2 , 4 6 2}$ & $\mathbf{1 1 4 , 6 0 9}$ & $\mathbf{2 0 9 , 5 3 2}$ & $\mathbf{6 6 5 , 3 8 1}$ & $\mathbf{2 8 4 , 8 2 4}$ & $\mathbf{1 2 6 , 3 1 1}$ & $\mathbf{1 , 5 1 3 , 1 2 0}$ \\
\hline
\end{tabular}

The base year origin-destination matrix representing the actual trip distribution as captured by the travel survey is presented in Table 8 .

\begin{tabular}{|c|c|c|c|c|c|c|c|}
\hline \multicolumn{8}{|c|}{ Table 8 } \\
\hline \multirow{3}{*}{ AM Peak Period Base Year Origin Destination Matrix Summary } \\
\cline { 2 - 9 } & \multicolumn{7}{|c|}{ Destination } \\
\hline Halton & $\mathbf{7 2 , 7 1 9}$ & 145 & 1,342 & 14,166 & 23,689 & 9,613 & $\mathbf{1 2 1 , 6 7 4}$ \\
\hline Durham & 234 & 98,778 & 10,710 & 34,088 & 1,893 & 125 & $\mathbf{1 4 5 , 8 1 9}$ \\
\hline York & 560 & 2,464 & 115,451 & 79,074 & 9,602 & 180 & $\mathbf{2 0 7 , 3 3 1}$ \\
\hline Toronto & 4,180 & 7,661 & 60,061 & 445,296 & 47,919 & 975 & $\mathbf{5 6 6 , 0 9 2}$ \\
\hline Peel & 12,323 & 839 & 12,246 & 75,422 & $\mathbf{1 8 6 , 0 5 4}$ & 1,486 & $\mathbf{2 8 8 , 3 7 0}$ \\
\hline $\begin{array}{c}\text { Hamilton- } \\
\text { Wentworth }\end{array}$ & $\mathbf{1 6 , 5 1 0}$ & 75 & 250 & 3,418 & 3,831 & 103,706 & $\mathbf{1 2 7 , 7 9 0}$ \\
\hline Total & $\mathbf{1 0 6 , 5 2 6}$ & $\mathbf{1 0 9 , 9 6 2}$ & $\mathbf{2 0 0 , 0 5 1}$ & $\mathbf{6 5 0 , 4 6 4}$ & $\mathbf{2 7 2 , 9 8 8}$ & $\mathbf{1 1 6 , 0 8 5}$ & $\mathbf{1 , 4 5 7 , 0 7 6}$ \\
\hline
\end{tabular}


The difference between these two matrices is presented in the Table 9 .

\begin{tabular}{|c|c|c|c|c|c|c|c|}
\hline \multicolumn{8}{|c|}{$\begin{array}{c}\text { Table } 9 \\
\text { Difference Between Projected and Observed AM Peak Period Traffic Volumes }\end{array}$} \\
\hline \multirow[b]{2}{*}{ Origin } & \multicolumn{7}{|c|}{ Destination } \\
\hline & Halton & Durham & York & Toronto & Peel & $\begin{array}{l}\text { Hamilton- } \\
\text { Wentworth }\end{array}$ & Total \\
\hline Halton & 22,817 & $(325)$ & $(2,661)$ & $(13,516)$ & $(140)$ & $(12,544)$ & $(6,369)$ \\
\hline Durham & $(459)$ & (853) & $(4,007)$ & 1,523 & $(2,073)$ & $(67)$ & $(5,935)$ \\
\hline York & $(2,472)$ & $(2,274)$ & 10,109 & 4,668 & $(16,940)$ & (353) & $(7,261)$ \\
\hline Toronto & $(6,091)$ & (536) & 1,919 & $(37,294)$ & 27,171 & $(1,871)$ & $(16,703)$ \\
\hline Peel & $(12,959)$ & $(600)$ & $(13,939$ & 35,149 & $(13,409)$ & $(4,187)$ & $(9,945)$ \\
\hline $\begin{array}{l}\text { Hamilton- } \\
\text { Wentworth }\end{array}$ & & (59) & (902) & $(4,449)$ & $(6,446)$ & & $(\mathbf{9 , 8 3 2 )}$ \\
\hline Total & $(5,936)$ & $(4,647)$ & $(9,481$ & $(13,917)$ & $(11,836)$ & $(10,226)$ & $(56,044)$ \\
\hline
\end{tabular}

The number of trips generated by the model appears to be slightly higher than the number of trips captured by the survey. This is one reason why a discrepancy exists between the matrices summarized in Tables $\mathbf{7}$ and $\mathbf{8}$. Some discrepancy between the two matrices are also to be expected given that any developed model for trip distribution represents a simplification of a complex real world phenomenon. Alternatively, additional discrepancies are likely to result as a result of the assumptions applied in developing the gravity model, namely, the use of a simplified street network (beyond the extents of the Town of Oakville), as well as the application of an impedance matrix based on the travel distance between zones, as opposed to alternative travel costs (i.e. travel time).

\subsection{TRAFFIC ASSIGNMENT}

The purpose of traffic assignment is to predict the flow of trips between pairs of origins and destinations over the transportation network. In building the model the intent is to replicate the amount of traffic on the principal routes of the transportation network. 
The Stochastic User Equilibrium procedure was applied to generate the traffic assignment documented below. The this method of estimating the assignment was selected because it accounts for the that users, seek to maximize their travel utility, but do so based on imperfect information regarding alternative paths through the network.

This assignment method also acknowledges that the transportation link costs depend on the volume using the link. In this method the link performance function discussed in an earlier section of the report is assumed to be valid. Thus, as more volume is assigned to a particular link, travel times over the link increase. When travel times over a link increase, subsequent road users are discouraged from using the link. In this way, the assignment method applies the principles of supply and demand, in that, as routes become congested, the available capacity over the route is diminished (supply), resulting in a fewer additional travelers using the route (demand).

The results of the traffic assignment procedure are illustrated in Figure 20. Details of the traffic assignment are presented in Appendix $\mathbf{E}$. The equilibrium condition was reached after 7 iterations. In addition to indicating the assigned traffic volumes on the roadways, Figure 20 also indicates the volume to capacity $(\mathrm{v} / \mathrm{c})$ ratios for the roadway sections. The ratios indicate the extent to which the roadway capacity is utilized by the assigned traffic. Sections in green indicate that the assigned traffic volumes are below the roadway capacity. Those coloured red are over capacity. Sections in black indicate assigned volumes more than twice the roadway capacity. 


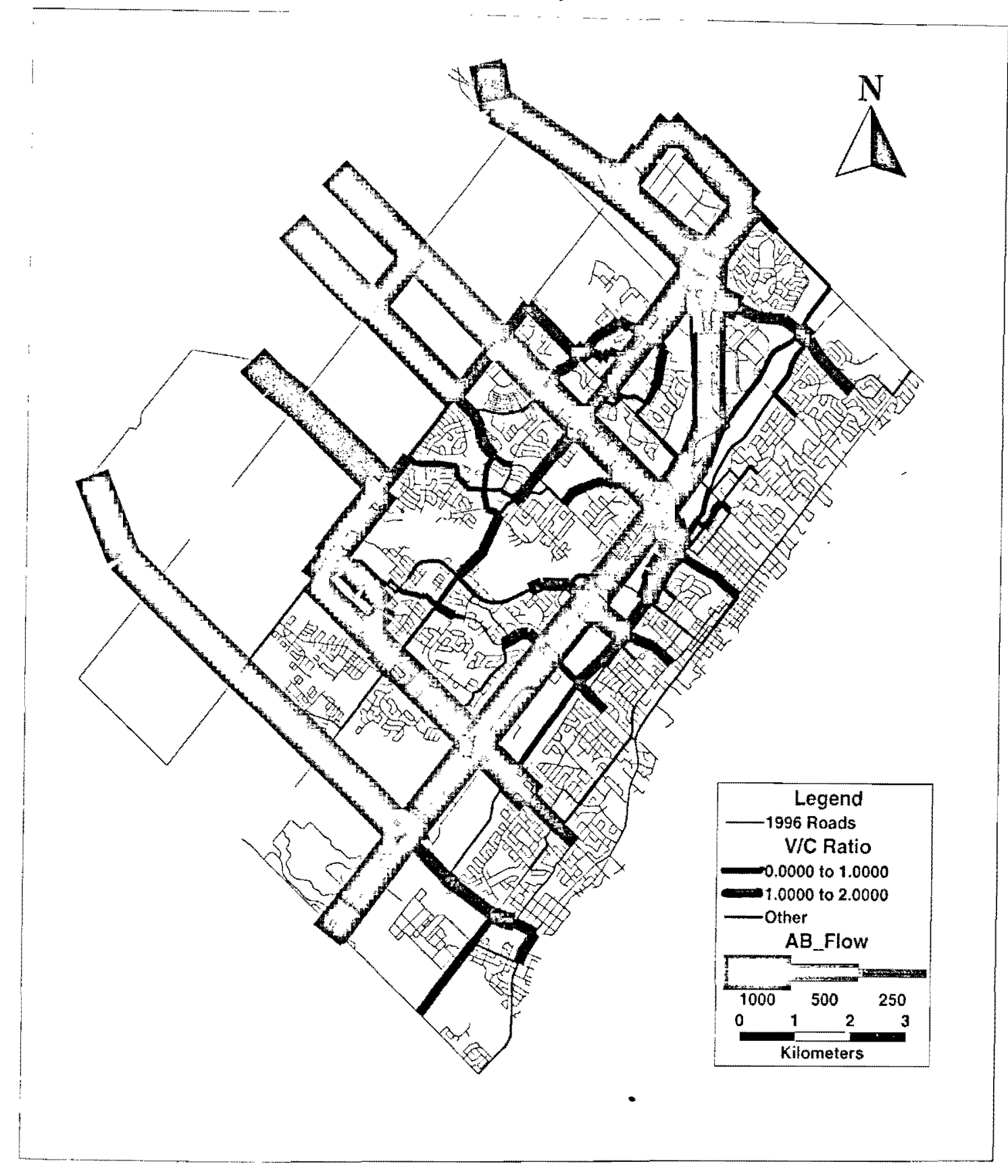

Figure 20 Town of Oakville, Assignment of AM Peak Hour Trips 


\subsection{GREATER TORONTO AREA CORDON COUNT PROGRAM}

The Greater Toronto Area Cordon Count Program is an initiative to assemble and manage the vast number of traffic counts that are taken annually by various jurisdictions throughout the GTA. The Data Management Group has been entrusted with assembling and maintaining the cordon database.

A number of Working Papers have been prepared by the Joint Program in Transportation that present summaries of the cordon data. A series of screenlines are used to across which traffic flows are measured. These screen lines represent cross sections through principal travel corridors throughout the Greater Toronto Area. These screenline volume summaries present an opportunity to evaluate the accuracy of the traffic volumes predicted by the model. The screenlines are illustrated in Figure 21. 


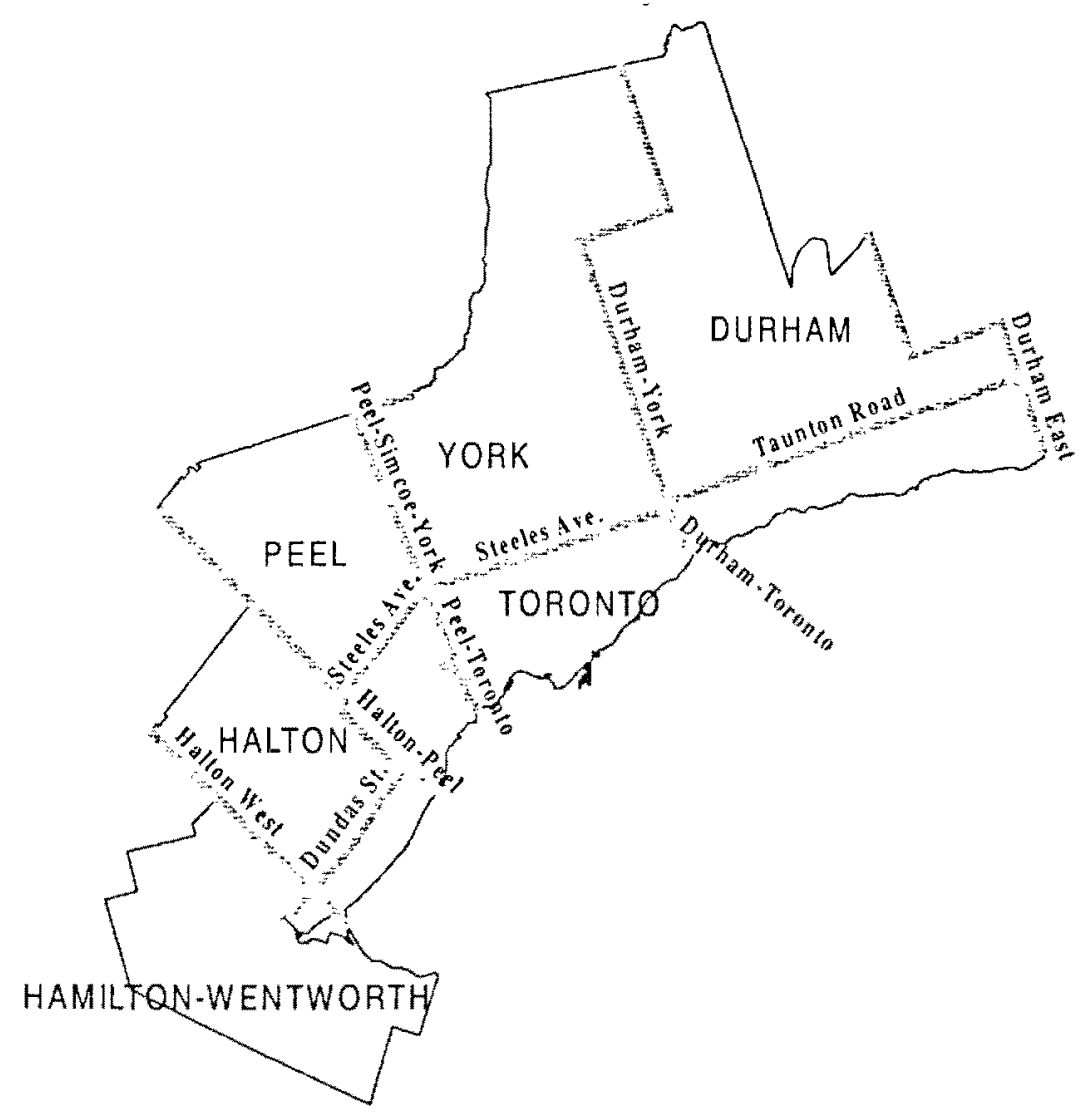

Figure 21: Screenline Definition 


\subsection{MODEL VALIDATION}

The model predicts traffic levels on roadways within the Town based on the population and employment data contained in the TTS travel survey. Validation of the model requires some comparison of the modeled traffic volumes, to actual vehicular volumes on the study area roadways.

The predicted traffic volumes were compared to traffic volume data contained in the Greater Toronto Area Cordon Count Program discussed in Section 6.7. The comparisons were made based on a screenline level of detail. In this case modeled traffic volumes crossing the screenlines identified in the Cordon Count Program, with the volumes identified in the Program.

\begin{tabular}{|c|c|c|c|c|}
\hline \multicolumn{5}{|c|}{ Table 10 } \\
Comparison of AM Peak Hour Traffic Volumes \\
\hline \multirow{3}{*}{ Screenline } & Cordon Program & \multicolumn{2}{c|}{ Model } \\
\cline { 2 - 5 } & NB/EB & SB/WB & NB/EB & SB/WB \\
\hline Halton West & 14,379 & 10568 & 9,500 & 8,200 \\
\hline Halton Peel & 19,680 & 10,421 & 13500 & 15,900 \\
\hline Peel Simcoe & 9,544 & 4,508 & 10,500 & 11,500 \\
\hline Steeles Avenue & 27,378 & 40,500 & 26,000 & 33,300 \\
\hline Durham York & 1,995 & 6,463 & 2100 & 6,600 \\
\hline Durham Toronto & 8,715 & 25,031 & 12,200 & 20,000 \\
\hline
\end{tabular}

Screenline analysis indicates some differences between the modeled traffic volumes, and those captured in the Cordon Count Program. At some screenlines the modeled volumes are higher than those in the Cordon Counts, at others the model underestimates the traffic volumes. A number of factors could contribute to these differences. 
Seasonal Variation - the Transportation Tomorrow Survey was conducted in the fall, while the cordon data to which the modeled traffic volumes were compared were collected in the months of May and June. There is the strong possibility that traffic volumes peak during the summer months, thereby exaggerating any differences between the modeled and counted volumes. Seasonal variation in traffic volumes is illustrated in Figure 22.

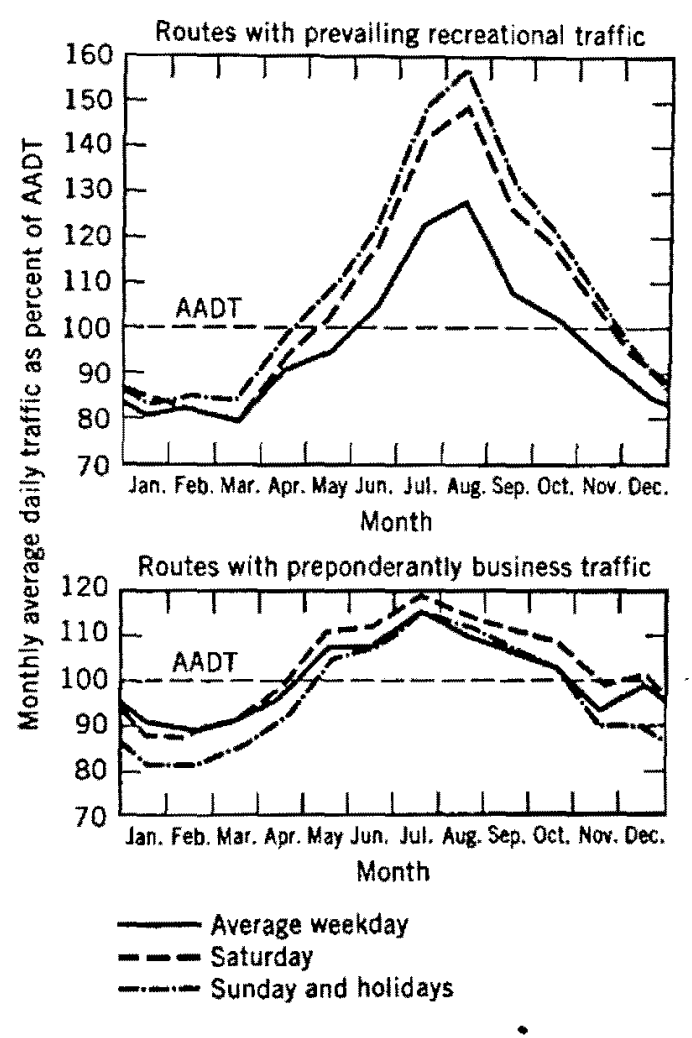

Figure 22: Monthly Variation in Average Annual Traffic Volumes (Mannering and Kilarski)

It is important to note that the trip generation rates were determined based on the trips enumerated by the Transportation Tomorrow Survey. The survey is a household survey that was never intended to capture commercial vehicle trips (i.e. heavy 
vehicles, and others). Thus, modeled traffic volumes are likely to be lower than traffic counts by at least the number of commercial vehicles on the roadway.

There is also a component of through traffic (traffic not destined to zones within the GTA) on the study area roadways. Particularly, on the Highway 401 corridor.

Through trips on such roadways were not captured in the household survey. 
CHAPTER 7

CONCLUSION 
This report documents the development of an urban travel demand model of the Town of Oakville. The purpose of the model was to predict traffic demand on study area roadways during the morning peak hour. The model focused on the prediction of auto travel trips. This project utilized 1996 TTS data extracted from the DMG database via the Data Retrieval System available through the internet. The model predicted traffic volumes on study area roadways. The modeled volumes were then compared to cordon count data for the GTA. The comparison revealed some discrepancies between the modeled and observed volumes.

Sources of these discrepancies likely include seasonal variation in traffic volumes, as well as traffic volumes passing through the GTA. It should also be noted that the Transportation Tomorrow Survey upon which the model was based, was a household telephone survey, and as such did not capture commercial vehicle trips.

Despite these shortcomings, the model did with some success predict the traffic volumes on the Town's streets. Having been developed the model may be used to predict future travel demands by updating the socio-economic data.

TransCAD GIS based transportation modelling software proved to be an effective tool in the undertaking of this exercise. 
REFERENCES AND BIBLIOGRAPHY 


\section{References/Bibliography}

1 Martin Wohl and Brian V. Martin, Traffic System Analysis for Engineers and Planners, McGraw-Hill Book Company, 1967.

2 Data Management Group, 1996 GTA Boundaries, University of Toronto Joint Program in Transportation, 1998.

3 Data Management Group, 1986-1996 Travel Trends in the GTA \& HamiltonWentworth, University of Toronto Joint Program in Transportation, March 1998.

John Black, Urban Transportation Planning, The Johns Hopkins University Press Baltimore and London, 1981.

Michael D. Meyer and Eric J. Miller, Urban Transportation Planning, McGrawHill, 2000.

Caliper Corporation, Travel Demand Modeling with TransCAD 4.0, Caliper Corporation, 1998.

Adib Kanafani Transportation Demand Analysis, University of California, Berkeley, McGraw-Hill Book Company, 1983.

U.S. Department of Commerce, Traffic Assignment Manual for Application with a Large, High Speed Computer, Bureau of Public Roads Office of Planning Urban Planning Division, 1964.

9 Moshe Ben-Akiva and Steven R. Lerman, Discrete Choice Analysis: Theory and Application to Travel Demand, The MIT Press, 1985.

10 Institute of Transportation Engineers, Manual of Transportation Engineering Studies, Prentice Hall, 1994.

11 Peter Dalton, GTA A.M. Peak Model - Working Draft, Toronto Area Transportation Planning Data Collection Steering Committee, April 2001.

12 John E. Baerwald, Traffic Engineering Hand Book, Third Edition, Institute of Traffic Engineers, 1965.

13 Peter Dalton, 1996 Transportation Tomorrow Survey Discretionary Travel, University of Toronto Joint Program in Transportation, January 1999. 
14 Said M. Easa, Traffic Assignment in Practice: Overview and Guidelines for Users, Journal of Transportation Engineering, American Society of Civil Engineers, 117(6), $1991,602-623$.

15 Said M. Easa, Urban Trip Distribution in Practice, I: Conventional Analysis, Journal of Transportation Engineering, American Society of Civil Engineers, 119(6), $1993,793-815$.

16 Said M. Easa, Urban Trip Distribution in Practice, II: Quick Response and Special Topics, Journal of Transportation Engineering, American Society of Civil Engineers, $119(6), 1993,816-834$.

17 Juan D. Ortuzar and Luis G. Willumsen, Modelling Transport, John Wiley and Sons Limited, 1990.

18 http://www.transportationtomorrow.on.ca

(Web page of the transportation tomorrow survey)

19 http://www.jpint.utoronto.ca

(Web page of the Joint Program in Transportation)

20 Data Management Group, Data Management Group Annual Report 1999, Joint Program in Transportation, University of Toronto, 1999.

21 Fred L. Mannering and Walter R. Kilarski, Principles of Highway Engineering and Traffic Analysis, Second Edition, John Wiley and Sons, 1998. 


\section{APPENDIX A}

\section{TRANSPORTATION TOMORROW SURVEY BOUNDARIES, AND DATA ATTRIBUTES}




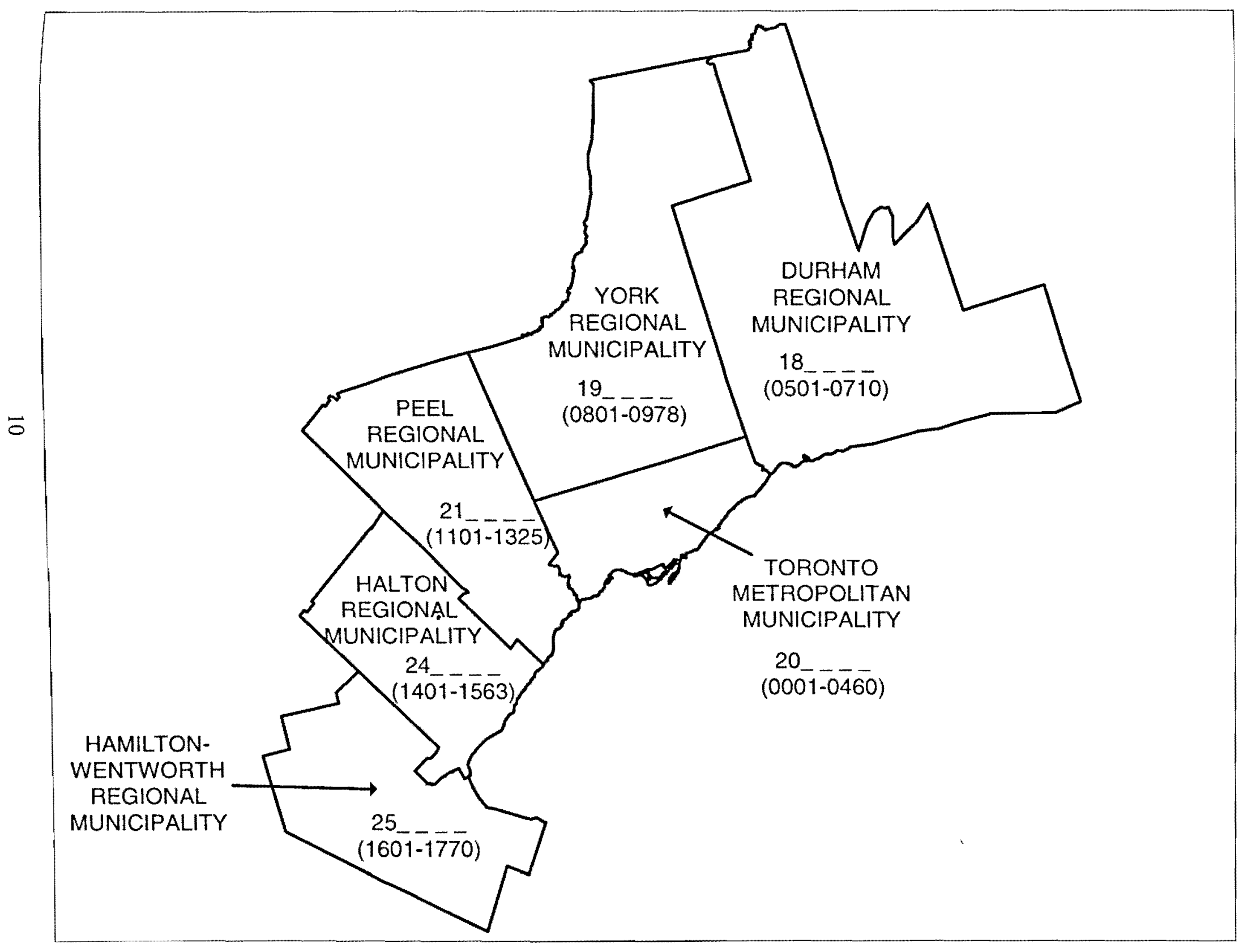

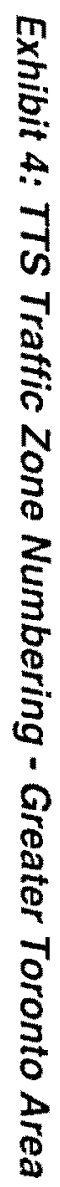




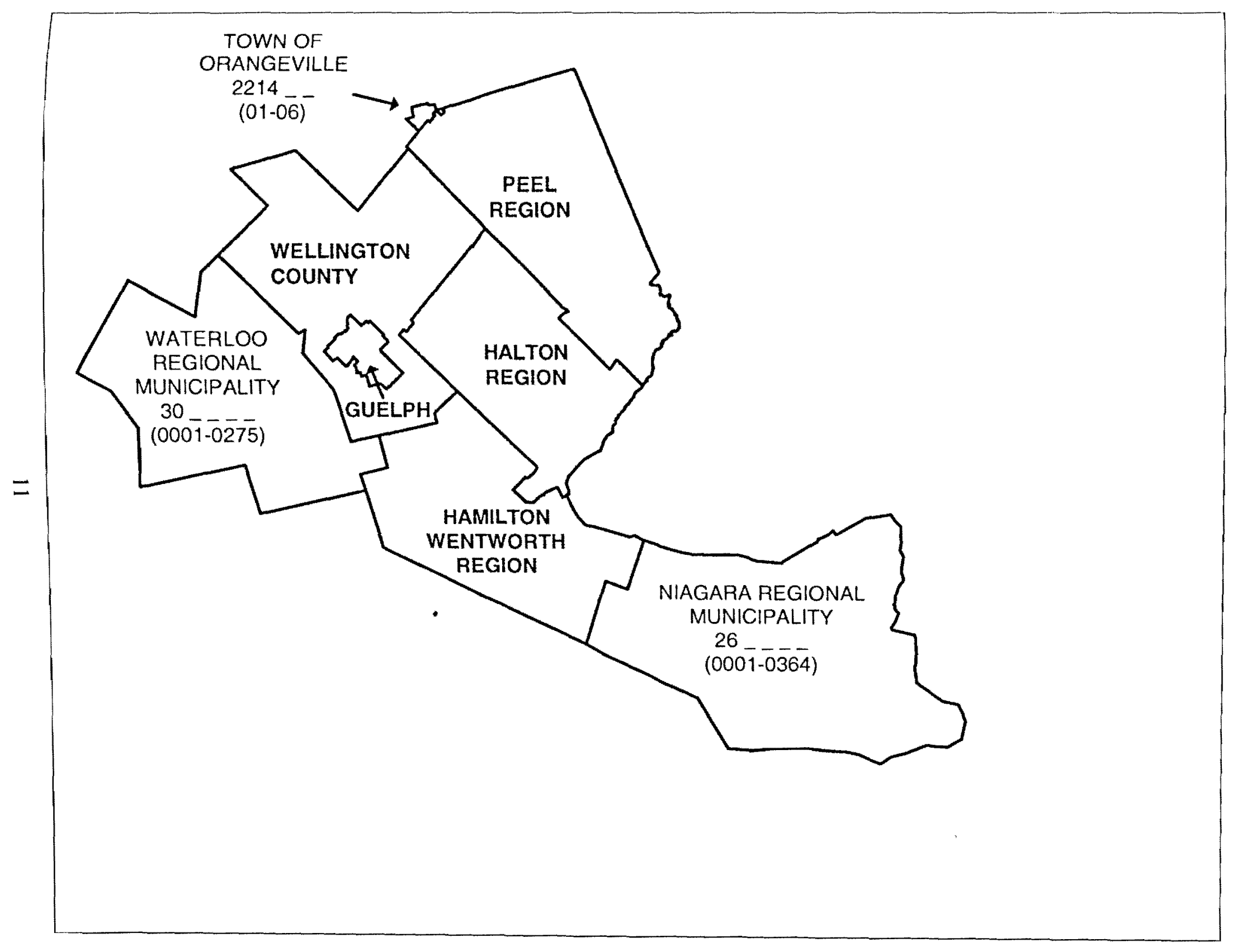

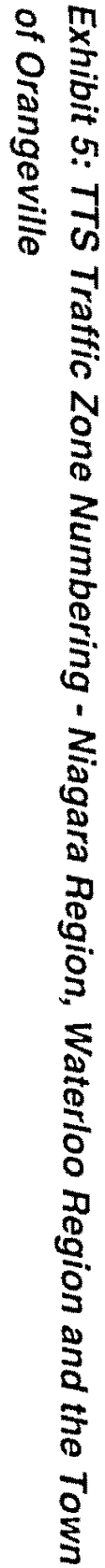




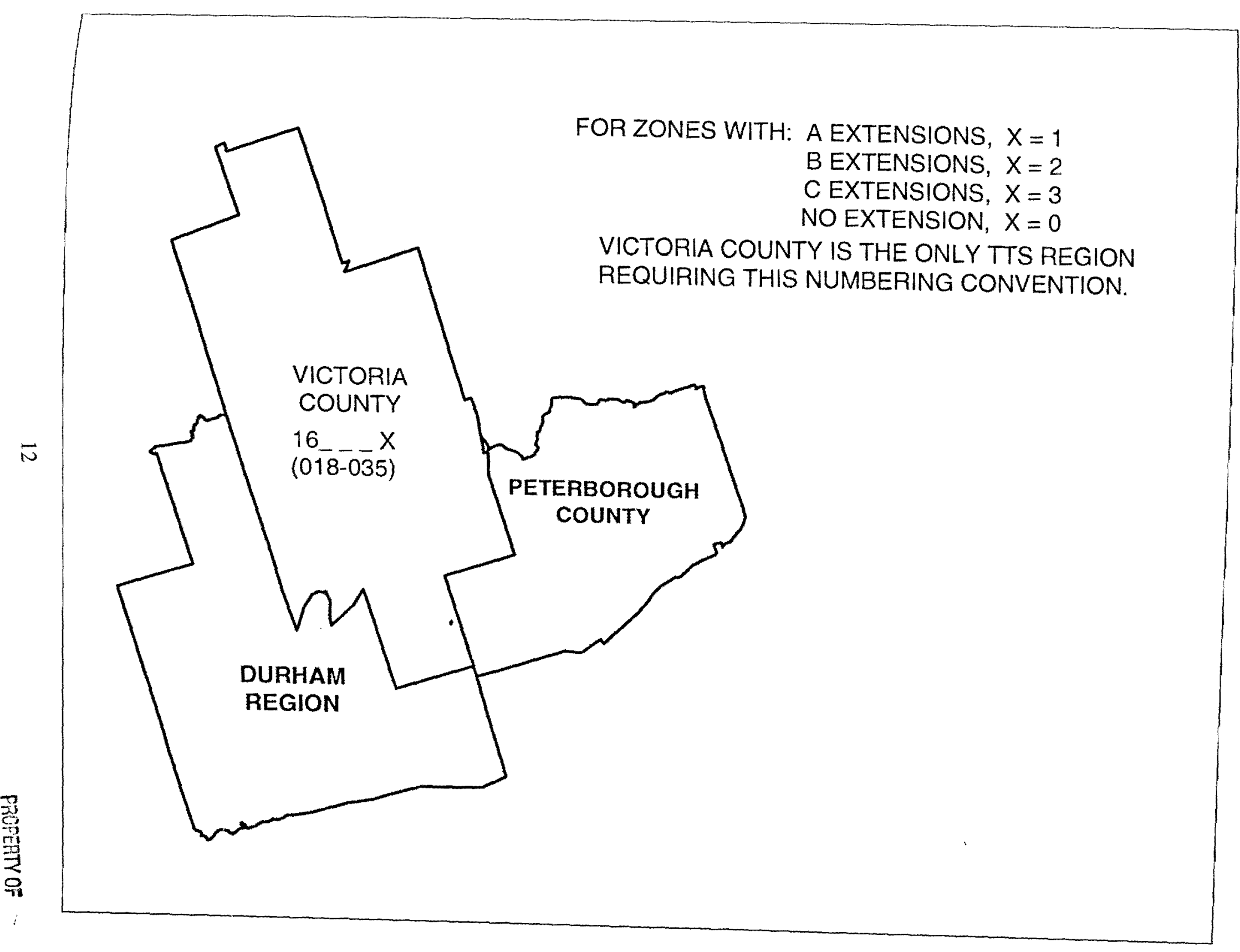


CENSUS SUBDIVISIONS WERE USED AS TRAFFIC ZONES IN WELLINGTON AND

PETERBOROUGH COUNTIES (INCLUDING BOTH SURVEY AND NON-SURVEY AREAS).

THE THIRD AND FOURTH DIGITS OF THE ZONE NUMBER INDICATE THE CSD.

WELLINGTON COUNTY

$$
23 \ldots 00
$$

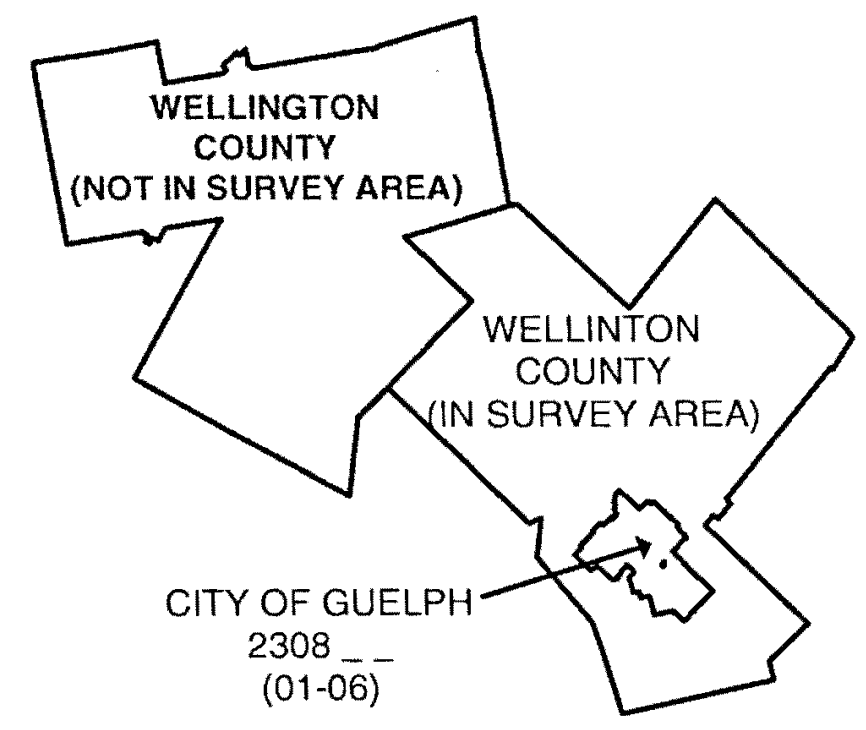

\section{PETERBOUROUGH COUNTY}

$15 \ldots 00$

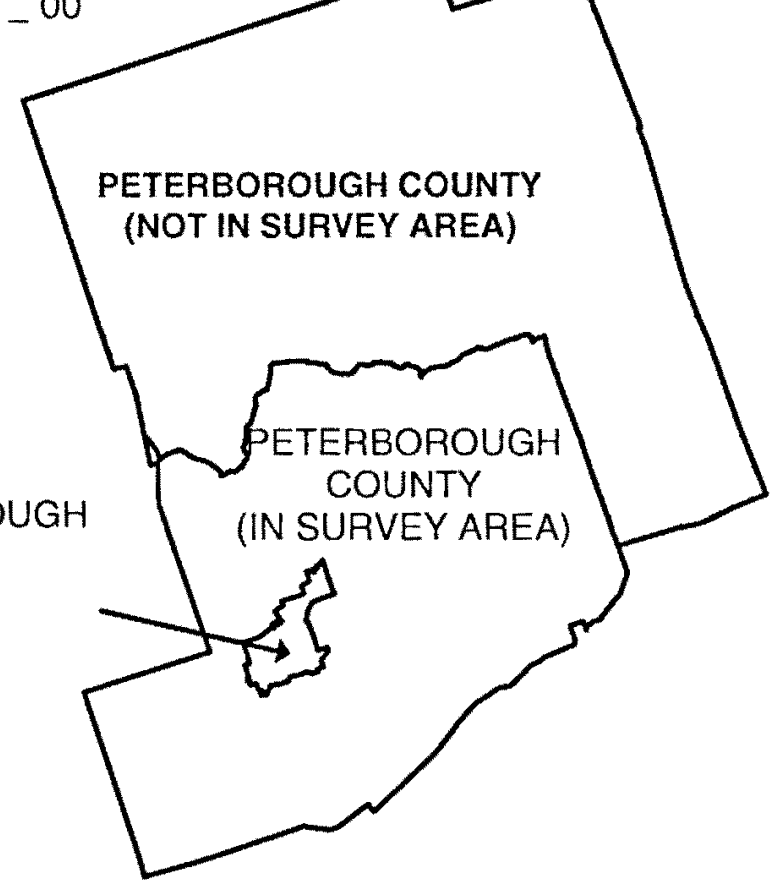


CENSUS SUBDIVISIONS WERE USED FOR TRAFFIC ZONES IN THE PORTION OF SIMCOE COUNTY OUTSIDE THE SURVEY AREA. THE THIRD AND FOURTH DIGITS INDICATE THE CSD.

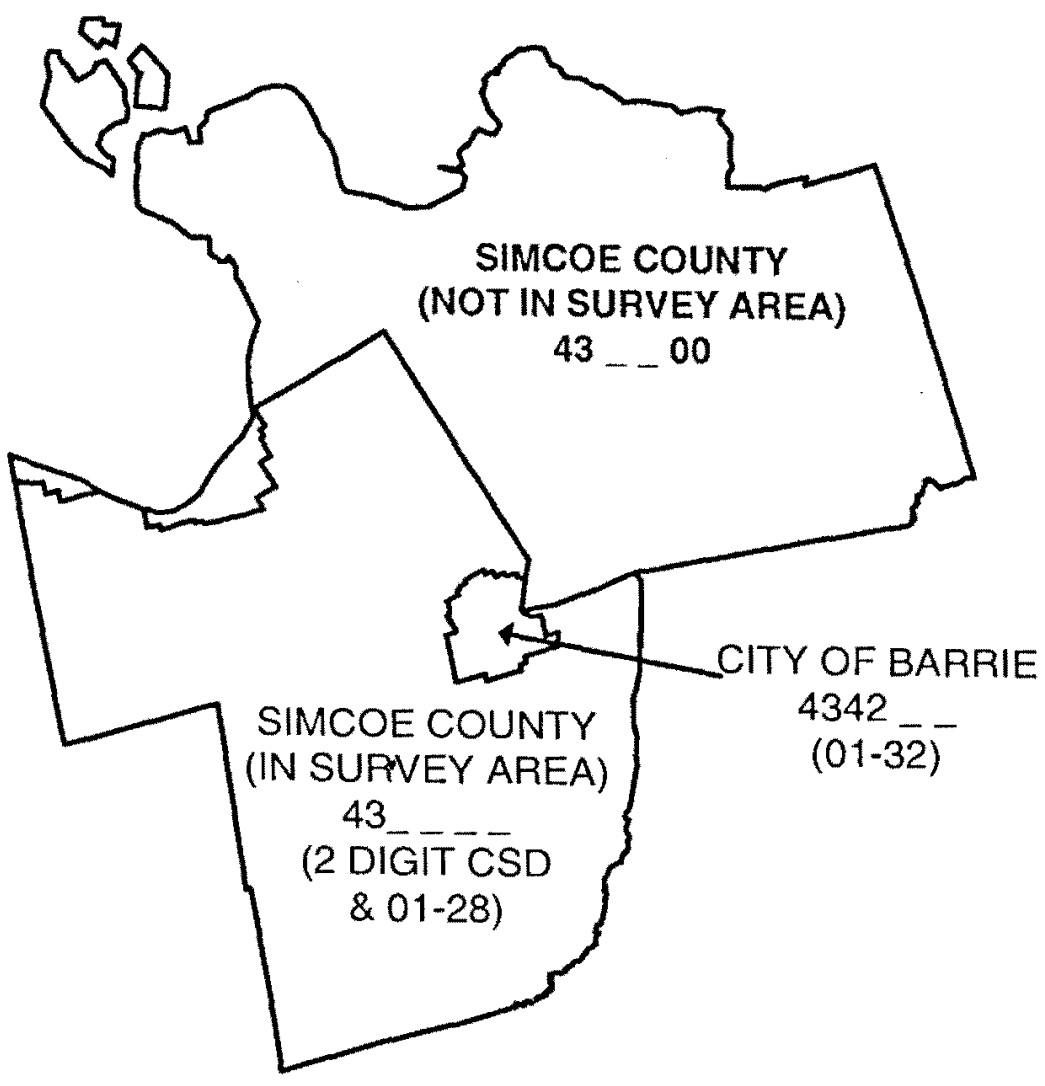




\section{Databases for 1996 TTS Version 2.1, 1991 TTS Version 4.1 and 1986 TTS Version 3.1}

\section{Household Attributes}

The following data was collected or calculated from the TTS for each household that was surveyed in 1996. The attributes and categories are the same for 1986 and 1991 unless noted otherwise.

\section{Exhibit 15: Household Attributes}

Attribute

hhld num

region hinld

$\begin{array}{ll}\text { pd_hhid } & \begin{array}{l}\text { Planning district of household } \\ \text { ct_uid }\end{array} \\ \text { gzon_hnid } & \begin{array}{l}\text { Census Canada census tract unit } \\ \text { identification } \\ \text { Traffic zone of the household } \\ \text { (1996 only) }\end{array} \\ \text { gta91_hhld } & \text { GTA zone of the househoid } \\ \text { ex_fac } & \text { Expansion factor for the household } \\ \text { utmx_hhid } & \text { UTM X coordinate of the household } \\ \text { utmy_hhid } & \text { UTMY coordinate of the household }\end{array}$

\section{Code}

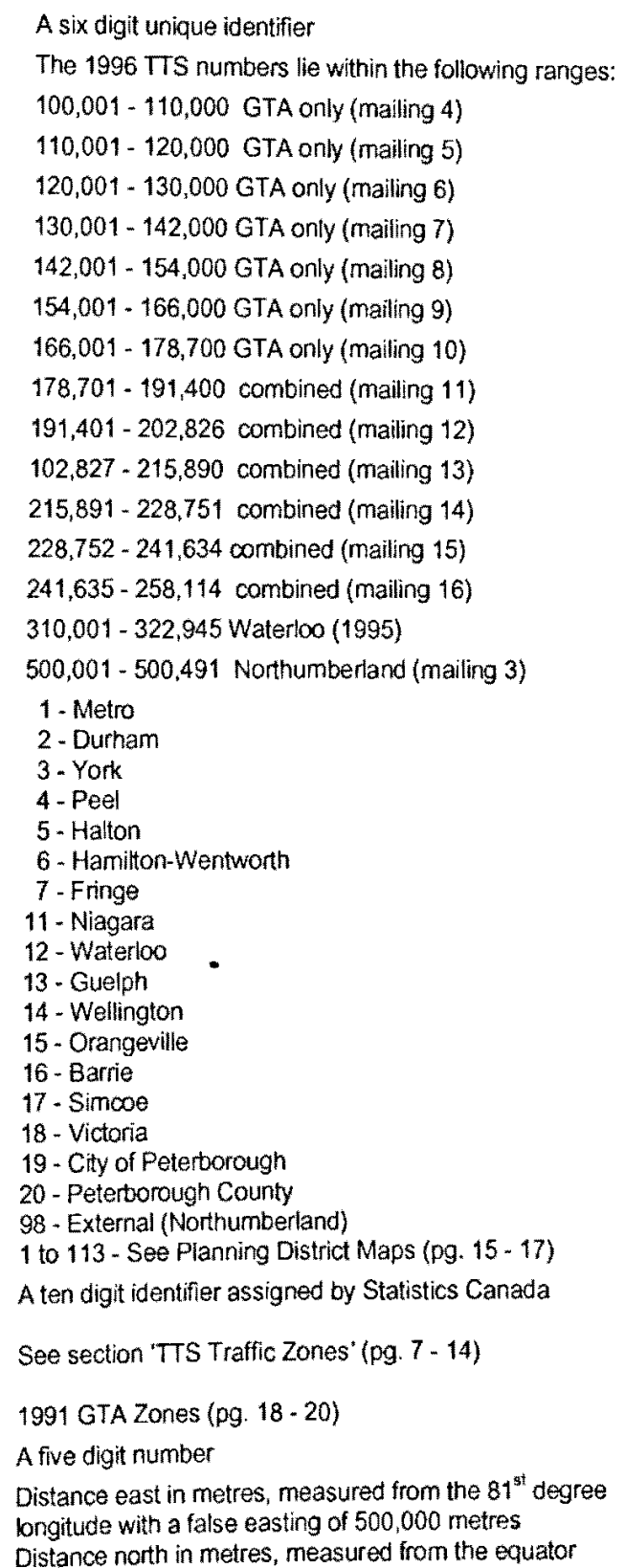




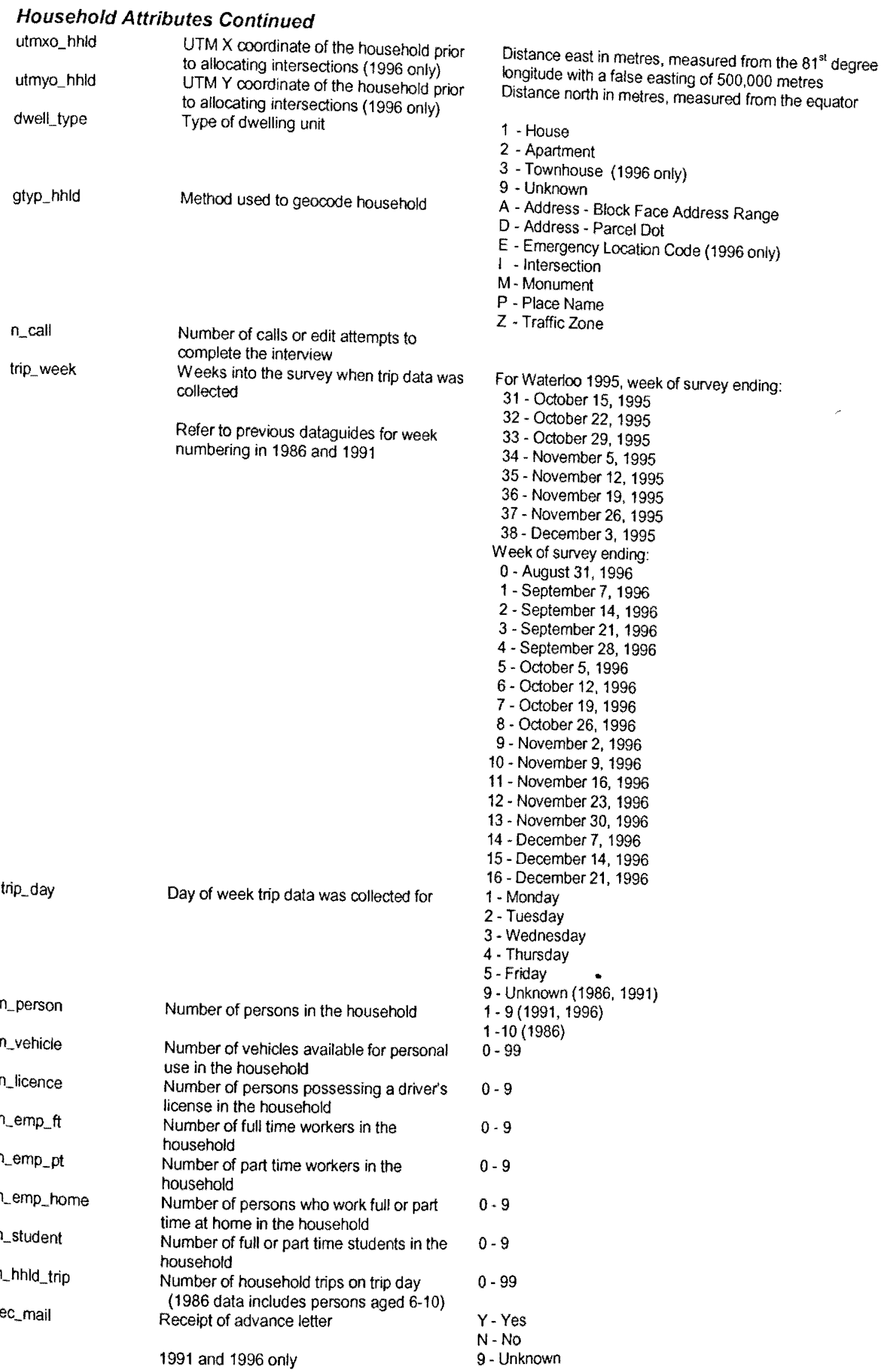




\section{Person Attributes}

The following data was collected or calculated for each person in the households surveyed in 1996. The attributes and categories are the same for 1986 and 1991 except as noted.

\section{Exhibit 16: Person Attributes}

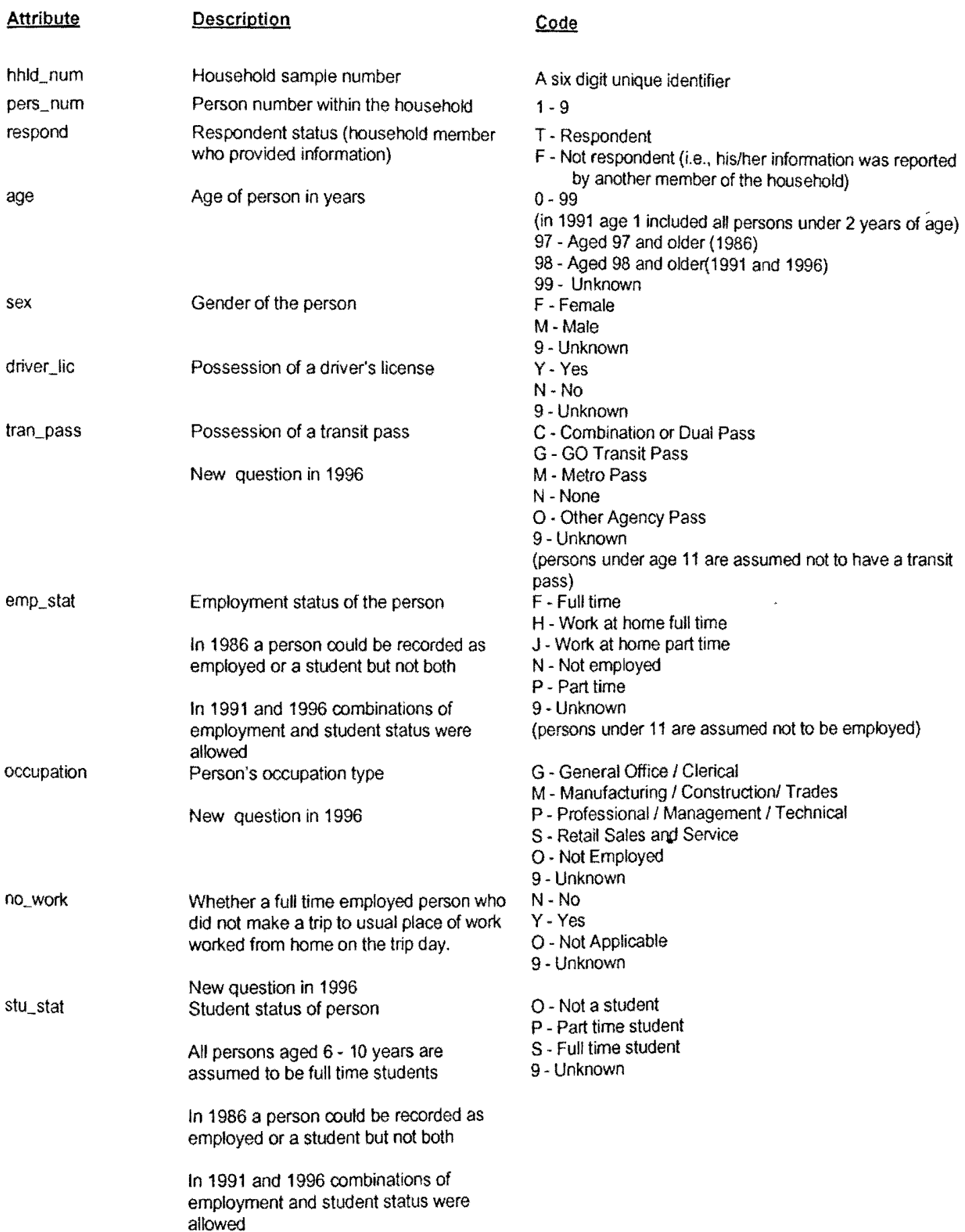




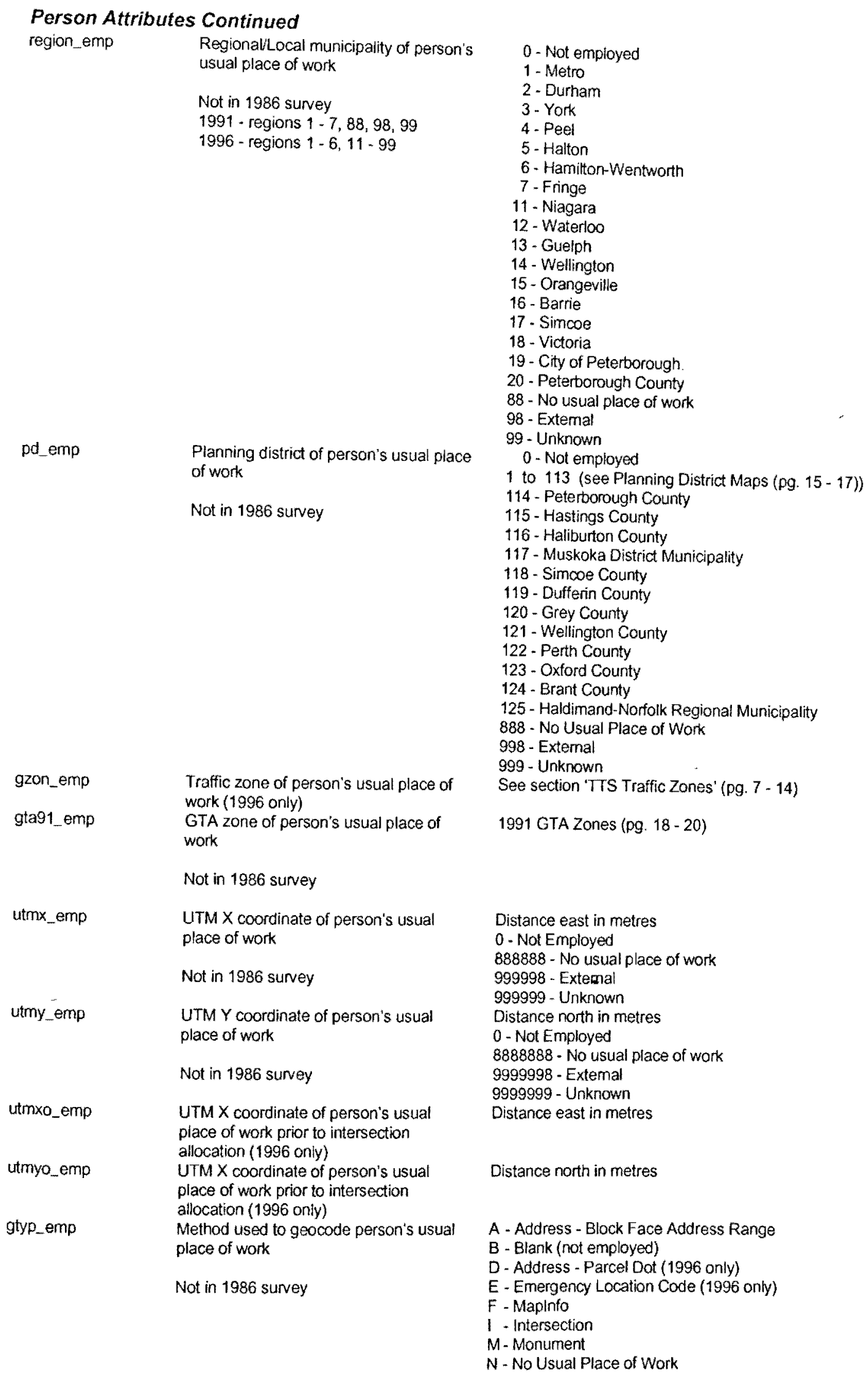




\section{Person Attributes Continued}

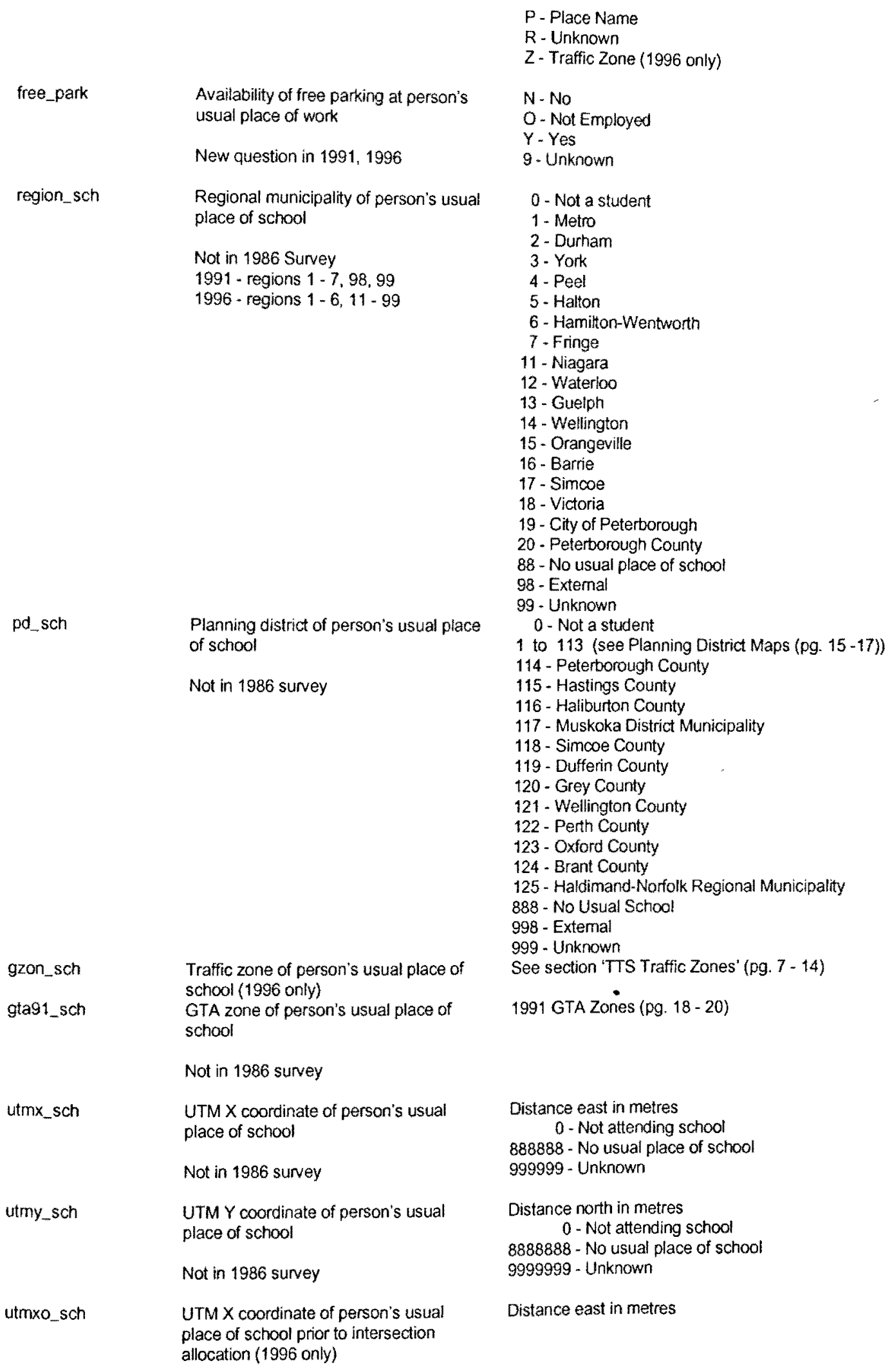




\section{Person Attributes Continued}

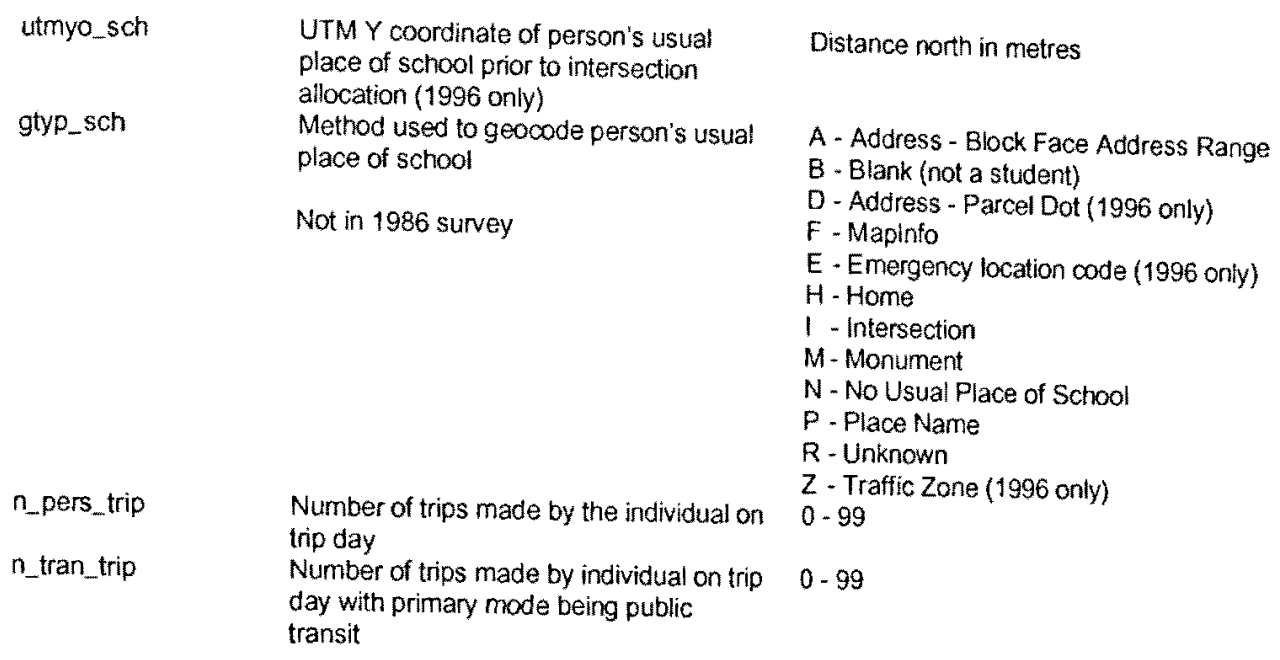




\section{Trip Attributes}

The following data was collected or calculated for each trip made on the trip day for each person 11 years old and older in the households surveyed in 1996. The attributes and categories are the same for 1986 and 1991 except as noted. Trip information was collected for household members 6 years old and over in 1986, and 11 and older in 1991.

\section{Exhibit 17: Trip Attributes}

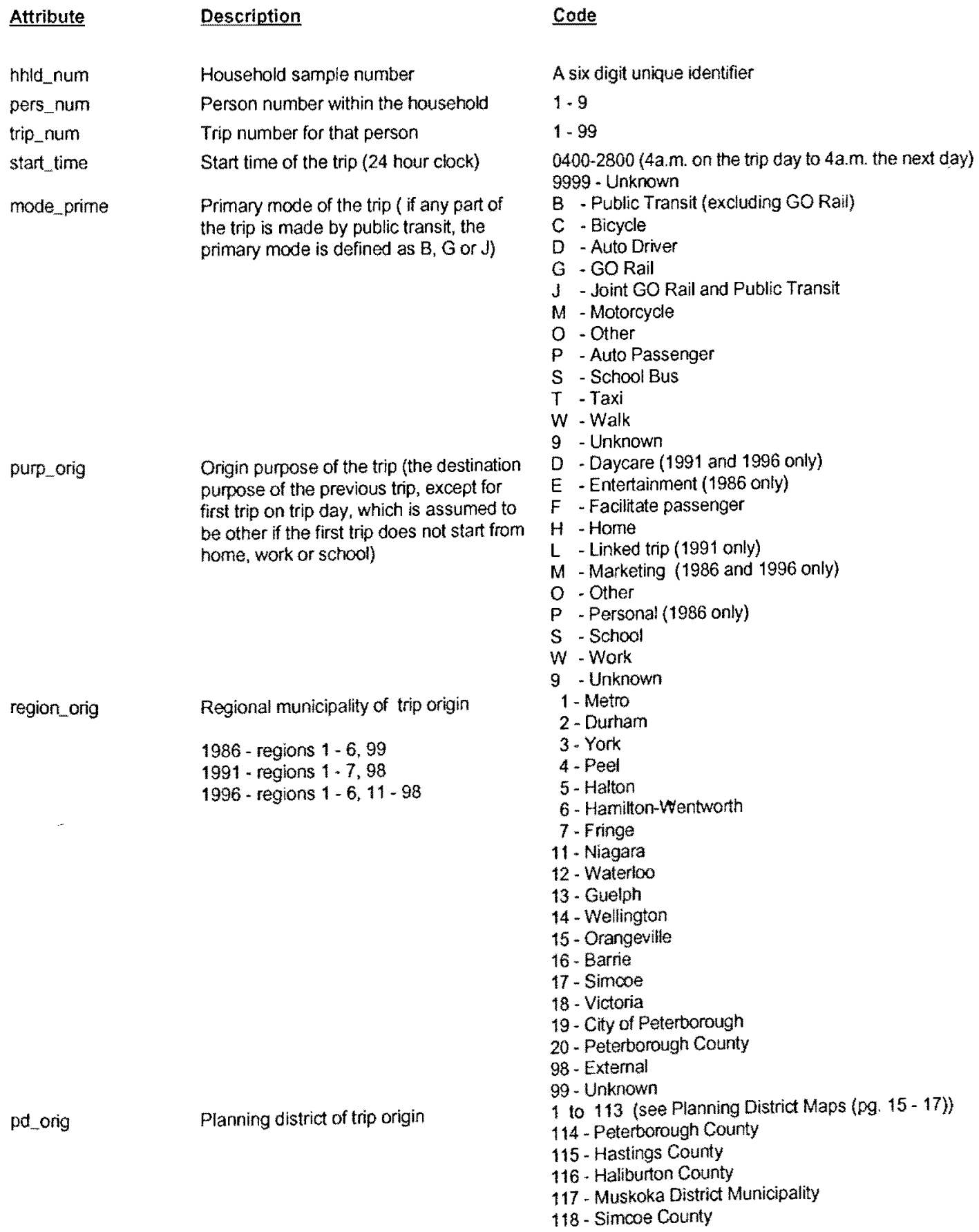




$\begin{array}{ll}\begin{array}{l}\text { gzon_ong } \\ \text { gta91_orig }\end{array} & \begin{array}{l}\text { Traffic zone of trip origin } \\ \text { GTA zone of trip origin }\end{array} \\ \text { utmy_orig } & \text { UTM } \times \text { coordinate of trip origin } \\ \text { utmxo_orig } & \text { UTM Y coordinate of trip origin } \\ \text { utmyo_orig } & \begin{array}{l}\text { UTM } \times \text { coordinate of trip origin prior to } \\ \text { intersection allocation }\end{array} \\ \text { gtyp_ong } & \text { UTM Y coordinate of trip origin prior to } \\ \text { intersection allocation } \\ \text { Method used to geocode trip origin }\end{array}$

purp_dest

region_dest

pd_dest

gzon_dest
Destination purpose of the trip

Regional municipality of trip destination

1986 - regions $1-6,99$

1991 - regions $1-7,98$

1996 - regions $1-6,11-98$

Planning district of trip destination

Traffic zone of trip destination

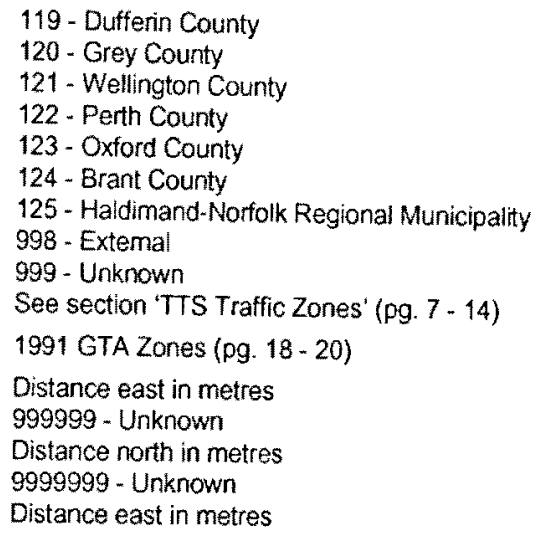

Distance north in metres

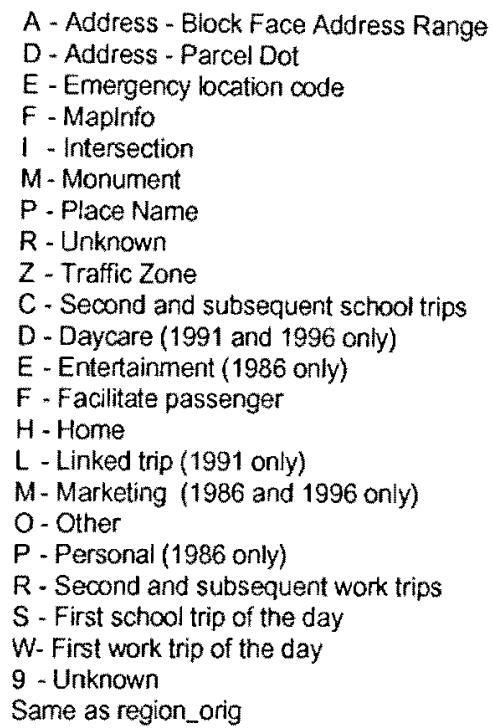

1 to 113 (see Planning District Maps (pg. 15-17))

114 - Peterborough County

115- Hastings County

116- Haliburton County

117 - Muskoka District Municipality

118- Simcoe County

119 - Dufferin County

120 - Grey County

121 - Wellington County

122- Perth County

123 - Oxford County

124 - Brant County

125 - Haldimand-Norfolk Regional Municipality

998 - Extemal

999 - Unknown

See section 'TTS Traffic Zones' (pg. 7 - 14) 
Trip Attributes Continued

gta91_dest

utmx dest

utmy_dest

gtyp_dest

trip_km
GTA zone of trip destination

UTM $X$ coordinate of trip destination

UTM $Y$ coordinate of trip destination

Method used to geocode trip destination

Straight line trip length in kilometres
1991 GTA Zones (pg. 18-20)

Distance east in metres

Distance north in metres

A - Address - Block Face Address Range

D - Address - Parcel Dot

E - Emergency location code

F - Maplnfo

1 - intersection

$M$-Monument

P. Place Name

$R$ - Unknown

Z- Traffic Zone 
APPENDIX B

\section{DATA RETRIEVAL SYSTEM}




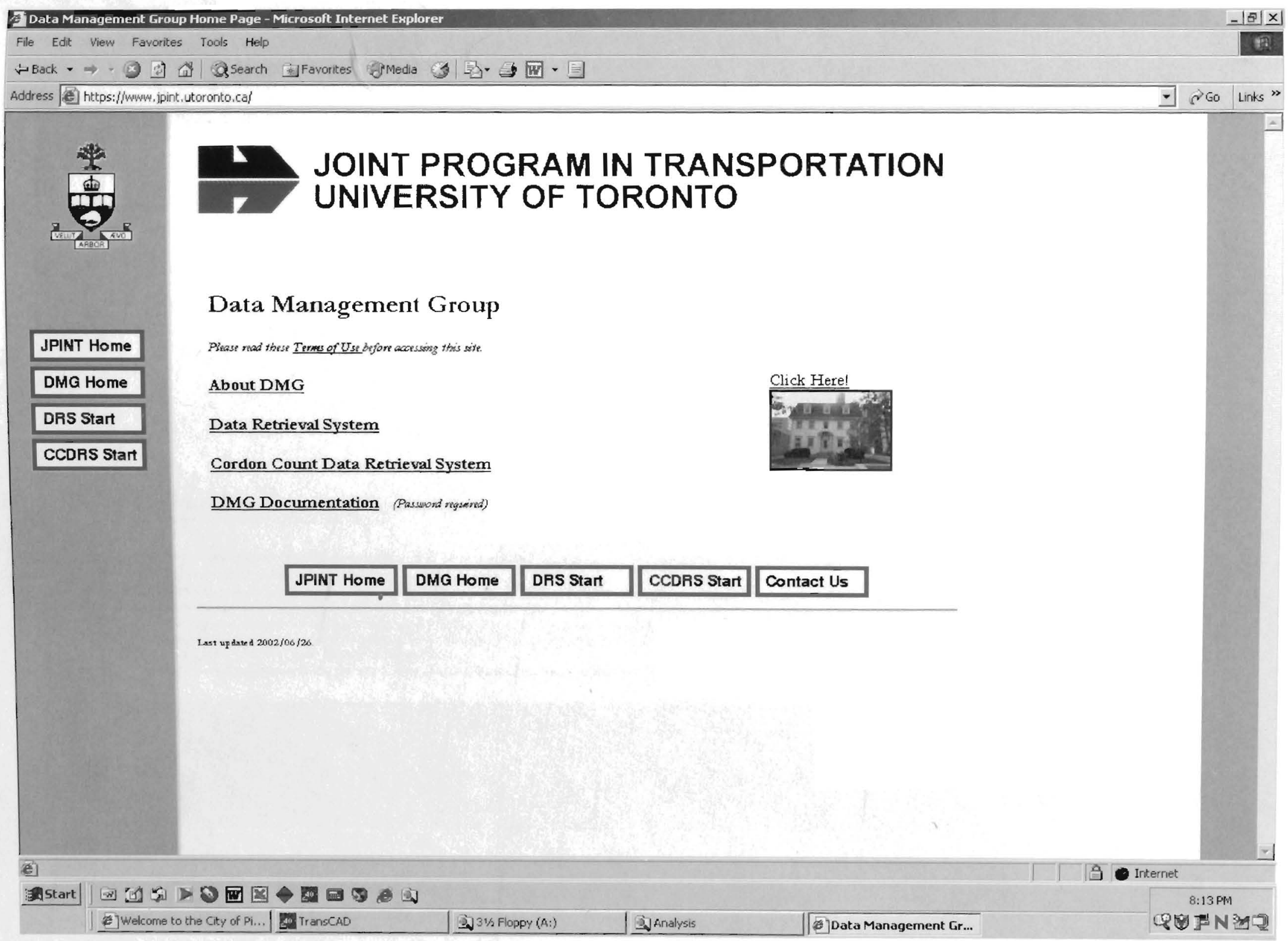




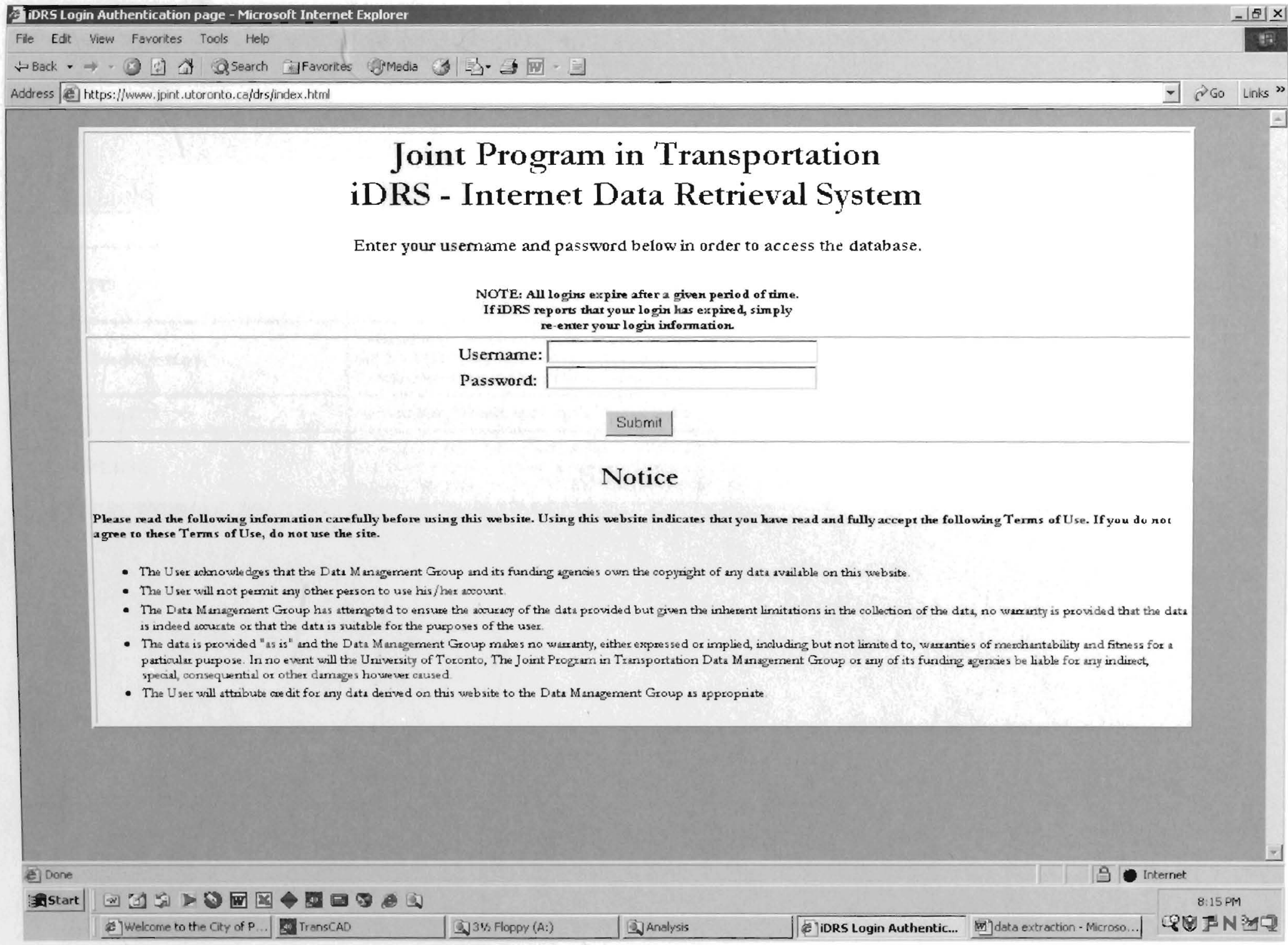


File Edit Wiew Fayorites Tools Help

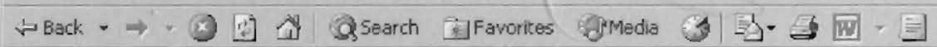

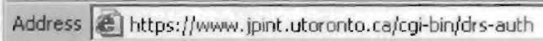

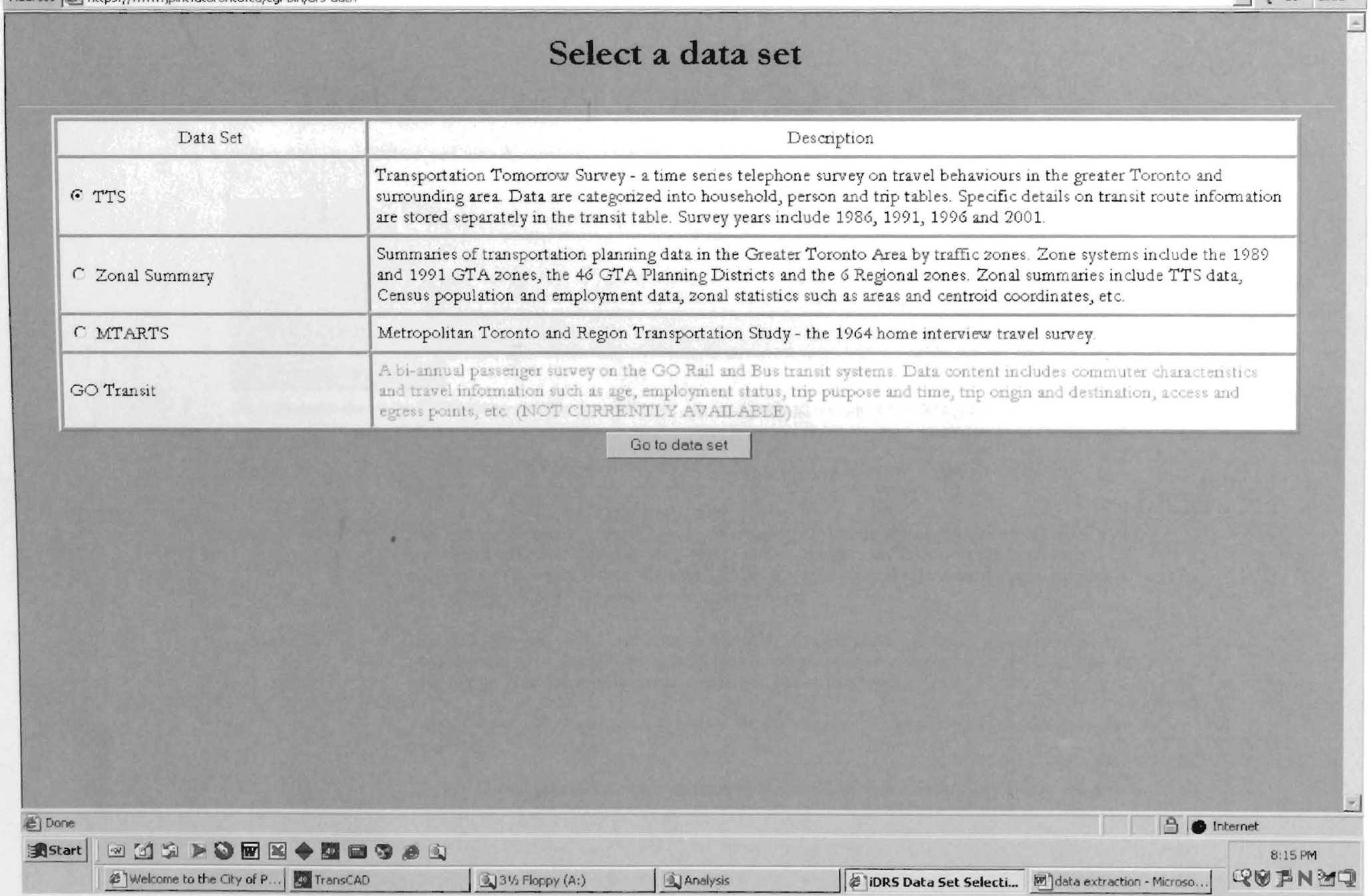




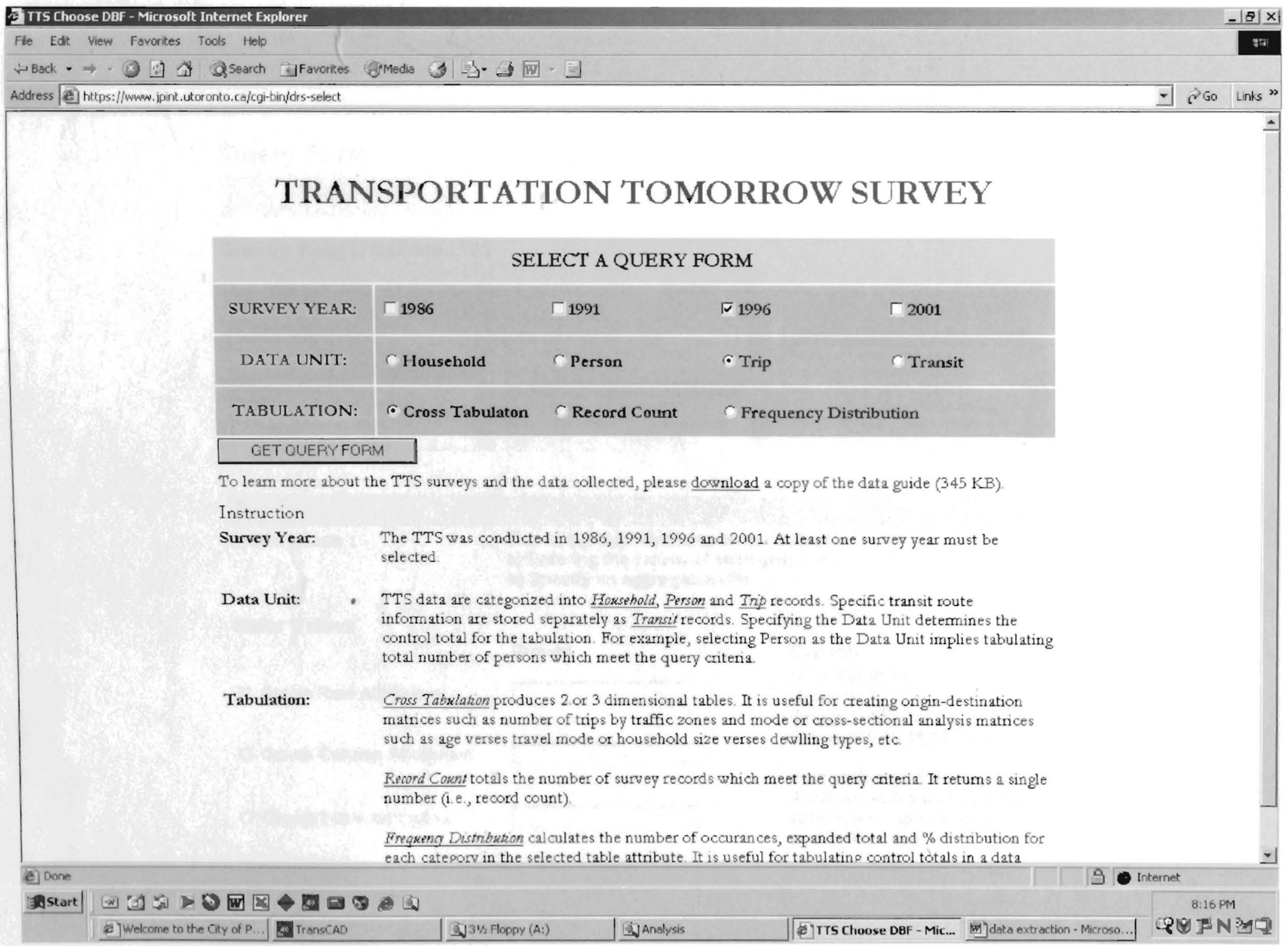




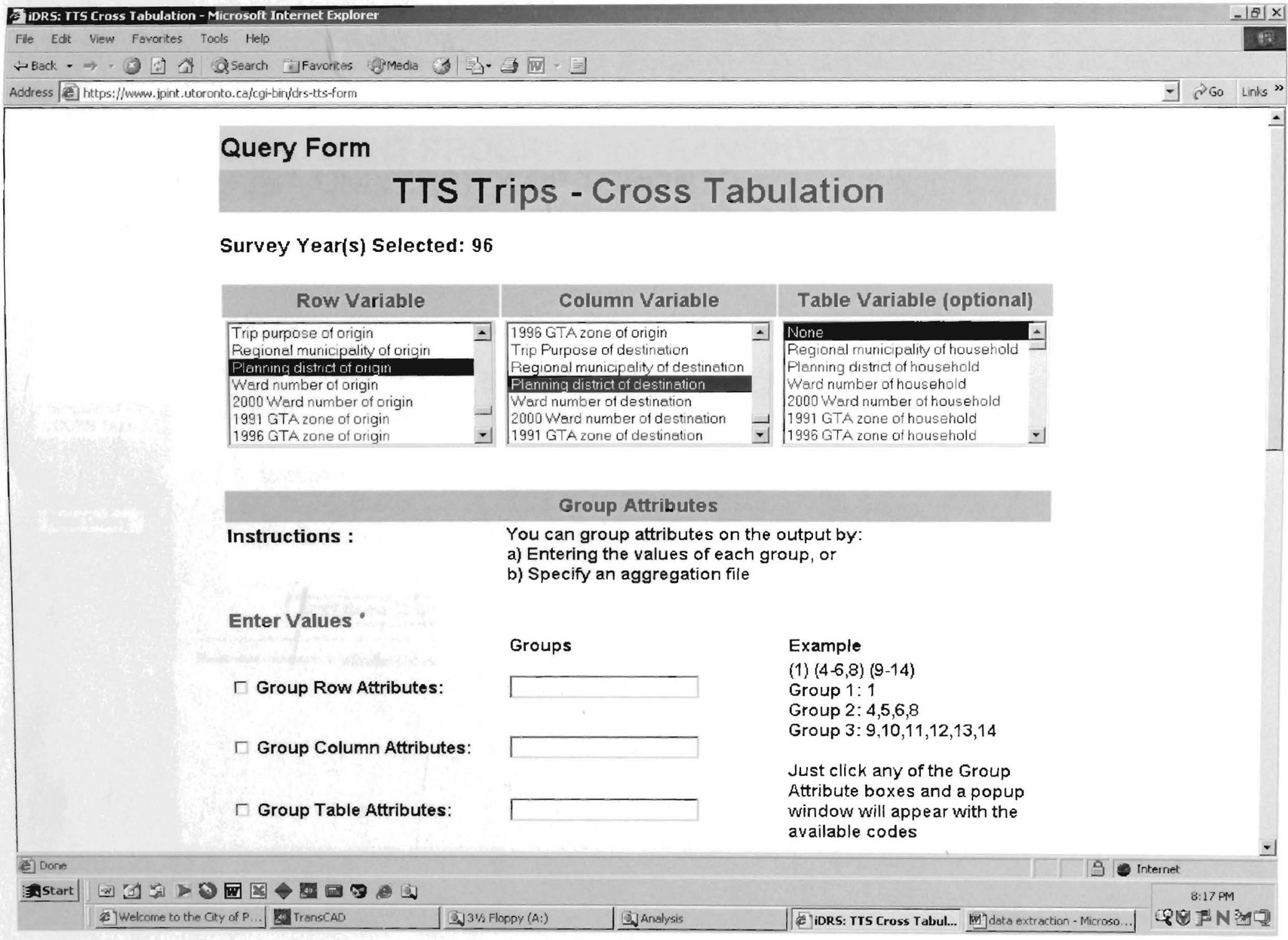




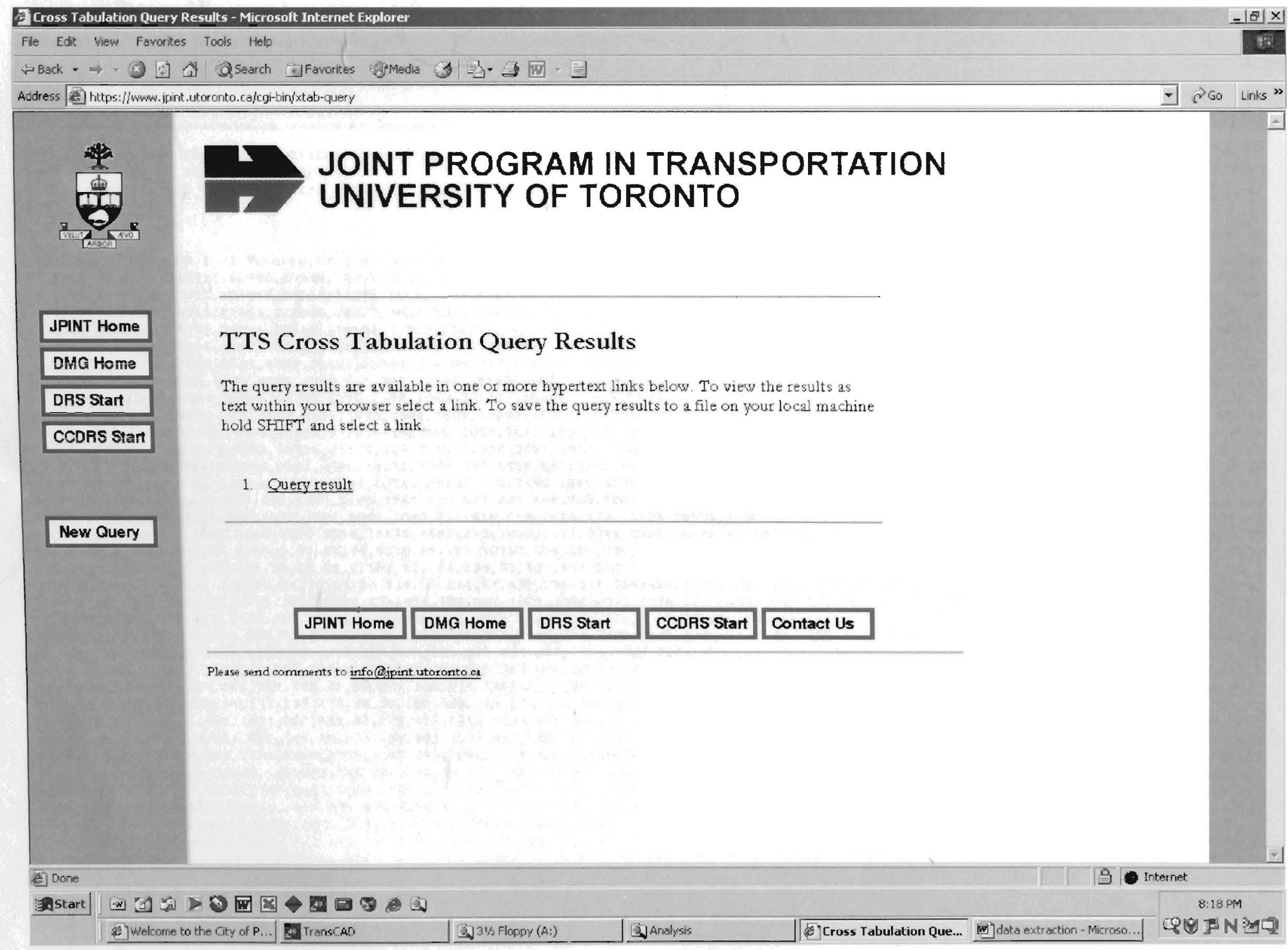


USER : Lukasz Paulouski - Dillon Consulting

DATE : Apr $282003 \quad(20: 09: 20)$

DATA : 1996 TTS Vers 2.1 Trips

$\begin{array}{l:l}\text { ROW: } & \text { pd_or } 19 \\ \text { COLUnN : pd dest }\end{array}$

,PD 1 of Toronto, PD 2 of Toronto, PD 3 of Toronto, PD 4 of Toronto, PD 5 of Toronto, PD 6 of Toronto, PD 7 of Toronto, PD 8 of Toronto, PD 9 of Tor, PD 1 of Toronto, 218711, 68740,39948, 74791, 19935,66973,7805,24718,6649,14075,21166,11468,25103,9121,7586,21120,96,486,399,6079,4675,3624,3533,!

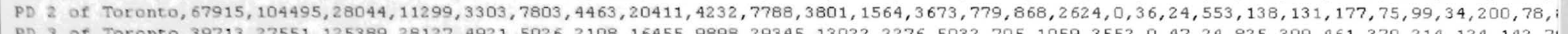

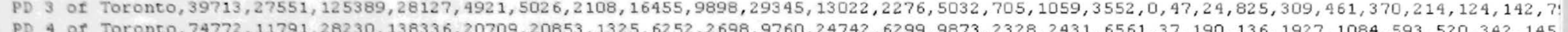
PD 4 or Toronto, $74772,11791,28230,138336,20709,20853,1325,6252,2698,9760,24742,6299,9873,2328,2431,6561,37,190,136,1927,1084,593,520,342,145$

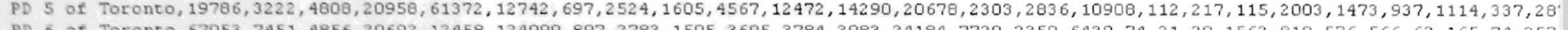
PD 6 of Toronto, 67053,7451,4856,20692,12458, 124099,897,2783,1505,3695,3784,3983,24184,7729,2350,6439,74,21,20,1563,818,576,566,63,165,74,257

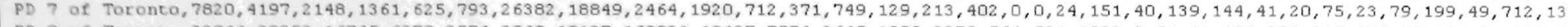
PD 8 of Toronto, 23944, 20353, 16745,6270,2574,3049, 19127, 169021,19427,7574,3645, 1090,2278, 564,531, 1803,0,51,41,454,299,215,275, 58, 101,91,332,2

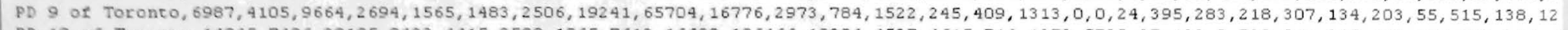
PD 10 of Tozonto, 14045, 7496,29195,9432,4415,3598, 1865, 7613,16698, 106466, 18284,4537, 4615,714, 1373, 5738, 37, 123,0,728, 011,245,434,159,372,214,1: PD 11 of Toronto, $21918,3582,12735,25152,12417,3942,718,3692,2950,17855,99505,14595,5755,1052,1985,9595,81,76,92,1291,713,514,553,239,151,201$ PD 12 of Toronto, $10912,1714,2361,6498,14032,3860,433,1116,857,4422,14811,37141,8229,901,1719,16480,55,172,67,1817,886,627,703,296,228,182,91$ PD 13 of Toronto, 24531,3815, 4749, 10517,20755,23282,710,2480,1592, $4376,5816,8405,160878,21819,19890,43357,147,145,230,6556,4125,1825,2498,785$ PD 14 of Totonto, $9677,777,642,2161,2165,7741,127,667,203,648,769,1083,21616,23133,4962,4521,0,0,0,1225,559,281,184,146,0,0,81,62,277,143,163$ : PD 15 of Toconto, 8385, 792, 1075, 2582, 2841, 2040,215,418,469, 1464,1732, 1754, 19712,5130, 38925, 11942, 18, 158, 110,5177, 1910, 1170, 1036, 442, 38, 19, 160

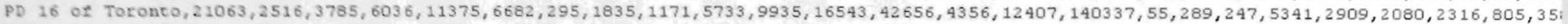
Brock, $96,0,0,55,131,55,0,25,0,37,81,74,92,0,18,129,10365,506,582,129,55,112,267,19,984,54,349,38,110,129,443,37,37,0,0,129,19,0,0,0,0,0,0,0,1$ Uxbridge, $502,18,76,260,251,46,21,95,0,101,51,186,294,51,107,163,513,15861,880,401,137,439,274,96,557,232,536,152,355,1341,1259,25,177,0,19,1$ : Seugog, $436,24,48,117,115,20,24,18,24,24,116,71,234,24,152,209,616,924,19408,600,215,1238,4030,867,82,42,113,25,68,121,386,0,41,24,20,62,0,0$, Pickering, 6353, 498, 736, 1849, 1928, 1331, 173, 454, 486, 827, 1423, 1828, 6771, 1089, 5027, 5031, 165, 428, 664, 73555, 14503, 5811, 5456, 1818, 21, 17, 244,96, 755, $\mathrm{AJax}, 4805,156,372,904,1451,684,77,318,218,789,736,1025,4162,577,1583,3123,59,182,351,14412,58985,6427,7487,1977,0,0,58,97,355,132,1996,0,372$ Whicby, $3512,189,436,755,888,413,60,254,257,280,579,629,1860,319,1028,2249,130,461,1168,5453,6671,77523,29749,5471,85,0,100,58,315,108,1823,1$ Gehava, 3498,222, 353,496, 1205, 653, 144, 258, 300, 416, 523, 655,2441, 185, 1002, 2357, 171, 284, 3888, 5744, 7033, 29927, 198100, 20352, 81,0, 189, 119, 403, 337, 1

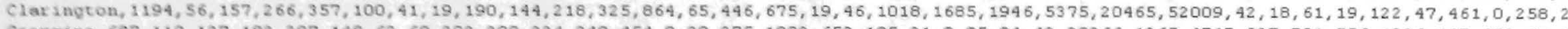
Georgina, $687,119,127,183,307,148,63,60,203,309,234,248,454,0,38,375,1003,652,105,21,0,85,84,42,29266,1365,4747,837,781,556,1326,147,459,67,1$ East Guldimbury, $680,34,177,265,270,38,58,108,128,159,222,125,180,0,36,312,72,226,42,36,0,17,0,18,1411,6842,8039,829,769,528,1115,282,433,0,1$ Nevnarket, $2747,261,663,1031,822,282,82,908,458,1311,1504,850,662,81,181,856,368,514,93,249,58,99,185,102,4868,8124,75268,8812,3604,1259,2927$ Aurora, $2010,135,458,955,552,144,59,256,158,645,1313,463,648,42,0,470,38,121,25,97,117,97,119,19,877,854,8691,33379,4578,655,2069,2066,1664,2$ Richmond $8111,8114,986,2288,3694,2775,1353,249,1090,1138,4587,6830,3535,2286,275,561,4163,164,403,86,725,416,294,363,141,862,757,3857,4452,8$ Whitchurt-Stourrvi11e, $969,145,205,166,294,241,49,171,148,167,493,370,868,137,204,1086,152,1354,121,536,132,108,312,25,493,479,1502,777,1324$, Narkthave, 17754, $2253,3683,7746,8476,5118,660,2126,1556,6573,14433,11487,13708,1474,2903,30743,369,1312,407,4148,2041,1871,1748,458,1385,1101,3$ King, $983,164,397,446,110,173,116,371,809,1279,422,168,106,45,25,132,37,75,0,01,25,103,0,0,167,280,2182,2027,2086,192,735,0483,3046,756,473,4$ Vaughan, 20606, 3745, 10321, 6678, 2870, 2049, 1125, 4815, 8827, 25842, 18938, 2673,2740,346,764, 3039, 37, 174, 41, 615, 337, 398, 213,215, 500, 560, 1776, 1563, 13 Caledon, $1287,239,693,495,163,124,169,941,1557,1169,201,102,82,0,19,39,0,0,24,0,0,73,22,62,67,0,238,160,293,0,344,848,2089,29530,10000,4631,8$. e. Done

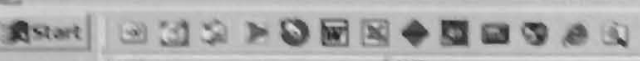

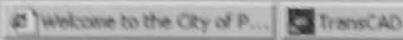

Q3w Fheper (A:)

Q Anowpes

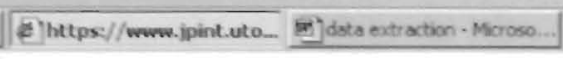




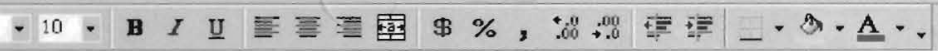

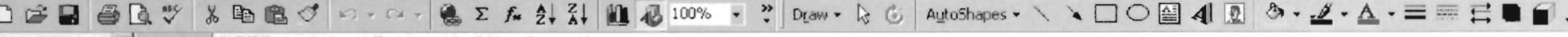
A1 $\quad-\quad=$ USER Lukasz Pawlowski-Dillan Cansulting

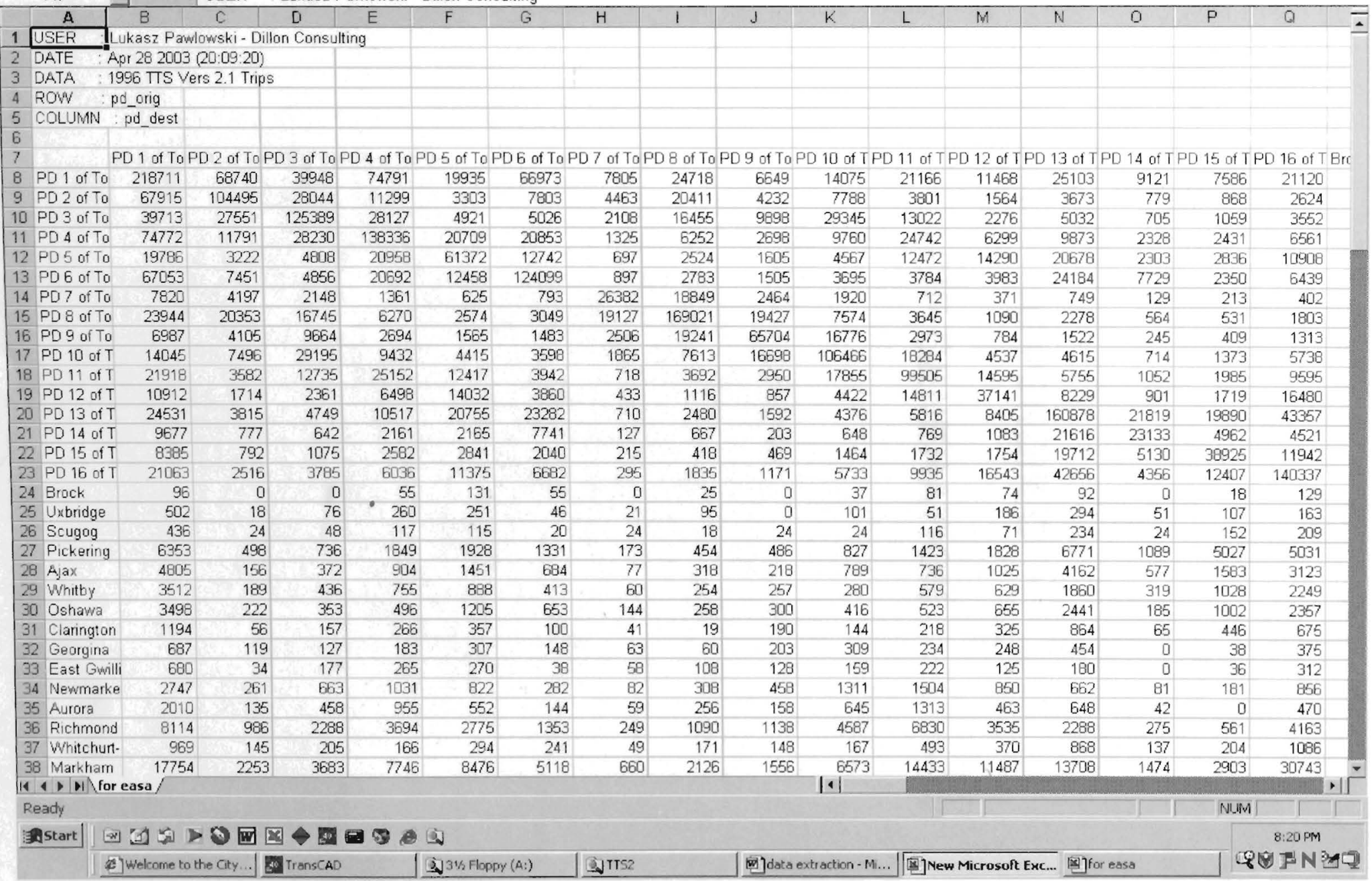




\section{APPENDIX C}

\section{TRIP GENERATION}




\section{Trip Generation Rates}

Region

1 Durham Region

2 York Region

3 City of Toronto

4 Peel Region

5 Halton Region

6 Hamilton-Wentworth Region

\begin{tabular}{|c|c|c|c|c|c|}
\hline \multirow[b]{3}{*}{ Population } & \multirow[b]{3}{*}{ Employment } & \multicolumn{2}{|c|}{ Auto Origins } & \multicolumn{2}{|c|}{ Auto Destinations } \\
\hline & & & Rate per & & Rate per \\
\hline & & Origins & Capita & Destinations & Employee \\
\hline 450354 & 149552 & 149106 & 0.331 & 114738 & 0.767 \\
\hline 567689 & 275724 & 210847 & 0.371 & 209782 & 0.761 \\
\hline 2305558 & 1257005 & 572624 & 0.248 & 666340 & 0.530 \\
\hline 812512 & 389275 & 293109 & 0.361 & 284576 & 0.731 \\
\hline 328264 & 141390 & 125808 & 0.383 & 112142 & 0.793 \\
\hline 461990 & 181219 & 135220 & 0.293 & 125542 & 0.693 \\
\hline
\end{tabular}


APPENDIX D

TRIP DISTRIBUTION 
sample of 1996 base year auto driver od for report USER : Lukasz Pawlowski - Dillon Consulting

DATE : May $62003(10: 23: 55)$

DATA : 1996 TTS vers 2.1 Trips

FILTER 1 : start_time $=>600-900$

FILTER 2 : mode_prime $\Rightarrow$ Auto driver

gta96_orig gta96_dest number

$\begin{array}{lll}1 & 3 & 40\end{array}$

$1 \quad 5 \quad 59$

$1 \quad 6 \quad 20$

$\begin{array}{lll}1 & 7 & 20\end{array}$

$110 \quad 59$

$1 \quad 11 \quad 40$

$1 \quad 13 \quad 20$

$1 \quad 14 \quad 59$

$1 \quad 16 \quad 20$

$1 \quad 18 \quad 40$

$\begin{array}{lll}1 & 22 & 62 \\ 1 & 27 & 20\end{array}$

$1 \quad 45 \quad 20$

$1 \quad 51 \quad 20$

$1 \quad 95 \quad 20$

$1 \quad 155 \quad 20$

$1206 \quad 20$

$1214 \quad 20$

$\begin{array}{lll}1 & 219 & 20 \\ 1 & 235 & 20\end{array}$

$1 \quad 306 \quad 20$

$1 \quad 311 \quad 20$

$1 \quad 346 \quad 20$

$\begin{array}{rrr}1 & 440 & 20\end{array}$

$1 \quad 1509 \quad 20$

$\begin{array}{lll}1 & 1522 & 20\end{array}$

$1 \quad 1542 \quad 40$

$1 \quad 1543 \quad 59$

$\begin{array}{lll}1 & 1549 & 18 \\ 1 & 1598 & 20\end{array}$

$1 \quad 1602 \quad 20$

$\begin{array}{lll}1 & 1603 & 59 \\ 1 & 1609 & 20\end{array}$

$1 \quad 1610 \quad 20$

$\begin{array}{lll}1 & 1619 & 20\end{array}$

$\begin{array}{lll}1 & 1628 & 20 \\ 1 & 2029 & 20\end{array}$

$1 \quad 3582 \quad 20$

$\begin{array}{rrr}1 & 2 & 211 \\ 2 & 3 & 42\end{array}$

$\begin{array}{lll}2 & 4 & 21 \\ 2 & 5 & 63\end{array}$

$2 \quad 65$

$2 \quad 9 \quad 42$

$2 \quad 10 \quad 42$

$\begin{array}{lll}2 & 11 & 21 \\ 2 & 12 & 21\end{array}$

$\begin{array}{lll}2 & 14 & 21 \\ 2 & 18 & 20\end{array}$

2221

$\begin{array}{lll}2 & 28 & 21 \\ 2 & 37 & 21\end{array}$

$\begin{array}{lll}2 & 40 & 21 \\ 2 & 41 & 21\end{array}$

$\begin{array}{lll}2 & 43 & 21 \\ 2 & 48 & 42\end{array}$

Page 1 


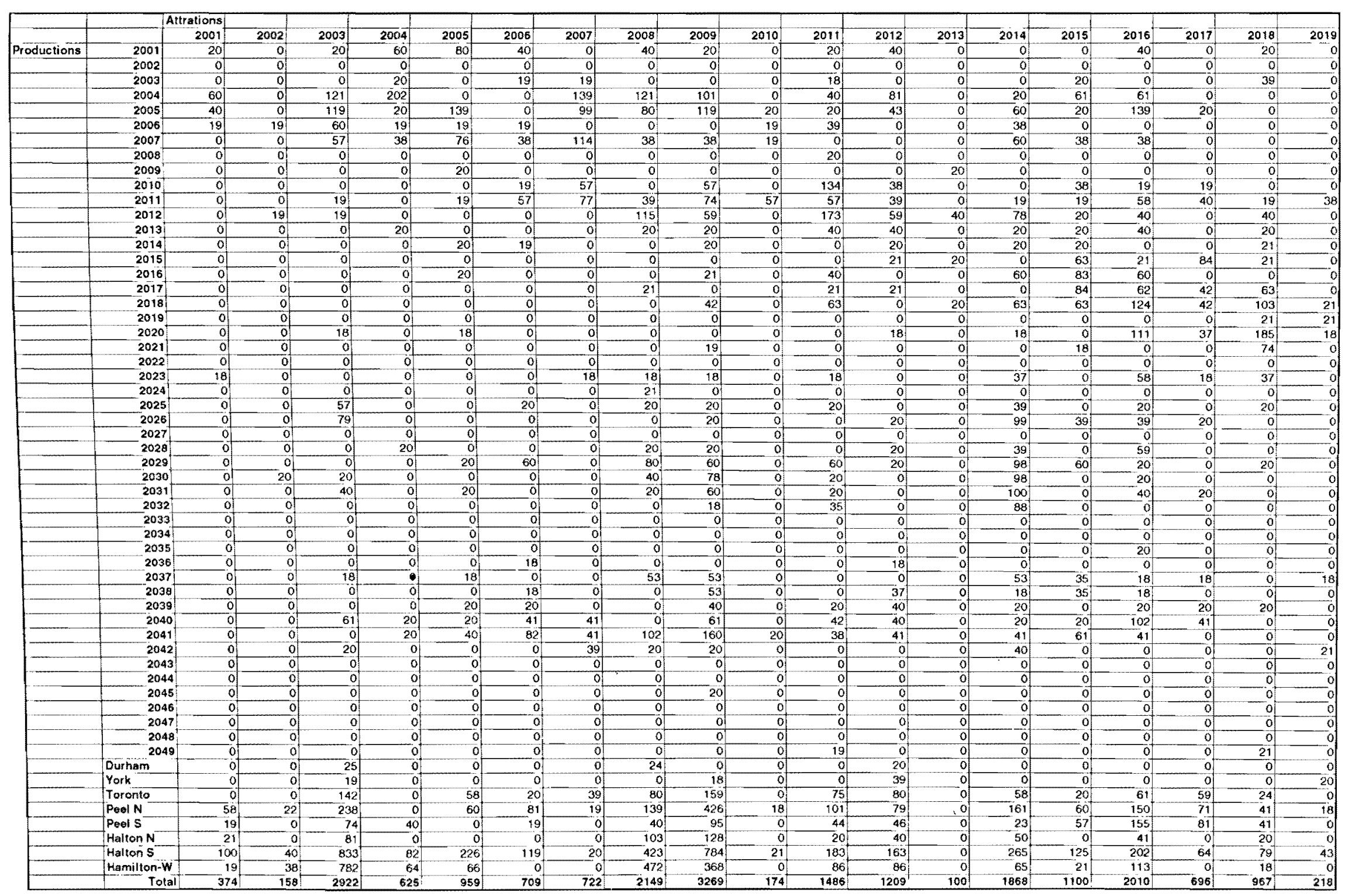

File: base year production attu action matrix 


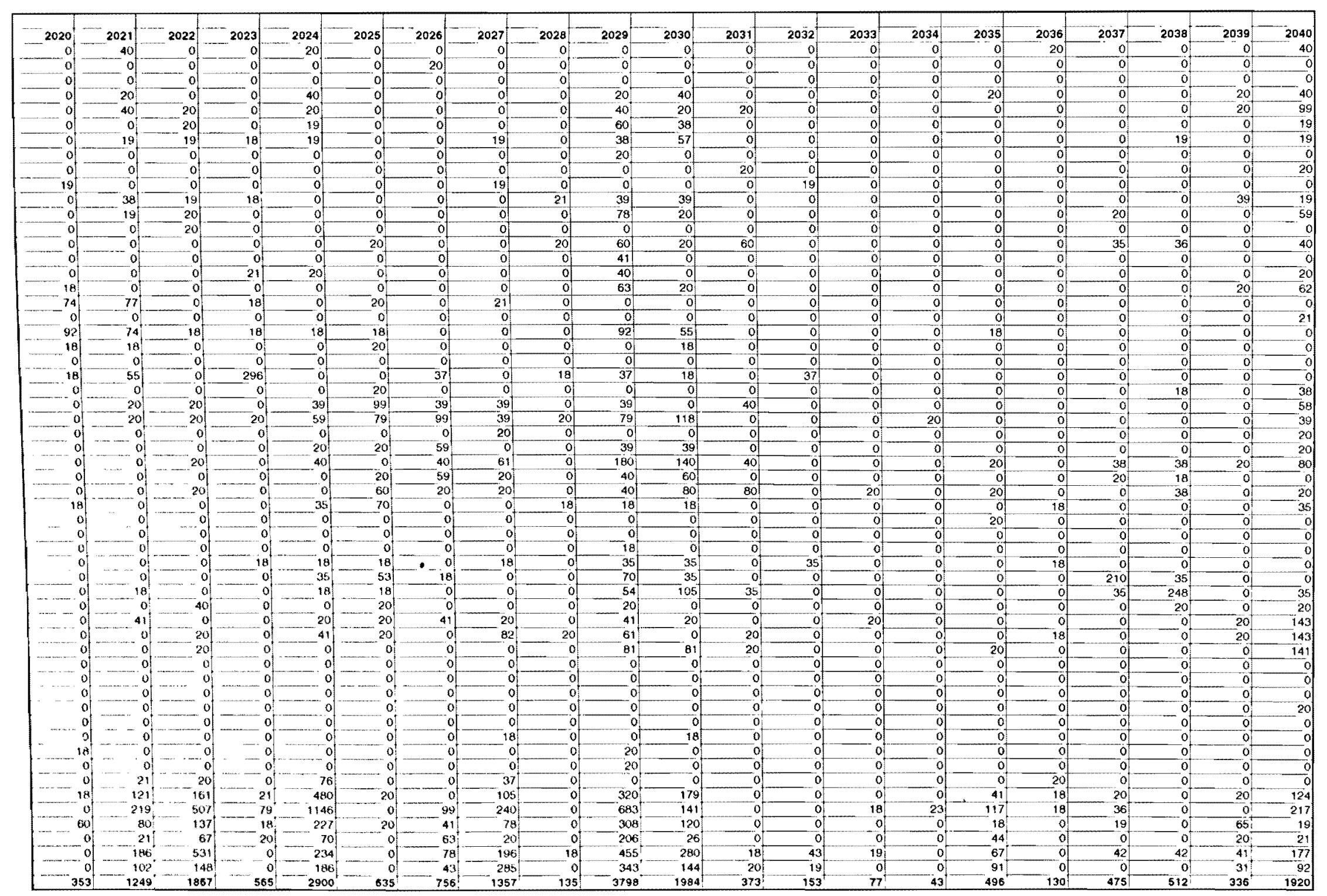

File: base year production attraction matrix
Wokshert: base year production attraction 


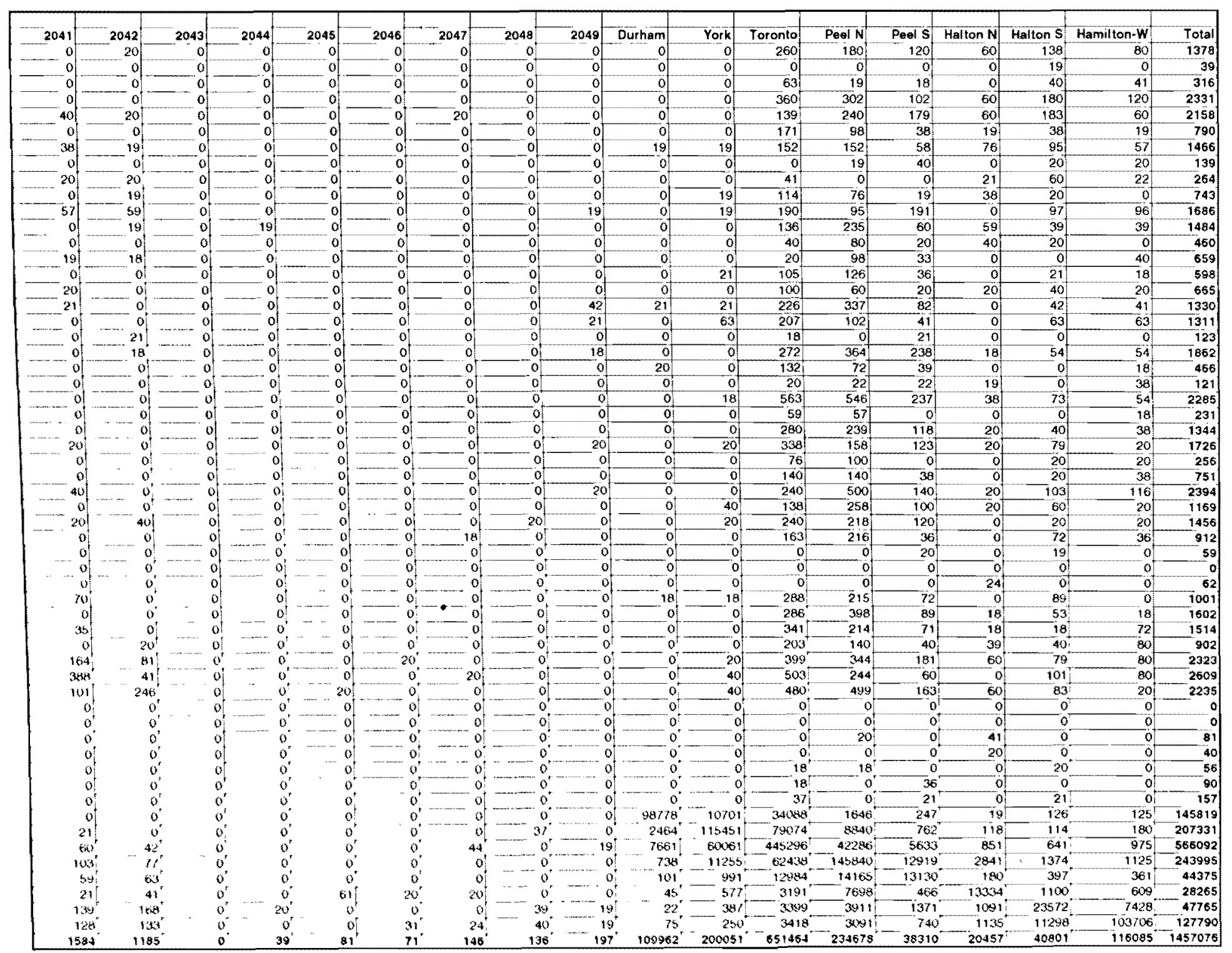

Fine base year production attaction matrix 


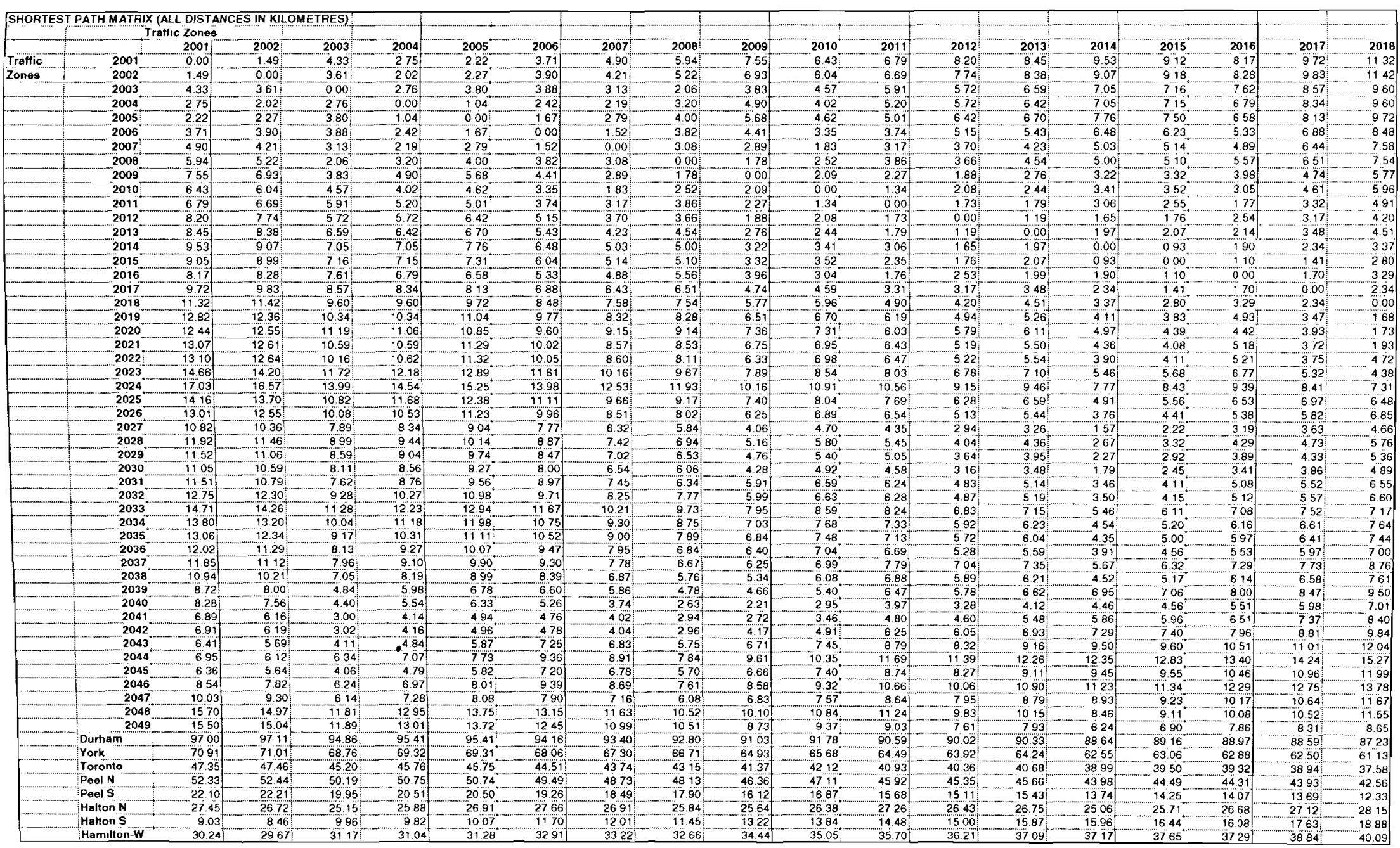




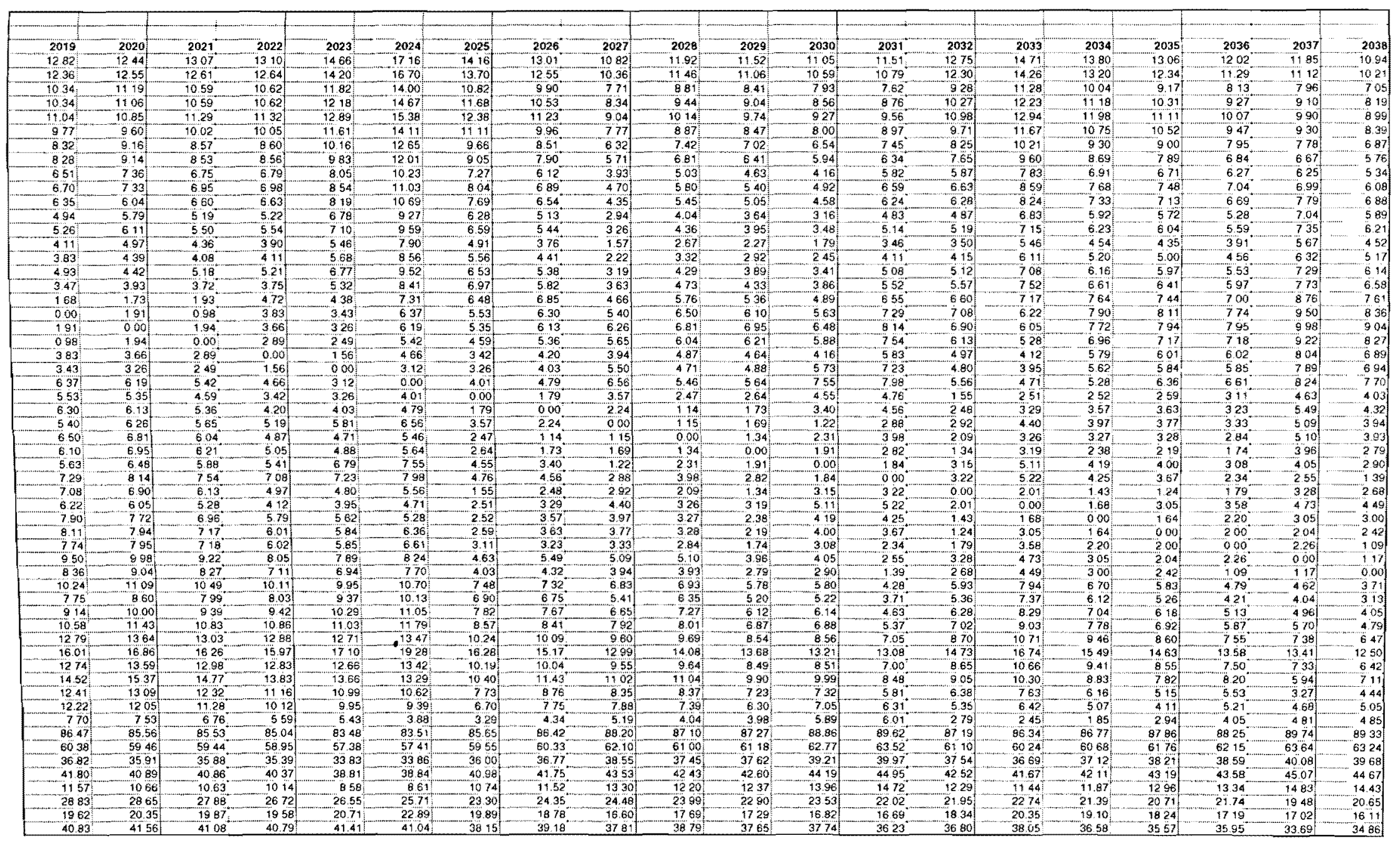

File stictest path and impedance?
Worsteet SHORTST PATH EXPOET 


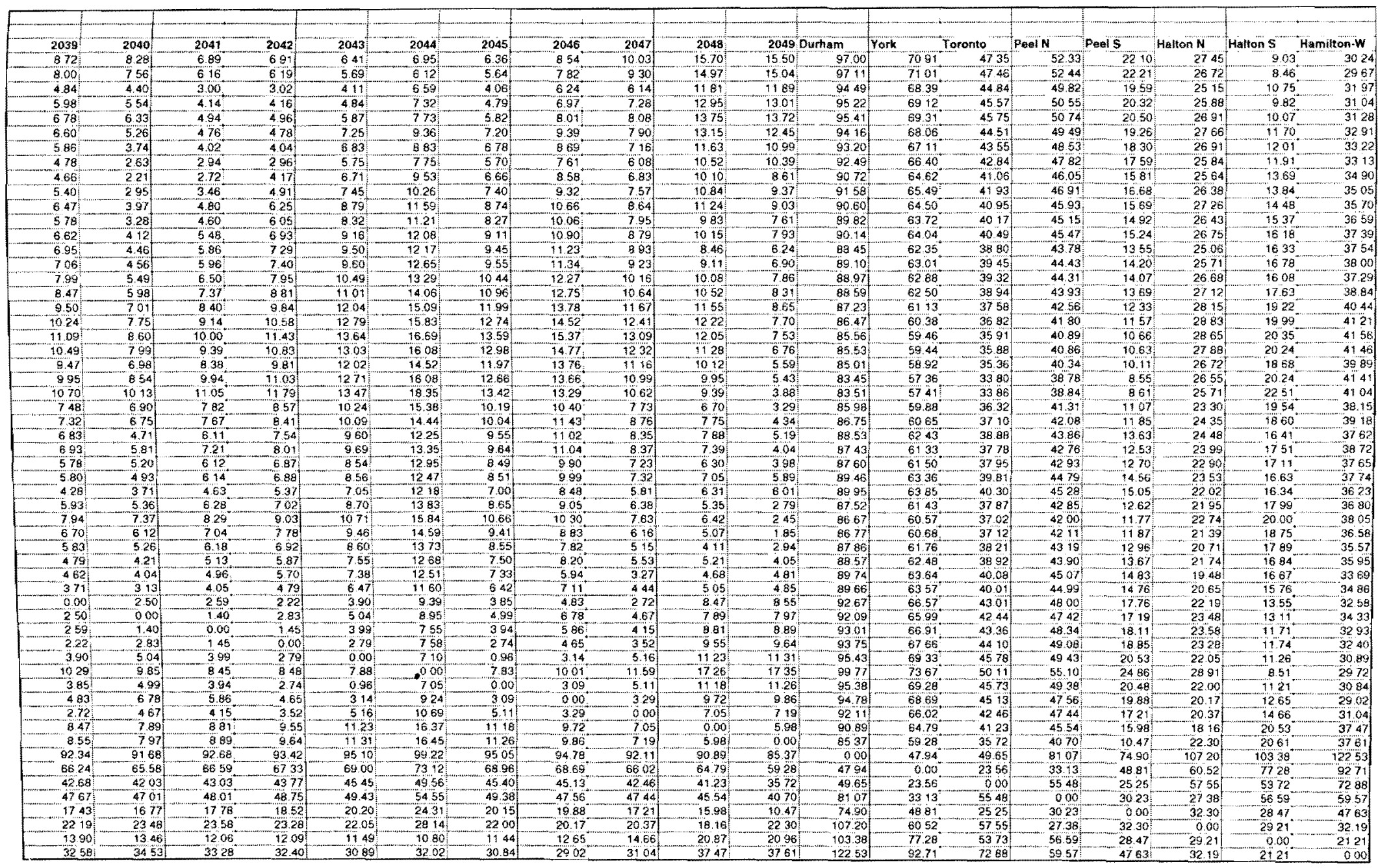

File shonesi fath and Irnpesdarceer
Worisheot SHORTEST PATH EXPORT 


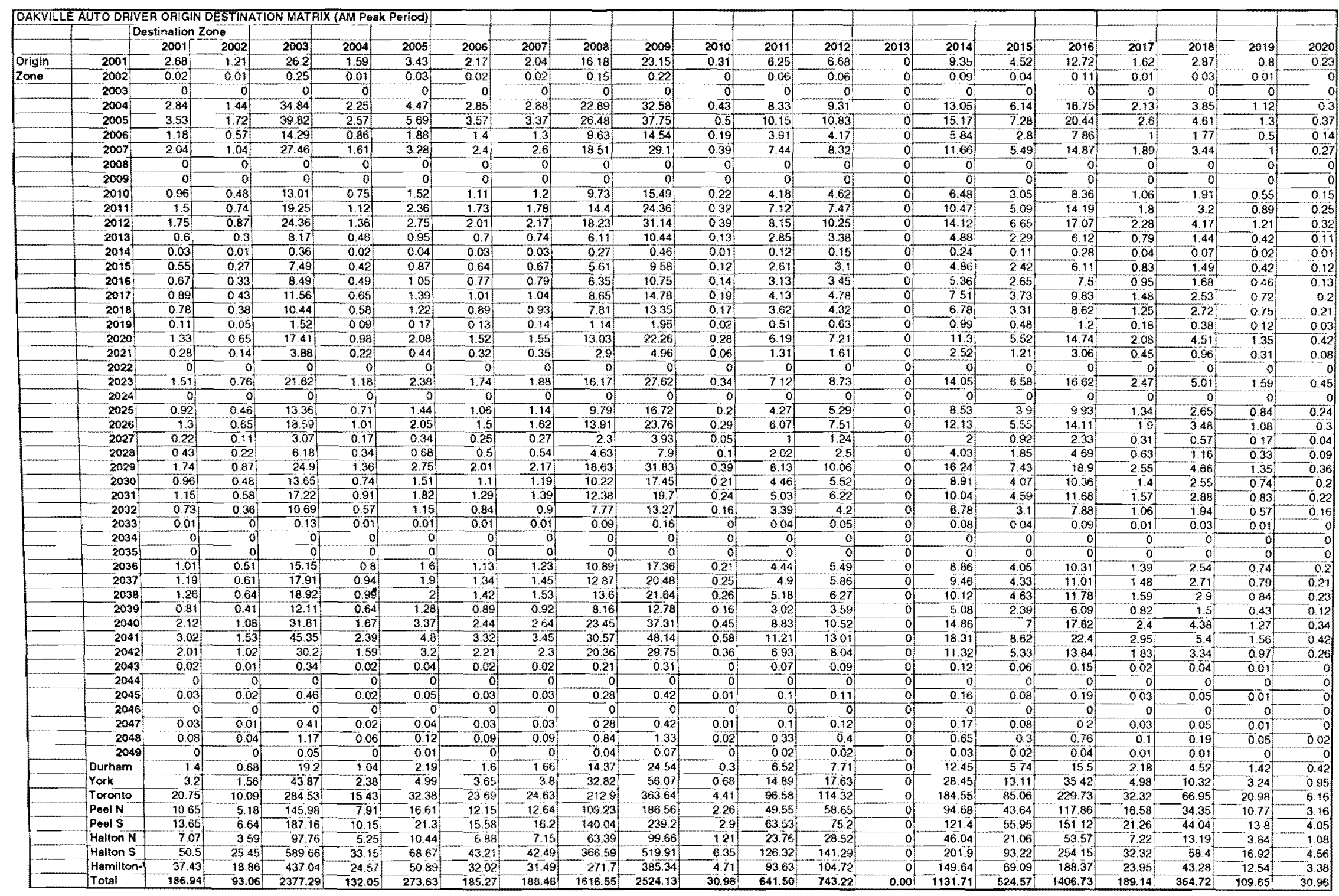




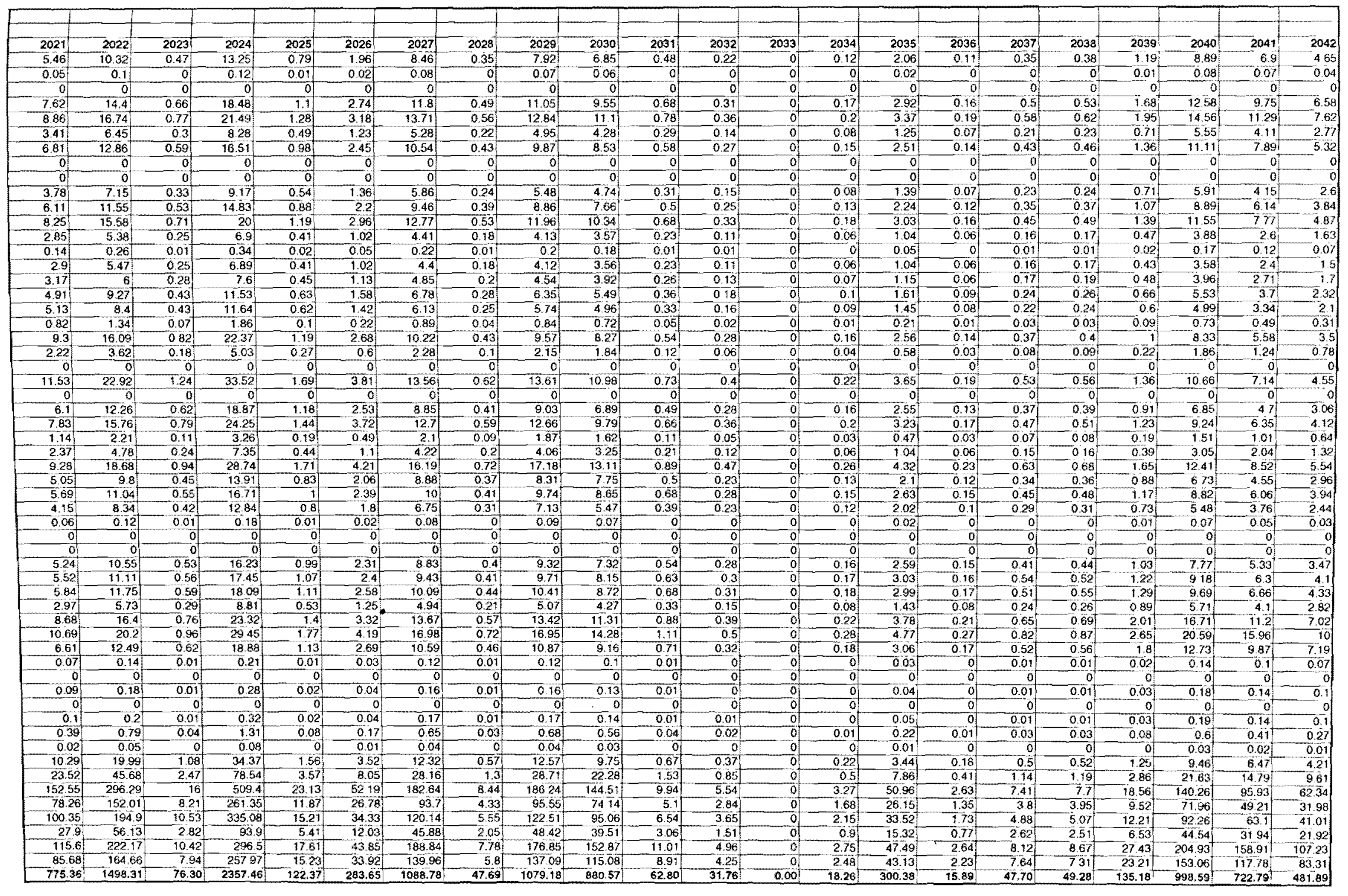

File: shortest path and impedarce?
Worksteft: oakville_odt_export 


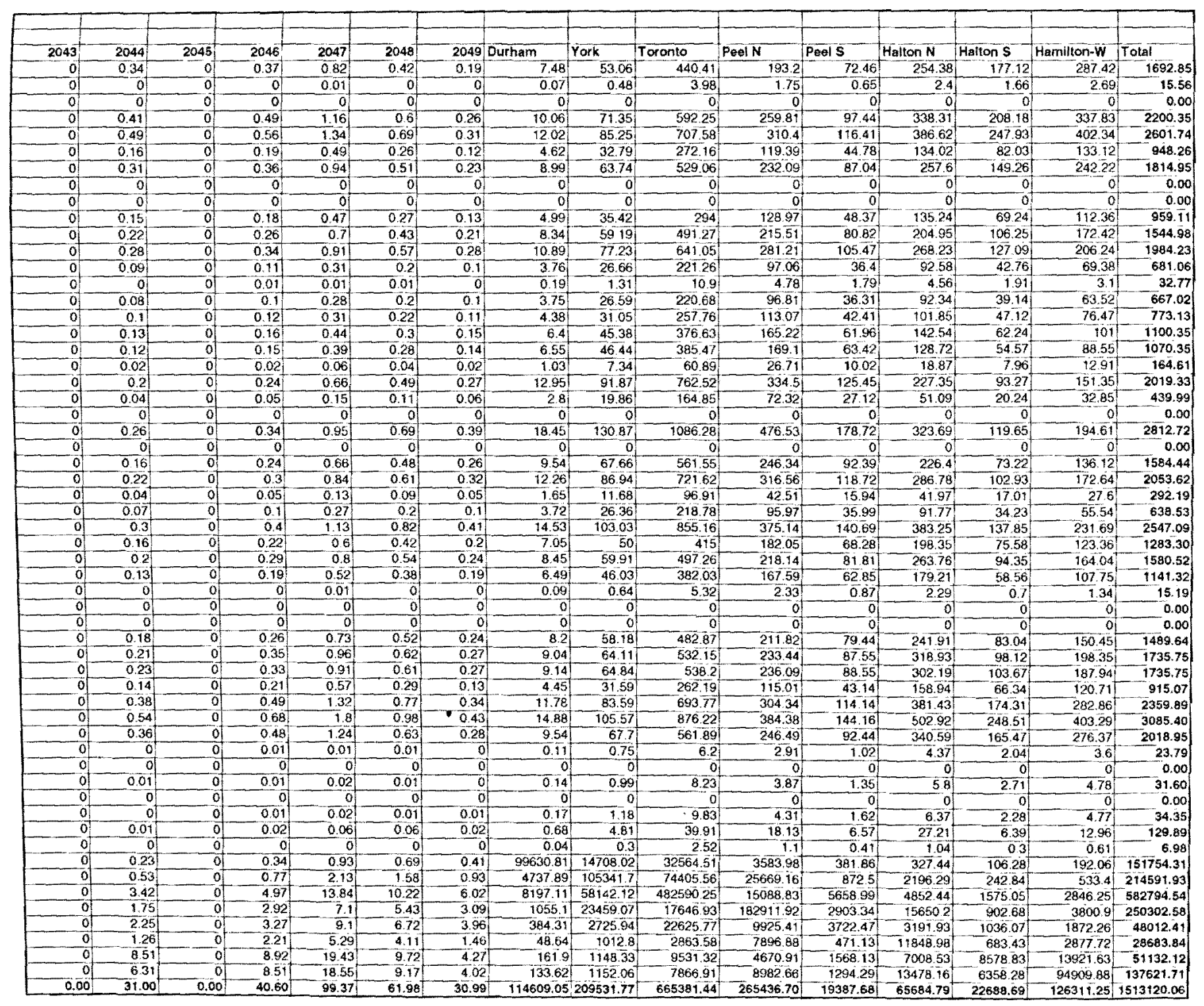




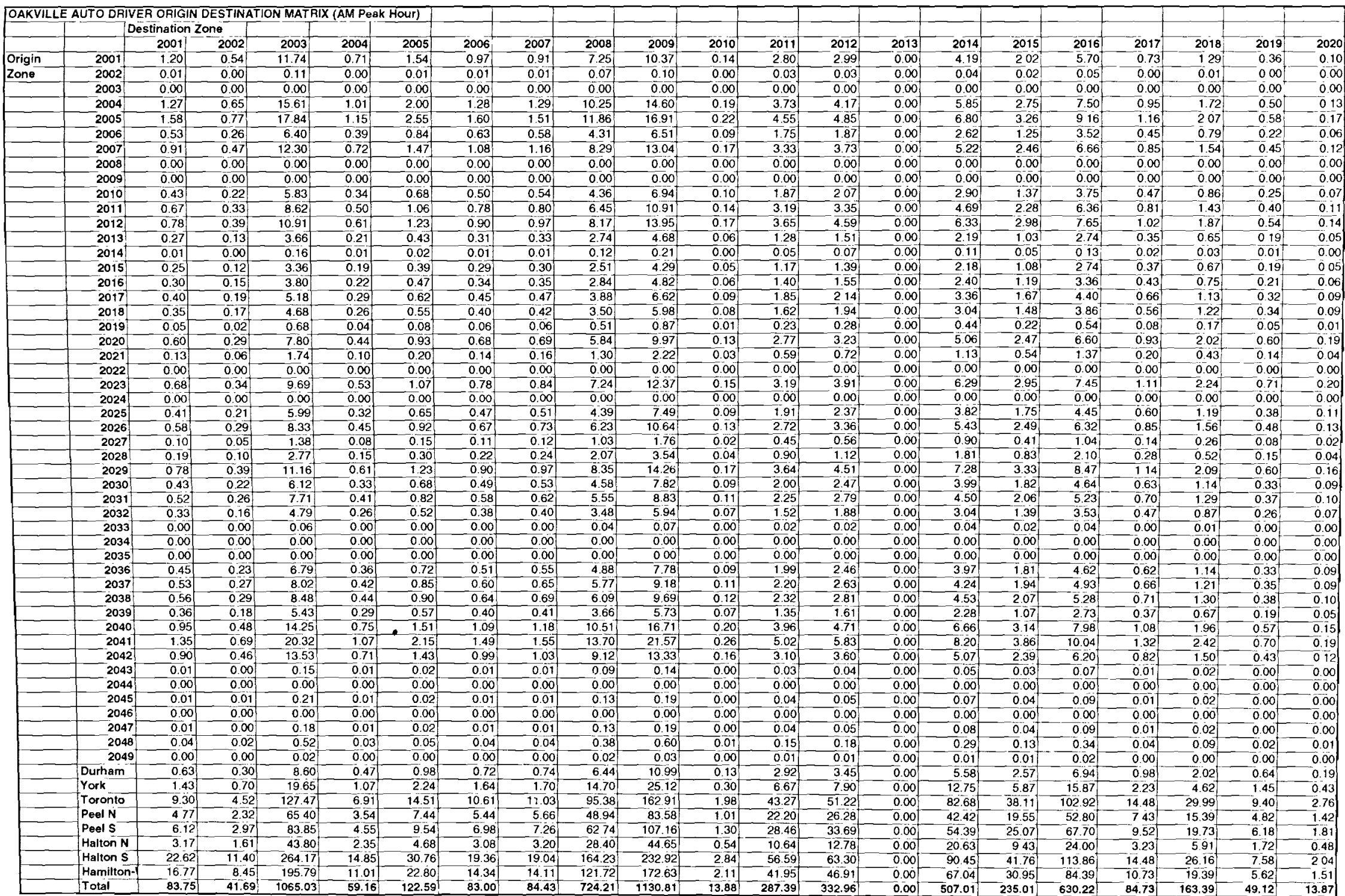




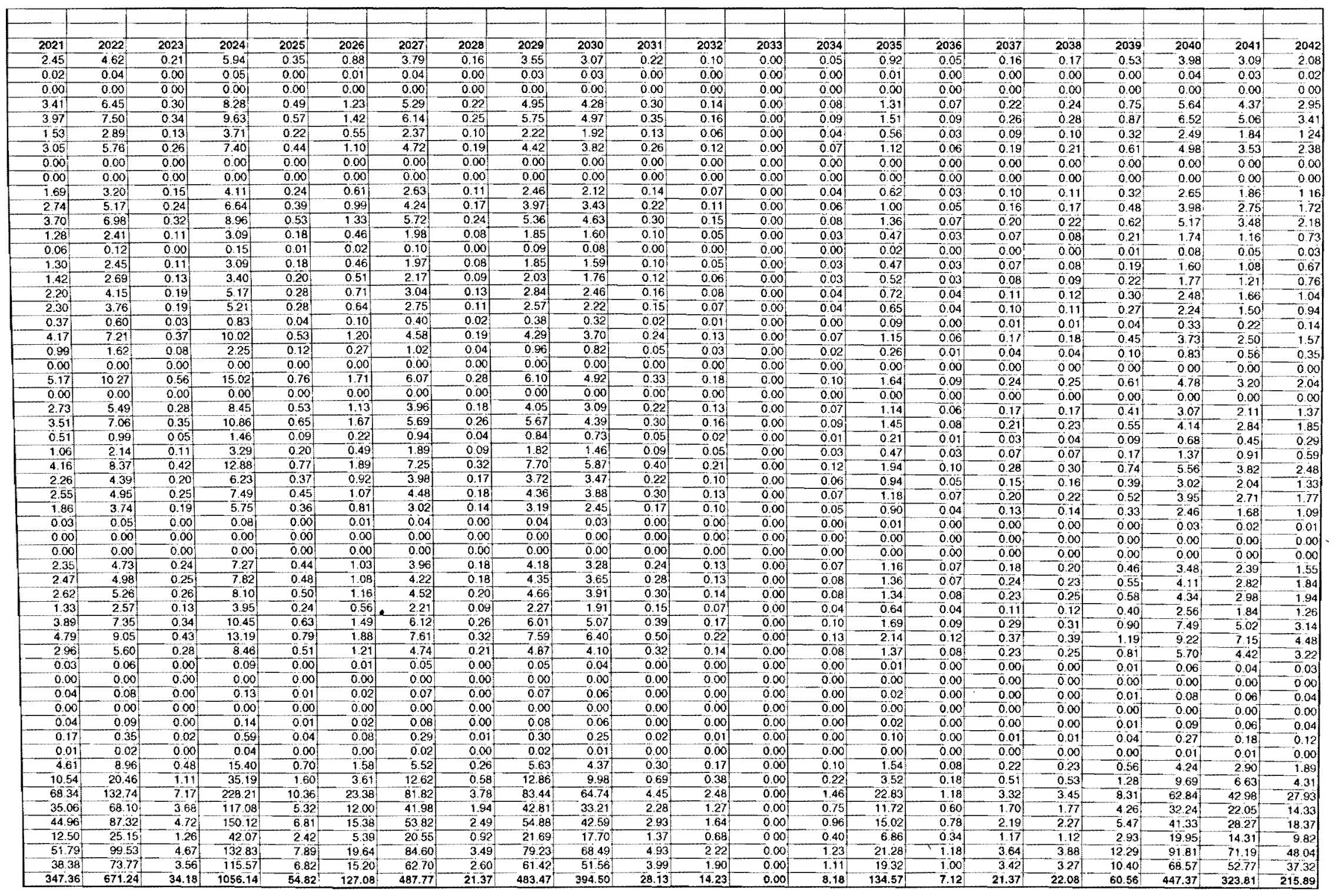

File: shertest path and impediancere?

Workshert: a akvilie od4 export_AM PK__ti 


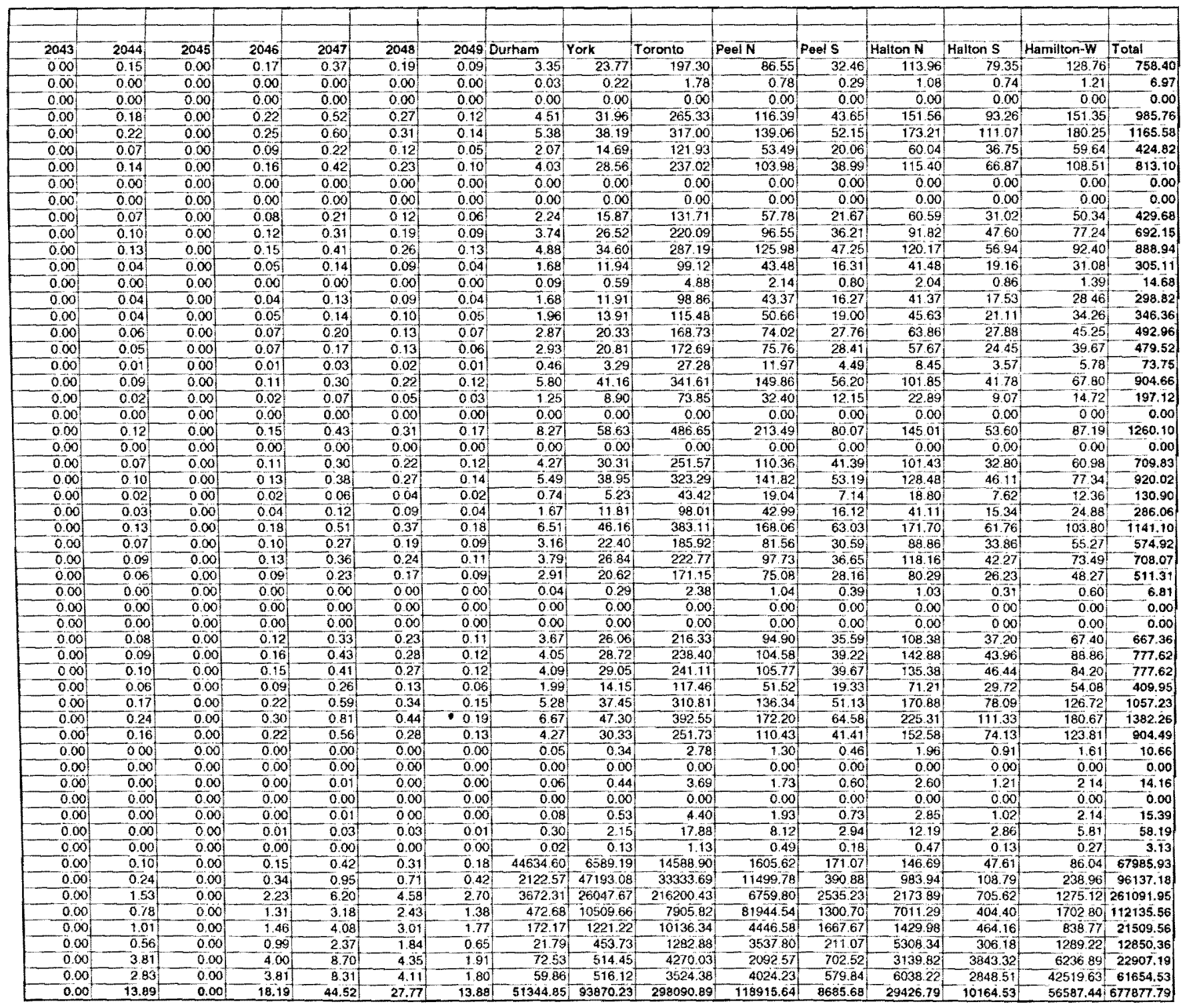

Fite: shortest path and impedance? 


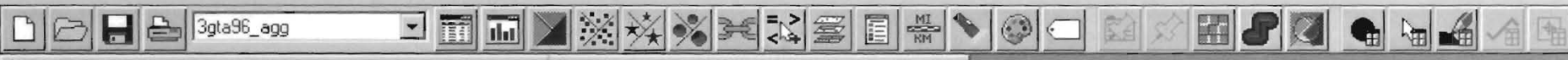

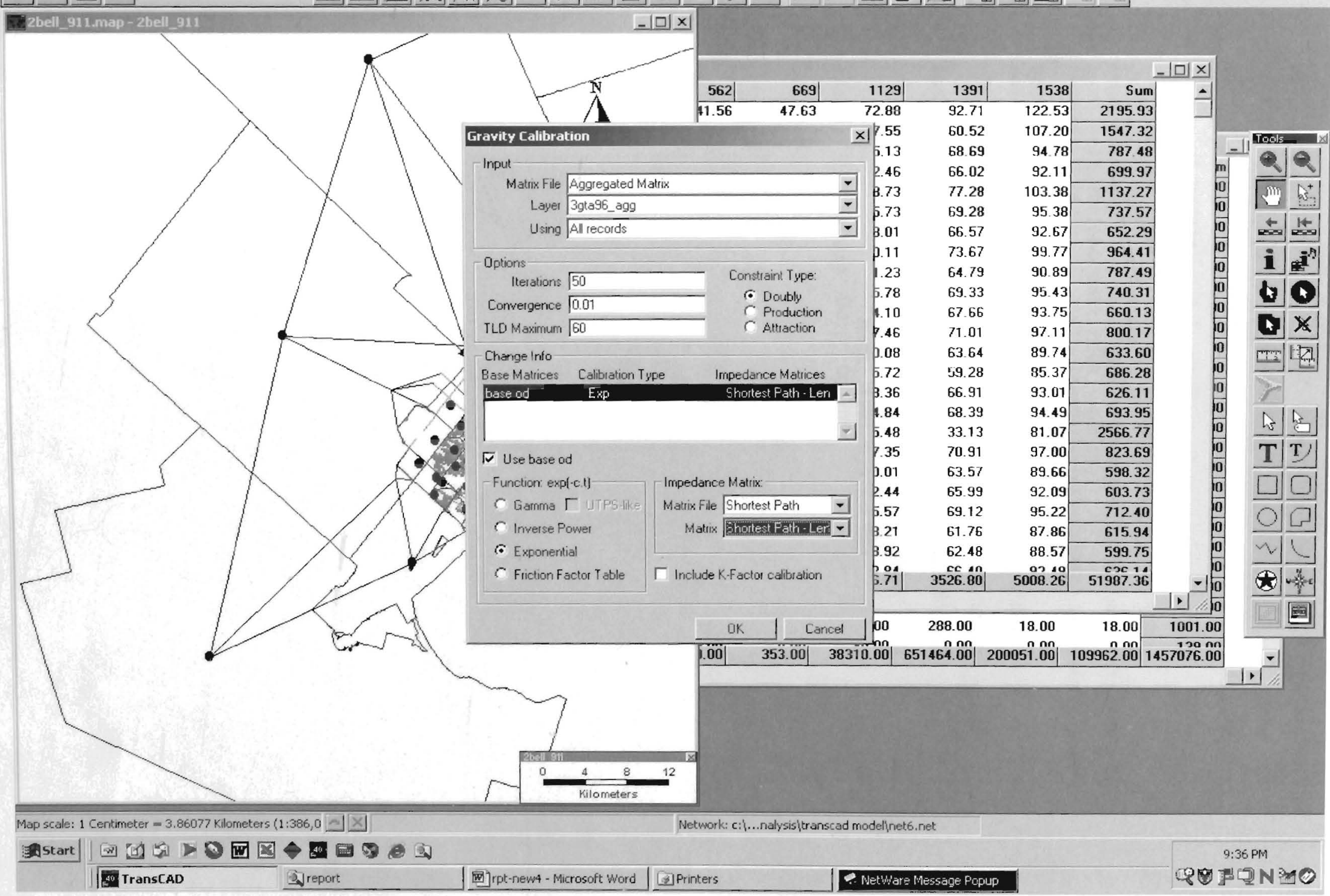




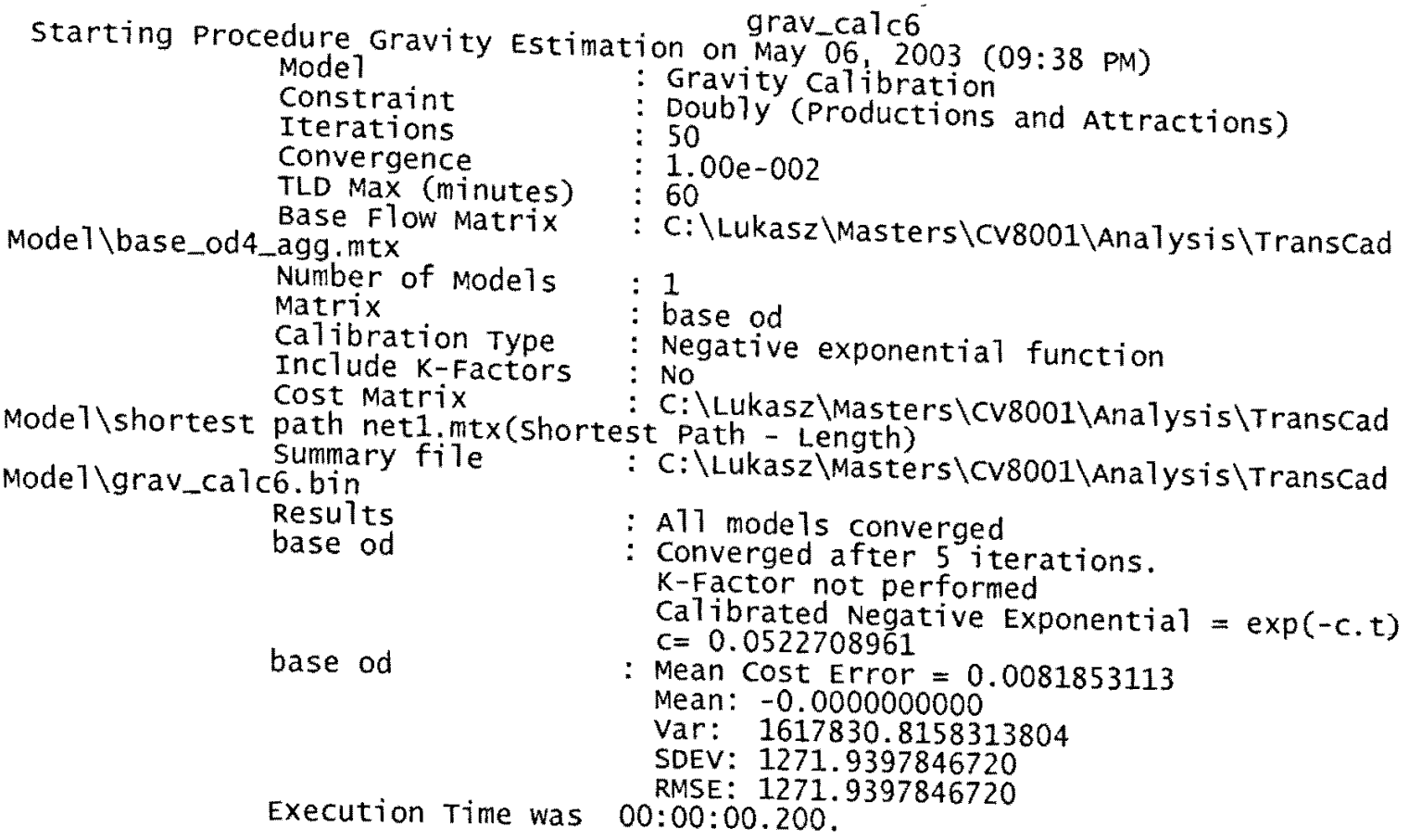




\section{APPENDIX E}

\section{TRAFFIC ASSIGNMENT}


New Text Document (3)

Starting Procedure Traffic Assignment on May 07, 2003 (03:53 AM) Iteration Relative Gap Max. Flow change

$\begin{array}{lll}1 & 0.121476 & 14138.995376 \\ 3 & 0.256812 & 7072.828433 \\ 4 & 0.023381 & 1433.929309 \\ 5 & 0.015481 & 909.448079 \\ 6 & 0.011069 & 1116.728223 \\ \text { INPUT FILES } & 0.006203 & 744.485482\end{array}$

Model $\backslash$ net6.net

$==========$

Network

: C: \Lukasz\Masters\CV8001\Analysis\Transcad

Demand Table

Mode1 \oakvi17e_od4.mtx

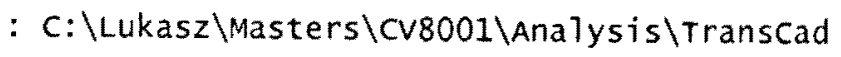

OUTPUT FILES

$=========$
Flow Table

Mode $1 \backslash a s s i g n m e n t \_o a k v i 17 e$ od4_net6.bin

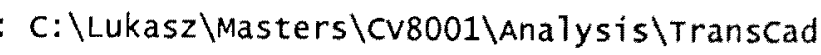

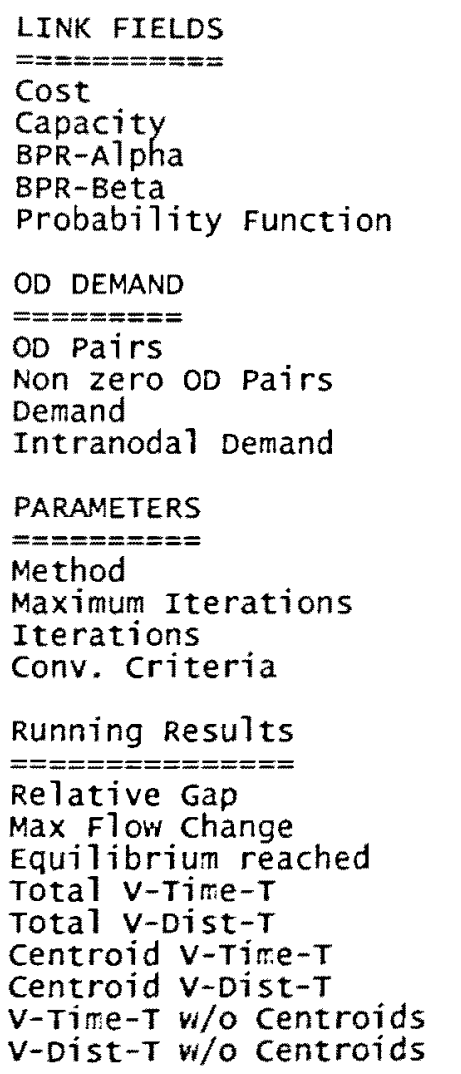

: time

[capacity *]

BPRA

BPRB

Normal

OD DEMAND

OD Pairs

Non zero OD Pairs

Demand

3249
2544
$\vdots$
677877.76
443367.92

PARAMETERS
Stochastic user Equilibrium
20
0.01

Total Running Tine 00:00:02.883. 